\title{
Relative Humidity: A Control Valve of the Steam Engine Climate
}

\author{
Rainer Feistel ${ }^{1 *} \odot$, Olaf Hellmuth ${ }^{2} \odot$ \\ ${ }^{1}$ Leibniz Institute for Baltic Sea Research, 18119 Warnemünde, Germany \\ ${ }^{2}$ Leibniz Institute for Tropospheric Research, 04318 Leipzig, Germany
}

Received 06 March 2021; Revised 14 May 2021; Accepted 21 May 2021; Published 01 June 2021

\begin{abstract}
In the words of Heinrich Hertz in 1885, the Earth is a "gigantic steam engine". On average, of the planet's cross section exposed to sunlight, $72 \%$ belong to the global ocean. With a delay of only 2-3 months, most of the heat absorbed there is released by evaporation rather than by thermal radiation. Water vapour is the dominating "greenhouse gas" of the marine troposphere with a typical relative humidity $(\mathrm{RH})$ of $80 \%$ at the surface. Observing the heat transport across the ocean surface permits insight in the powerhouse of the "steam engine", controlled by the RH at the surface, a quantity that is often considered the "Cinderella" among the climate data. RH of the troposphere also controls cloud formation that is equally fundamental as challenging for climate research. As a precise and perfectly consistent thermodynamic basis for the description of such processes, the new oceanographic standard TEOS-10 was introduced by UNESCO/IOC in 2010 and IUGG in 2011. Its equations cover all thermodynamic properties of liquid water, seawater, ice and humid air, as well as their mutual equilibria and phase transitions. For harmonisation of the inconsistent RH definitions of humid air between meteorology and climatology, the relative fugacity has been defined as a physically more reasonable RH substitute that does not rely on the approximation of ideal gases.
\end{abstract}

Keywords: Climate; Humidity; Evaporation; Hydrological Cycle; Latent Heat Flux; Greenhouse Effect; Ocean Surface; Chemical Potential; Fugacity; TEOS-10; Global Warming; Uncertainty; Clouds; Thermodynamics; Seawater; Troposphere.

The sea surface interaction is obviously a highly significant quantity in simulating climate. Andrew Gilchrist, and Klaus Hasselmann, (1986)

Oceanographers have arrived late to the climate problem.

Raymond W. Schmitt, (2018)

\section{Introduction}

On 20 April 1885, only slightly more than a year before his pivotal discovery of electromagnetic waves in November 1886, Heinrich Rudolf Hertz (Figure 1) had held his inaugural lecture entitled "On the energy balance of the Earth" $\dagger$ at the former Technische Hochschule Karlsruhe. After he had passed away in Bonn already in 1894 from a rare severe illness, his lecture remained unpublished and almost forgotten for more than a century, until those 50 pages of handwritten Sütterlin eventually appeared in English translation [1, 2]. Many of the estimates he had made of the energy fluxes in the climate system turned out to be remarkably accurate. He concluded that a water layer of $1 \mathrm{~m}$ thickness, covering the entire globe, evaporates year by year under the influence of solar irradiation. The related latent heat serves

* Corresponding author: rainer.feistel@io-warnemuende.de

doi http://dx.doi.org/10. 28991/HEF-2021-02-02-06

$>$ This is an open access article under the CC-BY license (https://creativecommons.org/licenses/by/4.0/).

(C) Authors retain all copyrights.

$\dagger$ “Über die Energiebilanz der Erde" 
as the power source of a "gigantic steam engine". Shortly before that publication, the 1994 AGU Chapman Conference on Water Vapor in the Climate System at Jekyll Island, Georgia [3] had emphasised in the same sense that "monitoring long-term changes in water vapor, which are closely linked to other climate variations and trends, is needed to both predict and detect changes to improve our understanding of water vapor in the climate system", and Ebeling \& Feistel (1994) [4] discussed the role of the "climate engine ocean" of the "steam engine Earth" from the perspective of selforganisation. "The scientific community has identified the role of clouds in climate as one of the highest priorities of global-change research", was also noticed by IAMAS (1994) [5] at that time.

However, Flohn et al. (1992) [6] attested the atmospheric research a "widespread neglect of the most effective greenhouse gas, water vapour"* in climate evolution. Hermann Flohn $(1912,1997)$ was one of the pioneers of modern climate research [7, 8]. In fact, in certain textbooks on atmospheric radiation which in detail describe the radiative effects of water vapour, the latter is not considered a greenhouse gas [9].

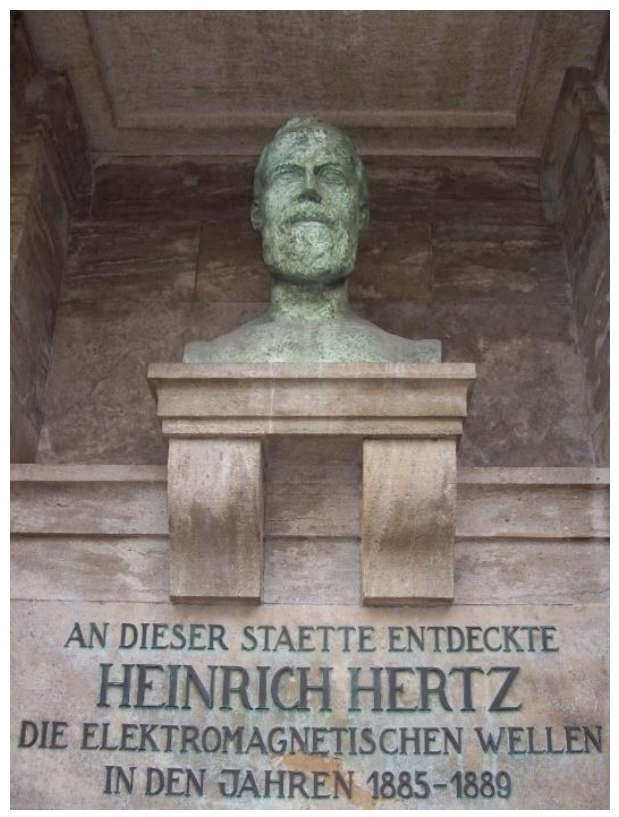

Figure 1: Bust of Heinrich Hertz at the Karlsruhe Institute for Technology, created by his daughter Mathilde and unveiled on 30 October 1925 at the occasion of $100^{\text {th }}$ anniversary of the University Fridericiana (Technical Highschool) Karlsruhe [2]. Photo by Klaus-Dieter Keller (public domain).

In the work quoted already before [6], it was further emphasised with regard to the future climate that ,it is difficult to understand why this dominant feedback by water vapour and its phase changes has been nearly completely neglected (a case of infectious amnesia?). There is nothing new or unexpected about this role; one can find it in most textbooks and monographs which line the bookshelves of every physically oriented climatologist. If the warming of the oceans ... proceeds - as one should expect for the next decades - the probability of a rapid retreat of the Arctic sea-ice should rise, even to its total (at least seasonal) disappearance. This may ultimately lead us, in the near future, into an amazing pattern of unipolar glaciation which controlled the Earth's climate during the late Miocene/early Pliocene, between about 14 and 3.3 million years ago.... With the inclusion of water vapour as an overwhelmingly powerful natural agent, available everywhere, processes leading to drastic and rather rapid climatic changes are already in full swing. They will ultimately lead to all kinds of extreme weather events beyond our imagination. We have to live with them while trying our best to decelerate their progress and to mitigate their impact. Strategies towards that goal have been elaborated, but immense common efforts are desperately needed."

"Around 1700, Edmond Halley published the results of evaporation measurements, thereby contributing significantly to closing the hydrological cycle. Nevertheless, it was not before 1802 that John Dalton became the first to give a complete and correct description of the cycle based on reliable observations" [10]. Among the first systematic studies of the energy balance at the sea surface are those of Wilhelm Schmidt (1915) [11], Wüst (1920) [12], Sverdrup (1936) [13] and Albrecht (1940) [14]. In 1948, Mikhail Ivanovich Budyko (1920, 2001), one of the leading European climate researchers, published a paper on evaporation under natural conditions, which marks the beginning of a long series of studies of the role of water in the energy balance of the climate system, and which eventually appeared in 1963 also in English translation [15-18]. His 1956 book on the heat balance at the terrestrial surface appeared in 1958 also in English language and served as the basis for a related course of lectures held by William D. Sellers at the University of Arizona, beginning in 1960 [19-21]. Closely related are Budyko's fundamental investigations of the role of water for the geo-

\footnotetext{
* "weitverbreitete Vernachlässigung [der Rolle] des effektivsten Treibhausgases, des Wasserdampfs".
} 
botanic regionalisation of the terrestrial surface, as well as of the balances of energy and matter of the phyto- and zoosphere as the two macroscopic constituents of the biosphere [18], corresponding to the historical determination of the term biosphere by the Austrian geologist Eduard Suess, the Russian geoscientist Vladimir Ivanovich Vernadski and the French paleontologist Pierre Teilhard de Chardin (see also Schimming, 2014 [22], with respect to the concept "biosphere").

Under the roof of the International Union of Geodesy and Geophysics (IUGG), its scientific associations IAPSO*, IAMAS $^{\dagger}$ and IAHS ${ }^{\star}$ are concerned with processes deeply involved in the global hydrological cycle [10, 23, 24]. "Hydrology is the science that deals with the processes governing the depletion and replenishment of the water resources of the land areas of the Earth, and treats the various phases of the hydrological cycle" [10]. While the IAHS, according to its mission statement, "promotes the study of all aspects of hydrology", it is in practice much focused on hydrological problems on land with only minor attention devoted to marine aspects such as air-sea interaction [10, 25].

Also, among the $20 \mathrm{key}$ questions that the pioneer of computer-aided weather forecast and climate research, the meteorologist Joseph Smagorinsky (1969) [26] raised, evaporation from the ocean surface was not even mentioned explicitly. „Perhaps the next generation will be talking about the dynamics of water systems“, described his scientific advisor Edward Lorenz (1969) [27] the expectations in those years at the end of his own article. Hasselmann's (2002) [28] question, "Is climate predictable?" did not consider water vapour. Despite intensive research and substantial progress, 50 years after Smagorinsky the water cycle still poses an immense scientific challenge [29-33]. Milz (2003) [29] underlines that in the discussion about the anthropogenic influence on climate, feedback on other gases must not be neglected, and that water vapour has the strongest impact on the greenhouse effect and contributes more to it than carbon dioxide, $\mathrm{CO}_{2}$, or methane, $\mathrm{CH}_{4}$. The General Assembly of the IUGG in Montreal 2019 devoted a larger number of presentations to the observation of the water-vapour content of the atmosphere [34]. The processes involved are extremely complex and extend over wide ranges of space and time. „Moisture is crucial to sustaining blocks“, for example, belongs to the current hypotheses for the reasons of the extreme European draught and heat wave in 2018 [35], which was associated with particularly long lasting meteorological blocking conditions ("block") of the otherwise prevailing westerlies.

In addition to its direct functions as a greenhouse gas and carrier of latent heat, the fundamental importance of atmospheric water vapour results from its role in the following physical processes [31]:

- Water vapour is the "material matrix" for the formation of condensates, hydrometeors and precipitable aggregates in liquid and solid form.

- Water vapour is one of the main sources for the formation of the hydroxyl radical in the upper troposphere and lower stratosphere. For its oxidation potential, this radical is considered one of the most important atmospheric "detergents" and influences the balances of methane, ozone and halogenated greenhouse gases in the atmosphere [36-38].

- Condensed and sublimated from water vapour, high clouds in the upper troposphere and the lower stratosphere affect the planetary albedo in the short wave range and the so-called "greenhouse effect" in the long wave range.

- Water in molecular and condensed form participates in chemical reactions that influence the stratospheric concentration of ozone [37].

Changes in the water-vapour content in the upper troposphere / lower stratosphere impact the radiative forcing more strongly than at other altitudes [39]. A rise in stratospheric water-vapour content modifies the radiation field there and leads to a cooling of the stratosphere. In the stratosphere, water vapour emerges by photolytic oxidation of methane which is transferred from the troposphere to the stratosphere by vertical movement [29].

Moreover, the amounts of heat associated with phase transitions of water cause density-induced buoyancy changes which exert substantial influence on the cloud dynamics and manifest themselves in meso- and macroscale variations of the atmospheric circulation. Exemplarily for the effects on the mesoscale, the influence may be mentioned on the vertical distribution of water vapour and on the humidity convergence during the development of high-reaching convection and of thunderstorm activity [40-44], as well as on the importance of the water-vapour distribution for the model-supported determination of the water-balance components precipitation and evaporation on the regional scale [45]. As an example for the effects on the macroscale, the influence of the latent-heat flux on the emergence of low-pressure cells (cyclogenesis) may be noted $[46,47]$.

\footnotetext{
* IAPSO: International Association for the Physical Sciences of the Oceans

$\dagger$ IAMAS: International Association of Meteorology and Atmospheric Sciences

$\$$ IAHS: International Association of Hydrological Sciences
} 
Based upon climate simulations of moisture transport induced by non-steady vortices, Wills et al. (2016) [48] demonstrated a strong influence of warming-related changes on the atmospheric dynamics in extratropical latitudes. In the course of global warming, the zonally (that is, over all meridians) averaged climatic water balance (precipitation minus evaporation) exhibits a tendency of redistribution following the rule ,wet gets wetter, dry gets drier“, which is accompanied by an increase of the zonal anomaly of the hydrological cycle (see also Section 9).

The knowledge of the fundamental physical conservation laws which govern climate "as the statistical entity of atmospheric states and processes in their spatio-temporal distribution"* [49, 50], as well as the in-principle possibility of simulating the spatio-temporal distributions of those states by long-term integration using numerical models, are a necessary rather than a sufficient condition for a reliable prediction of future developments. The latter requires, first of all, a precise determination of the conversion rates of the hydro-thermodynamic prognostic variables in the climate system. These conversion rates depend on the physical fluxes of mass, momentum and energy within the different subsystems of climate, and across their mutual interfaces. The adequate description of conversion rates and of the underlying fluxes is of fundamental importance for the closing of the global and local balances of energy and water, as well as for changes in the chemical and biological composition of the atmosphere and the terrestrial surface [51-53]. The current inability of making available highly precise global distributions of fluxes across the interface between the terrestrial surface (including the ocean) and the atmosphere is a critical and substantial source of uncertainty of the balance closures [51]. Among those fluxes, the ones caused by phase transitions of water are of particular relevance: „Currently, although various analyses of the surface energy and water budgets close to within the uncertainties, these uncertainties are large enough to preclude the data being able to answer numerous scientific questions. Much of the uncertainty in these estimations are to a large extent due to imbalances between the radiative and turbulent heat fluxes and the evaporation and precipitation across the ocean surface. The transfer of water from the ocean to the atmosphere, where it then becomes available to yield precipitation over both the ocean and land surfaces, is vital to life on land. However, our ability to predict the timing and magnitude of these variations is in part due to the uncertainties in the current global air-sea flux products which prevent them from being used to quantify the trends in either the heat or the moisture budget as uncertainties are on the order of 10 to $20 \%$ [51].

In this article, attention is focused in a strongly simplifying way on a specific branch of the hydrological cycle, namely on the energy export of the ocean on the global average, while largely excluding many other essential aspects such as the dynamics of ocean currents, of wind, clouds, precipitation or ice cover. "The continents play a very insignificant role for the cooling of the Earth" [54]. In this text, appreciation is given to a slightly larger number of references and literal quotations because the questions discussed here are sometimes controversial in the literature, and one may not rely on too few information sources. These authors are not active climatologists; they only reflect here the subjective picture they gained from studying the publications.

The new SI [55] does not define the year as a unit of time. Because the SI permits "ha" as the unit "hectar" for an area, it is refrained here from using the symbol "a" for the year and the English "yr" is employed instead. Decimal fractions keep the decimal point (rather than a comma) of the English literature also in German text parts. Long numbers group the digits by blanks (rather than a comma or a period) as recommended by the SI [55].

\section{Evaporation at the Ocean Surface: The Water Cycle}

On the annual average, to the global ocean belong $72 \%$ of the cross section of the Earth that is astronomically illuminated by the Sun (Figure 2). The most important energy source for the atmosphere, as already Hertz had underlined, is, on the global average, the latent heat of about $80 \mathrm{~W} \mathrm{~m}^{-2}$ of water evaporating from the planetary surface. "The by far largest part of heat conveyed to the air is in the form of latent heat during subsequent condensation along with cloud formation. The heat budget over the sea is mainly controlled by the latent heat released to the air" $\$$ [14]. For the atmosphere, the globally averaged net radiative cooling approximately balances the globally averaged latent-heat release. The latent heat is supplied by the evaporation of water from the surface" [56]. Of this water vapour, the major part originates from the ocean, namely about $85 \%$ [57]. The energy of the sunlight absorbed by the ocean $\left(168 \mathrm{~W} \mathrm{~m}^{-2}\right.$, Pierce et al., 2011 [58], equal to about $120 \mathrm{~W} \mathrm{~m}^{-2}$ if converted to the total global surface) is transferred to the troposphere mainly by evaporation (almost $60 \%$ ) and by thermal radiation [59, 60]; this fundamental process at the oceanatmosphere interface happens in a self-organised, feedback-controlled manner, mainly governed by humidity and turbulent transport processes. "This way, the heat released to the air in latent form is larger by a multiple than the [sensible] heat transferred immediately to the air"§ [14].

\footnotetext{
* "als der statistischen Gesamtheit atmosphärischer Zustände und Prozesse in ihrer raumzeitlichen Verteilung“.

$\dagger$ "Die Continente spielen bei der Abkühlung der Erde nur eine sehr unbedeutende Rolle".

¥ "Der weitaus größte Teil der Wärme wird der Luft in Form von latenter Wärme und nachfolgender Kondensation bei der Wolkenbildung zugeführt. ... Der Wärmehaushalt der Luft über dem Meere wird ... hauptsächlich durch die bei der Verdunstung an die Luft abgegebene latente Wärme bestimmt".

$\S$ "Die an die Luft in latenter Form abgegebene Wärme ist dabei um ein Vielfaches größer als die durch den Austausch unmittelbar".
} 
The estimate of Heinrich Hertz that "every year a water layer of $1 \mathrm{~m}$ thickness evaporates from the entire Earth"* was confirmed and improved in a series of later investigations (Figure 3). The later studies tend uniformly to values of about $1200 \mathrm{~mm}$ evaporation per year from the sea surface (or about $850 \mathrm{~mm}$ with respect to the global surface). Approximately $90 \%$ of the water evaporated from the oceans returns to them as precipitation, and only the remaining $10 \%$ fall over land and are discharged from rivers to the ocean. For comparison, about $500 \mathrm{~mm}$ per year evaporate from land where, however, about $750 \mathrm{~mm}$ of precipitation take place [61]; with respect to Germany, for example, the corresponding figures amount to 463 and $779 \mathrm{~mm}$, respectively [62]. Therefore, the average global evaporation per year is estimated to roundabout $1200 \mathrm{~mm} \times 71 \%$ (ocean) $+500 \mathrm{~mm} \times 29 \%$ (land) $\approx 1000 \mathrm{~mm}$, as appropriately foretold by Hertz already in 1885 , or $2.7 \mathrm{~mm}$ per day. Of this amount of water vapour and the associated latent heat, a percentage of $1200 \mathrm{~mm} \times$ $71 \% / 1000 \mathrm{~mm}=85 \%$ originates from the sea. The global precipitation amounts to $1200 \mathrm{~mm} \times 90 \% \times 71 \%$ (ocean) $+(1200 \mathrm{~mm} \times 10 \%+750 \mathrm{~mm}) \times 29 \%$ (land) $\approx 1000 \mathrm{~mm}$, which fairly well obeys the main law of the global water balance, according to which global evaporation matches global precipitation [63]. Land and mountain ranges, which cause clouds to form and rain to fall, play only a quantitatively minor role for the global water cycle. To the humans as land residents, climate delivers of course to a rather different and even slightly deceptive impression.

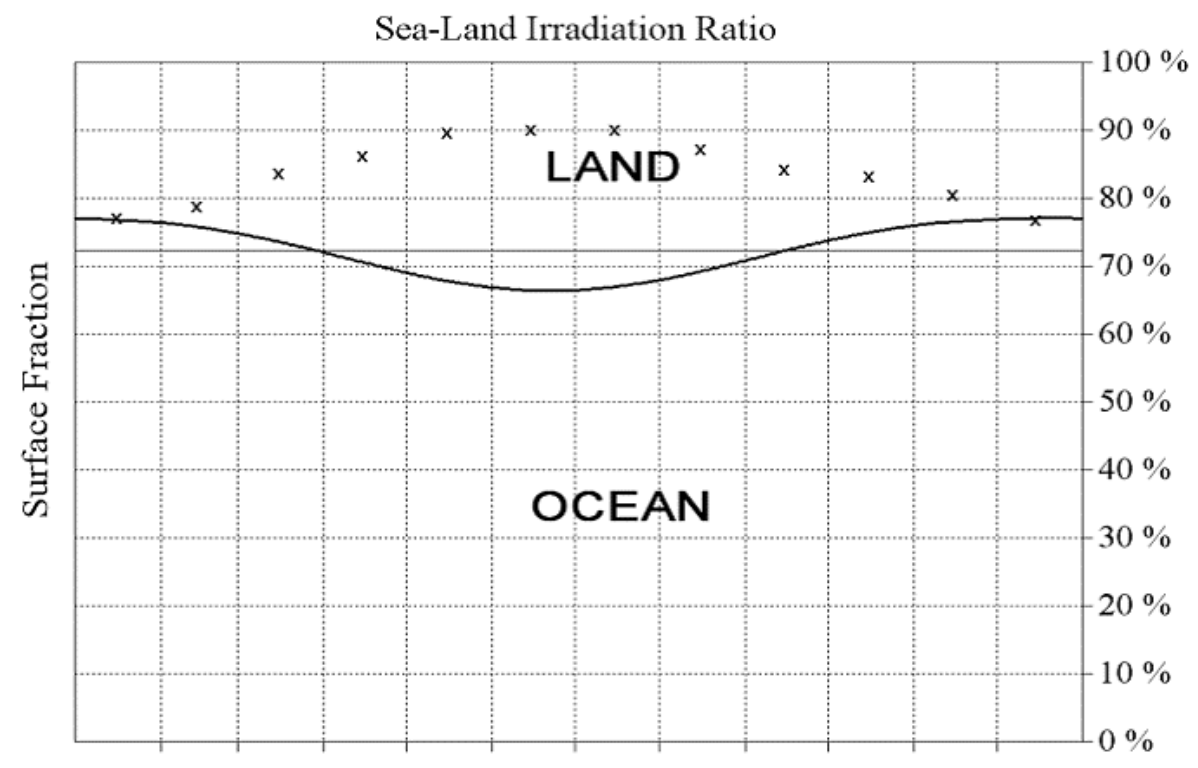

Jan Feb Mar Apr May Jun Jul Aug Sep Oct Nov Dec

Figure 2. Annual course of the oceanic fraction of Earth's daytime side. Of the terrestrial cross section astronomically exposed to sunlight, $72 \%$ belong to the ocean surface on the annual average, with some slight seasonal course of the daily means (bold curve, Feistel, 2013 [64]). The crosses (x) represent a similarly weak seasonal cycle of the monthly mean relative humidity at St. Helena Island in the South Atlantic [65].

With an evaporation enthalpy of ca. $2450 \mathrm{~kJ} \mathrm{~kg}^{-1}$ at $20{ }^{\circ} \mathrm{C}$, which corresponds to about $80 \mathrm{~W} \mathrm{~m}^{-2}$ with respect to $1000 \mathrm{~mm}$ per year, the $1200 \mathrm{~mm}$ evaporation observed as average over the global ocean surface [66, 67] imply an export of latent heat from the ocean to the atmosphere of about $96 \mathrm{~W} \mathrm{~m}^{-2}$, or $68 \mathrm{~W} \mathrm{~m}^{-2}$ in relation to the entire global surface, by adopting the ocean area fraction of $71 \%$.

The flux of latent heat is unevenly distributed over the oceans [57]. Evaporation in the subtropical trade-wind belt has typical values of $160 \mathrm{~W} \mathrm{~m}^{-2}$ and reaches maximum values exceeding $200 \mathrm{~W} \mathrm{~m}^{-2}$ over the Gulf Stream south of Nova Scotia, Canada, and over the Kuroshio south of Kyushu, Japan. Toward higher latitudes those values decrease systematically; at the Baltic Sea area, for example, about $50 \mathrm{~W} \mathrm{~m}^{-2}$ are reported [18]. Interestingly, also the entropy flux density out of the Baltic is about half as large as that of the global ocean $[68,69]$. Assuming the Arctic ice cover to gradually disappear, it may be speculated that the future evaporation of water from the then open Arctic Ocean will exceed the current sublimation rate of ice, thus enhancing the hydrological cycle and possibly resulting in a global cooling effect [70].

The mass of water vapour (more precisely, the integral water-vapour content) found in the worldwide troposphere is estimated to amount about $25 \mathrm{~kg} \mathrm{~m}^{-2}$ [71-73] or $21.6 \mathrm{~kg} \mathrm{~m}^{-2}$ with a strong regional variability between 0.1 and 78.1 $\mathrm{kg} \mathrm{m}^{-2}$ [74]. At a mean evaporation rate of $2.7 \mathrm{~mm} \mathrm{~d}^{-1}$, the residence time of water in the troposphere turns out to be about $(22 / 2.7$ to $25 / 2.7)$ days $\approx 8$ to 9 days. Condensed water in clouds has an average mass of $0.11 \mathrm{~kg} \mathrm{~m}^{-2}$ [71, 75],

an die Luft abgeführte [fühlbare] Wärme

* "jedes Jahr auf der gesamten Erde eine Wasserschicht von 1 m Dicke verdampft" 
corresponding to a mean residence time of a mere $(0.11 / 2.7)$ days $\approx 0.04$ days $\approx 1$ hour. Thus, the atmospheric time scales of water circulation are short compared to typical meteorological average periods for monthly mean values, and even much shorter than those for seasonal or annual means.

Global Oceanic Evaporation Rate in mm per Year

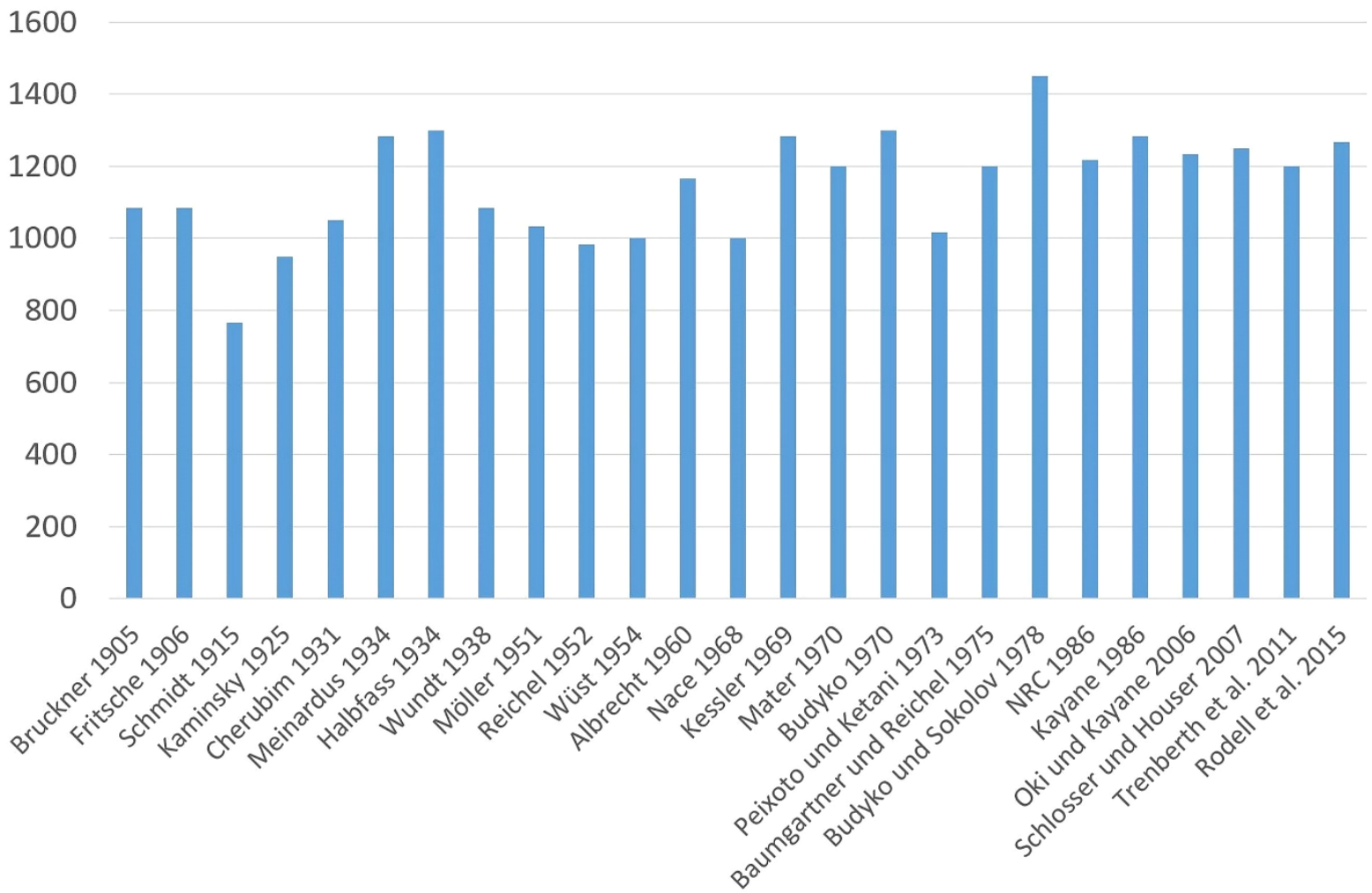

Figure 3. Global averages of the marine evaporation rate in $\mathrm{mm}$ per year from various estimates since 1905 . All values are adopted from the review article of Peters-Lidard et al. (2019) [61]; the references are also given there.

\section{Relative Humidity: Cause and Effect of Evaporation}

By dry air, a gas mixture is denoted which contains the atmospheric gases nitrogen, oxygen, argon, carbon dioxide, methane as well as traces of other gases in certain ratios of their amounts, but no water vapour. By contrast, humid (or moist) air is a mixture of dry air with water vapour. Humid air that is in thermodynamic equilibrium with liquid water across a planar mutual interface, or, at lower temperatures, in equilibrium with ice, is regarded as saturated. Relative humidity $(\mathrm{RH})$ is a measure for the degree of saturation which may vary between $0 \%$ (dry) and $100 \%$ (saturated). Ambient air has typical RH values between 50 and $70 \%$.

In many scientific and technical disciplines, RH is a key quantity. However, those who consequently may expect that $\mathrm{RH}$ is always uniformly defined, will be disappointed $[76,77]$. To the most important definitions belong the one in meteorology [78];

$$
\psi_{x}(x, T, p)=\frac{x}{x^{\mathrm{sat}}(T, p)}=\frac{p_{v}(x)}{p_{v}^{\mathrm{sat}}(T, p)}
$$

and the one employed in climatology [67, 79],

$$
\psi_{q}(x, T, p)=\frac{q(x)}{q^{\text {sat }}(T, p)}
$$

both of them simply termed "relative humidity" without distinction. Here, $\mathrm{x}$ is the mole fraction or relative amount of substance, namely the ratio of the number of water-vapour molecules to that of humid air; $p_{v}=x p$ is the partial pressure, $q$ is the specific humidity, namely the ratio of the mass of water vapour to that of humid air, and $x^{\text {sat }}(T, p), q^{\text {sat }}(T, p)$, respectively, are the related quantities of saturated air at equal temperature, $T$, and equal total pressure, $p$. In the ClausiusClapeyron equation, a convenient approximation formula for the saturation values, the latter ones increase exponentially with the temperature.

Commonly, $\psi_{x}$ und $\psi_{q}$ are reported in \%rh after multiplication of their values with 100 . The suffix "rh" after the percent symbol is preferably used to unambiguously indicate that the given figure is a relative humidity in $\%$ rather than 
a ratio of relative humidities in $\%$. In the marine troposphere, the numerical values of $\psi_{x}$ und $\psi_{q}$ differ from one another hardly by more than $1 \% \mathrm{rh}$, and therefore it is usually refrained from mentioning the definition used or properly converting the data. In fact, the uncertainty in practical RH measurement is rarely less than $1 \%$ rh, often even just $5 \%$ rh. However, here we shall argue (Section 7) that a systematic change in RH on the order of 1 \%rh in the climate system is by no means to be considered as negligibly "small". For this reason, attempts at the international level are underway to harmonise the definitions of RH among the various disciplines [77, 80], in order to render readings of different groups spatially and temporally better comparable, and to compute small RH trends free of doubt, see Section 7.

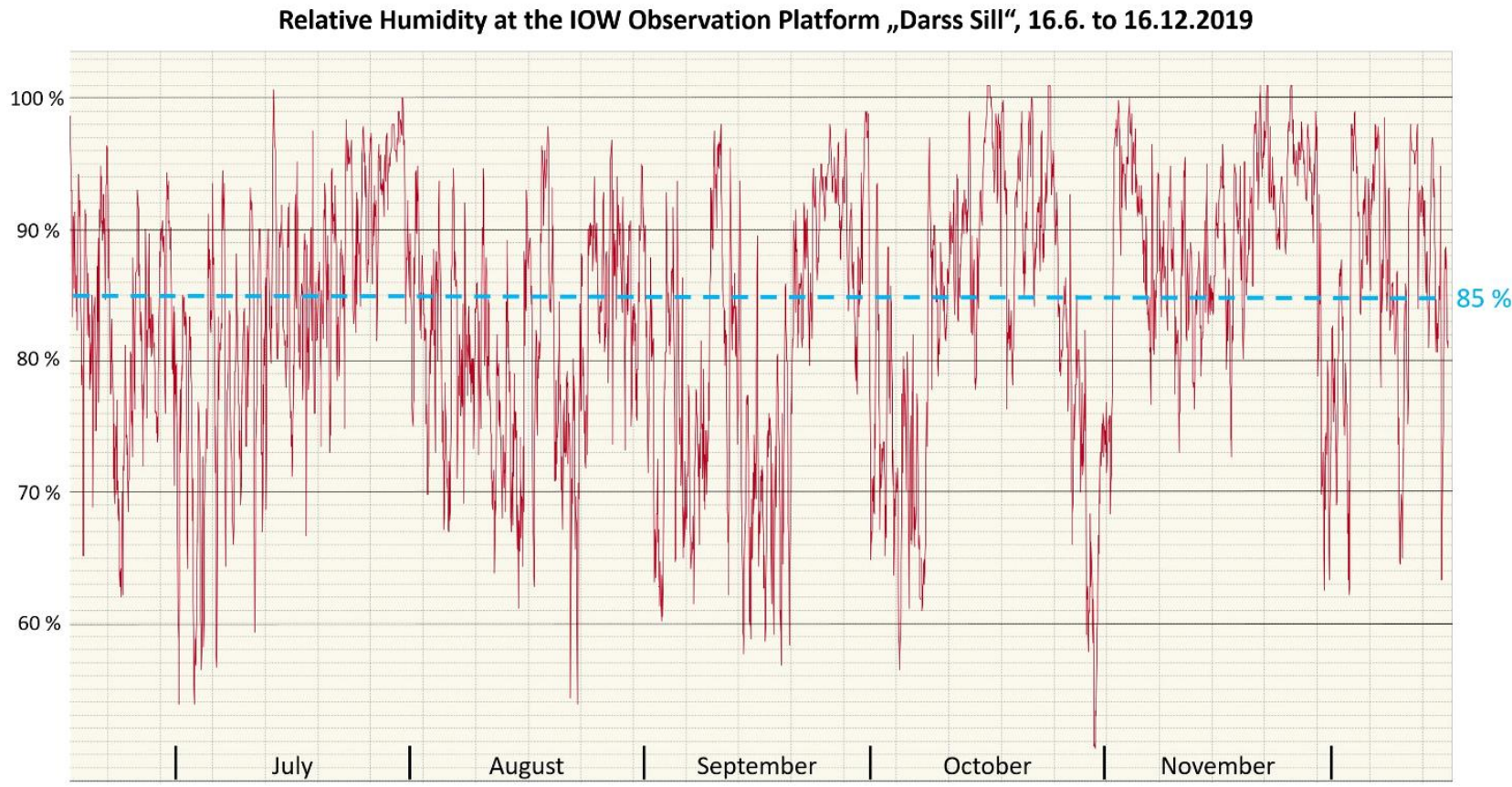

Figure 4. Recorded RH values from 16 June till 16 December 2019 at the IOW observation platform "Darss Sill", located in the western Baltic Sea between the islands of Hiddensee and Møn. The average over this period is $85 \%$ rh (dashed line).

As a rule, meteorological measurement results of RH fluctuate strongly (Figure 4) on the typical time scales of weather between an hour and a month. The mean residence times of water in the troposphere fall in the same interval, Section 2. The stochastic behaviour of RH is statistically similar to that of turbulent air motion [81]. In contrast, the RH values at the sea surface are remarkably stable on climatological timescales [82]. To the current knowledge, those values of about $80 \%$ rh are rather independent of season and region, and they do not exhibit any significant trend in the course of global warming. To this finding it may contribute that suspected systematic changes are expected to become visible only in the range of $0.1 \%$ rh or below, and that the present-day marine and atmospheric measurement technology is not accurate enough to resolve such effects. There is also the problem that long-term series of relative humidity are "almost not available" [77, 83] in quality and length comparable to those known for temperature and precipitation; this is true in particular for the marine atmosphere [84] and for the Arctic. "The water vapour distribution especially in Arctic regions is only poorly known and suffers from a limited reliability of some observational standard methods like radiosondes" [85]. Also the different - present and past - mutually inconsistent definitions of RH add to this difficulty.

Surprisingly enough, Figure 4 does not display any significant seasonal variation even though it extends from midsummer until winter. A very similar behaviour is observed for the monthly mean values of the near-surface relative humidity over the Great Plains (average over the region $35-38^{\circ} \mathrm{N}, 99-96^{\circ} \mathrm{W}$ ) [86]. There, the annual mean is about 70 $\%$ rh, and the average over the summer months June, July, August is $65.5 \%$ rh. While the observed seasonal cycle of RH is very smooth, the ensemble simulation produces an annual cycle with a pronounced summer minimum with an average of only $43.8 \%$ rh. At the German Baltic coast, the measured monthly means at Warnemünde vary between 77 \%rh in summer and $88 \%$ rh in winter [87]. Stations at land exhibit significantly stronger seasonal cycles and climatic trends than measurements over the open sea.

During the time interval of Figure 4 the RH is hardly changing any systematically even though the function $x^{\text {sat }}(T, p)$, Equation 1, depends strongly on $T$ via the Clausius-Clapeyron equation, and the station's air and water temperatures possess a pronounced seasonal cycle. Therefore, the particular water content $x$ of the sea air must compensate this temperature effect if $\psi_{x}(x, T, p)$ in turn is hardly affected at all. Invariance of $\psi_{x}(x, T, p)$ with respect to temperature changes is possible only if $x$ and $T$ are positively and nonlinearly correlated. For the convective continental boundary layer such a positive correlation induced by turbulence is empirically confirmed [88, 89]. 
With respect to global warming, the situation is similar to that of seasonal temperature variations. Between 1988 and 2003 , the water content of the troposphere of 22-25 kg m${ }^{-2}$, Section 2, increased by $0.4 \mathrm{~kg} \mathrm{~m}^{-2}$ per year. ,The regression values are very close to the $7 \% \mathrm{~K}^{-1}$ expected from Clausius-Clapeyron equation for the water-holding capacity of the atmosphere", Trenberth et al. (2005) [90] write. Rapp (2014) [91], however, considers the trend of $0.4 \mathrm{~kg} \mathrm{~m}^{-2}$ per year reported there as rather uncertain because of the climatologically short time span of only 15 years. While ,in the upper troposphere, the increases in water vapor with warmer temperatures are not large enough to maintain a constant relative humidity" [92], it is a widespread opinion among the experts that RH at the sea surface does not exhibit any significant trend in the course of global warming [84, 56]. Thomas \& Stamnes (1999) [93] assume an average RH of 85\%rh at the sea surface when considering the feedback of water vapour to the surface temperature, and note: "The relative humidity tends to remain fixed as the sea-surface temperature changes, whereas the absolute water content is exponentially dependent on temperature“. In a similar analysis of radiation feedbacks, which are not restricted to the ocean surface, Liou (2002) [94] states: "From the analysis of measured $\mathrm{H}_{2} \mathrm{O}$ concentrations across the globe, the mean annual relative humidity, RH, as a function of height, is fairly constant". "Hall and Manabe (1999) presented arguments in favor of a model that assumes that the relative humidity will not change as the Earth warms" [91]. "The relative humidity may vary in ways that are difficult to predict. In the absence of any better knowledge, most climate models make the assumption that relative humidity does not change with global warming, and a constant relative humidity implies an increase in absolute humidity as the Earth warms. The basis for the assumption that relative humidity does not change with global warming lies in some rather old radiosonde data. Clearly, the assumption of constant relative humidity rests on a weak foundation" [92].

Occasionally RH is even modelled as an empirically given constant [95-99]. "The assumption of constant RH is also supported by in situ observations [100] and satellite observations [101]" [99]. An investigation of the relevance of RH fluctuations regarding possible natural trends is not intended by such models. Maps of monthly means of RH [102] show typical variations between $75 \%$ rh in the subtropics and $85 \%$ rh in the tropics. Local peak values reach $90 \%$ rh over the Gulf Stream and the Kuroshio, but also at St. Helena Island in the South Atlantic in austral winter (Figure 2). In contrast to the ocean, a weak global trend of RH of $-0.08 \%$ rh per decade is observed over the land surface, where, however, only the subtropics get dryer but the tropics and high latitudes become wetter [103]. As long as we do not know why, whether and how exactly the marine RH is held constant by the climate system, model predictions based on the assumption of a fixed $\mathrm{RH}$ remain insignificant.

The thermodynamic driving force for the evaporation of liquid water is the difference between the chemical potentials of water on the two sides of the interface [104]:

$\mu_{\mathrm{V}}^{\mathrm{AV}}(x, T, p)-\mu_{\mathrm{W}}^{\mathrm{W}}(T, p)=R T \ln \psi_{f}$

Here, $\mu_{\mathrm{V}}^{\mathrm{AV}}$ is the (molar) chemical potential of water vapour (subscript $\mathrm{V}$ ) in humid air (superscript AV), $\mu_{\mathrm{W}}^{\mathrm{W}}$ is the chemical potential of pure liquid water, and $R$ is the molar gas constant. This difference (3) may be expressed as the quantity $\psi_{f}(x, T, p)$, the so-called relative fugacity of humid air, introduced by Lewis (1901) [105] more than a century ago. For saturated air, this difference disappears and $\psi_{f}$ takes the value of $100 \%$ rh:

$\mu_{\mathrm{V}}^{\mathrm{AV}}\left(x^{\mathrm{sat}}, T, p\right)-\mu_{\mathrm{W}}^{\mathrm{W}}(T, p)=0$.

Humid air in our atmosphere behaves similar to an ideal gas. For this asymptotic limiting case the formula for $\mu_{\mathrm{V}}^{\mathrm{AV}}(x, T, p)$ is well-known from thermodynamics, and from Equation 3 there follows the formula (1), i.e., the equality of relative fugacity and relative humidity, $\psi_{f}^{\text {id }}=\psi_{x}$, that is

$\mu_{\mathrm{V}}^{\mathrm{AV}}(x, T, p)-\mu_{\mathrm{V}}^{\mathrm{AV}}\left(x^{\mathrm{sat}}, T, p\right) \approx R T \ln \frac{x}{x^{\mathrm{sat}}(T, p)}$.

Under environmental conditions, the two quantities $\psi_{f}$ und $\psi_{x}$ differ from one another only within the measurement uncertainty of common moisture meters; also for this reason the simple formula (1) had been declared the de-facto standard in meteorology [78]. However, the sensitivity of the global heat balance with respect to trends of relative humidity is much too high, see Section 7, for appropriately capturing by this approximation the crucial processes of the energy fluxes across the sea surface. It would be manifest to use the thermodynamically rigorous definition (3) for relative humidity [80], see Section 8, and to use Equation 1 only as a practical proxy substituting it which is considered sufficiently accurate in today's meteorological practice.

Evaporation from the sea surface is a complex process whose observation is difficult at the open sea with wind, waves and whitecaps, and which can hardly be simulated realistically in the lab. Remotely sensed ocean evaporation data seem to suffer from significant systematic errors [106]. New promising insights may result independently from the analysis of the spatial distribution of marine water-vapour isotopic composition [107]. Following Equation 3, the relative fugacity, or approximately the RH, of a thin boundary layer of perhaps a few millimeters thickness over the water governs the evaporation rate. The salinity $S$ of seawater lowers the fugacity of water in the liquid phase, and the evaporation is driven by the difference between the chemical potentials of water in humid air, $\mu_{\mathrm{V}}^{\mathrm{AV}}$, and in seawater, $\mu_{\mathrm{W}}^{\mathrm{SW}}$, or equivalently, between the respective fugacities, $f_{\mathrm{V}}^{\mathrm{AV}}$ and $f_{\mathrm{W}}^{\mathrm{SW}}$, relative to that of saturated humid air, $f_{\mathrm{V}}^{\mathrm{sat}}[80,108$, 109]: 
$\mu_{\mathrm{V}}^{\mathrm{AV}}(x, T, p)-\mu_{\mathrm{W}}^{\mathrm{SW}}(S, T, p)=R T \ln \frac{f_{\mathrm{V}}^{\mathrm{AV}}}{f_{\mathrm{V}}^{\text {sat }}}-R T \ln \frac{f_{\mathrm{W}}^{\mathrm{SW}}}{f_{\mathrm{V}}^{\text {sat }}}$

The fugacity of the surface layer is itself being changed by fluxes of water vapour and heat from the sea, und by turbulent mixing with the air layers above and the water layers below. In the air, the water-vapour content, $x$ or $q$, is in good approximation conserved during the mixing process as long the air is sufficiently subsaturated to exclude condensation.

The early investigations of Wüst (1920) [12], Sverdrup (1936) [13] and Albrecht (1940) [14] of the evaporation from the sea used the thermodynamic forces, Equation 6, in the plausible approximation of the "vapour-pressure jump at the sea surface"* [14], which is a generalisation of the 1802 Dalton formula [110-112] for seawater. For this purpose, the logarithm in Equation 6 is linearised by means of $\ln x \approx x-1$, and the fugacities are replaced by their ideal-gas approximations, namely, by their corresponding partial pressures. This is valid accordingly over ice and snow cover. Over land, where the fugacity of the soil moisture is unknown, its value is tentatively estimated from the fugacity of water vapour immediately above the ground, and Equation 6 is therefore approximated by the vertical gradient of the water-vapour partial pressure within the bottom layer of humid air [14]. An overview over such parameterisations on land is given by Debski (1966) [111].

By contrast, certain later numerical models estimate the evaporation rate over the ocean also as being proportional to the vertical gradient of the specific humidity, $q$, above the surface $[17,40,76,99,104,113-120]$, similar to the Thornthwaite-Holzman equation [121-124]. "The rate of evaporation is proportional to the vertical gradient of specific humidity at the Earth's surface" [99]. This method, which replaces the "vapour-pressure jump" and the partial pressure by the specific humidity, corresponds to Equation 6 only in an even poorer approximation than that of Wüst (1920) [12], Sverdrup (1936) [13] and Albrecht (1940) [14] before. With respect to its genesis, this representation of the watervapour flux corresponds to the so-called exchange equation or mixing-path hypothesis [125-127], by which the vertical transport caused by turbulence is described as that of a passive substance admixed with air. For the amount of substance contained per mass unit, only two assumptions are made:

(i) The substance should be a conservative quantity during the transport, that is, the air particles which carry this property do not admix;

(ii) The substance should be passive (or inert), that is, its admixture to air does not affect the process of turbulence (ibid.).

Regarding meteorological applications of the mixing-path hypothesis to the planetary boundary layer, it may be referred here to the extensive literature [89, 128-135]. The model picture that the turbulent water-vapour flux may be driven or at least quantified by the gradient of specific humidity, holds for the redistribution of a passive substance within a fluid medium if the turbulent motion is the limiting factor of that flux. This picture is not or only conditionally valid if the flux is dominated by exchange processes across the boundary of the medium, as it may be assumed in particular for the ocean-atmosphere interface. For representing those fluxes which include the entire atmospheric ground layer, so-called bulk-aerodynamic parameterisations are applied [51, 89, 136-143]. The basic equations for the turbulent fluxes at the lower boundary of the atmosphere are identical for land and sea. However, over land and ocean different parameterisations of the so-called transfer coefficient (or the turbulent Dalton numbers) are in use in dependence of the thermal stability of the stratification and of the aerodynamic roughness length which possesses higher variability over the sea. While the roughness length over land is a function of the land use, this quantity depends on the wind speed over the sea and is parameterised with the Charnock formula as a function of the characteristic kinematic and convective velocities ("scaling velocities") $[136,142]$.

An idealised but nevertheless realistic model of the troposphere is that of an isentropic, perfectly mixed air column. In this model the specific entropy (often expressed by the potential temperature) and the specific humidity are vertically homogeneously distributed throughout the troposphere. These assumptions lead to realistic values of the adiabatic temperature gradient, and the atmospheric cooling rate of $2 \mathrm{~K} \mathrm{~d}^{-1}$ turns out to be consistent with the global entropy export of the Earth of $1 \mathrm{~W} \mathrm{~K}^{-1} \mathrm{~m}^{-2}[4,144-146]$, by the so-called "photon mill". In the isentropic model the troposphere at the sea surface is warm and sub-saturated, and the irreversible evaporation flux is driven there by the difference between the chemical potentials of water in the ocean and in the air, Equation 3, which is approximately controlled by the relative humidity, Equation 5. At the interface ocean-atmosphere, energy is strictly conserved in this model [147, 148]. With rising altitude, the temperature drops below the dew- or frost point, clouds form and precipitation removes the water again that was brought in by the sea before. There exists a net transport of water vapour from the sea surface to the clouds in absence of any vertical gradient of specific humidity, due to the idealisation of an infinitely fast turbulent exchange. Especially over the open ocean (as opposed to the land) a neutral isentropic stratification prevails that is largely independent of the seasonal cycle of solar irradiation. This means that the vertical exchange and transport processes are dominated by mechanically induced turbulence which is controlled by the wind velocity, independent of the specific-humidity gradient.

\footnotetext{
* "Dampfdrucksprung an der Meeresoberfläche"
} 
The opposite idealised limiting case is that of a laminar vertical air flow without any mixing. Water vapour is transported along such a flow filament without compositional changes of the moving air parcel. Also in this case there is a flux of latent heat whose strength cannot be parameterised by a gradient of specific humidity along the thread of the current. If air is ascending by thermal convection, specific humidity remains unchanged and the vertical humidity gradient vanishes, while the vertical moisture transport is determined exclusively by the mechanical motion and does not at all need to vanish.

The irreversible flux of water vapour into the troposphere is driven by the relative humidity at the ocean-atmosphere interface; in contrast to this process, vertical gradients of specific humidity cause irreversible redistribution of moisture only within the troposphere. However, there exist also significant convective and turbulent reversible transport processes of water vapour inside the troposphere along with negligibly small such gradients [149]. The consideration of such "nonlocal" fluxes requires the application of turbulence closure procedures of higher order [88, 141]. Additionally, reversible condensation occurs in clouds and by dew or frost in saturated air (100\% \% ). Contrary to these thermodynamic conditions, the turbulent transport model for this reversible system falsely calculates a vanishing flux of latent heat because a vertical gradient of specific humidity is lacking in the lower troposphere. It cannot be excluded that the substantial systematic problems with energy conservation at the interface between ocean and atmosphere, from which numerical climate models are suffering [59, 143], may in part be caused by the parameterisation used for marine evaporation rates if these - in contrast to the physical nature of the process - do not account for the relative humidity (more precisely, the thermodynamic activity of water, see Section 8) as the driving force at the sea surface.

In numerical models, the gradient appearing in the exchange equation for the turbulent water-vapour flux is mostly estimated by the difference $\left(q_{0}-q_{\mathrm{z}}\right)$ of the $q$ values at two different heights, for instance, at 1 and $10 \mathrm{~m}$ [57, 150, 151] Corresponding meso-meteorological observation methods at two levels over land had also been developed [138, 152]. This method is known as the bulk-aerodynamics (BA) method, see above. The errors of BA-based turbulent fluxes are caused by errors (i) in the determination of the state variables that are requisite for the calculation of the sea-surface temperature, the specific humidity and the wind-speed difference, as well as (ii) within the bulk parameterisation itself, by which the associated fluxes are compiled from the related property differences (ibid.). Adjustable coefficients permit the fitting of the formula so that it quantitatively reproduces the relations of the present world on average. Nevertheless, exploiting the BA parameterisation of the latent heat flux is a general source of substantial uncertainties of climate models and is subject to in-deep investigations [120]. For example, it follows from Equation 5 that in fact the evaporation rate is proportional to the logarithm of the water-vapour content $x$ rather than being dependent linearly. At the utmost, the parameterisation of the models works correctly for small deviations from the particular climatological value that was valid at the time the related coefficients were adjusted. In the course of global warming, however, the humidity at the sea surface is changing, but presumably, however, without updating the models' parameterisations, nor, more preferably, without their self-consistent predictions.

Simple examples may show that the linear approach is problematic also physically. If there is a $q$ gradient, but the air is saturated at the surface, $q_{0}=q^{\text {sat }}$, then evaporation is thermodynamically impossible but will nevertheless take place in the numerical model. Vice versa, if the turbulent mixing of air is strong enough, $q=q_{\mathrm{z}}=q_{0}$, then the gradient of $q$ disappears together with the model's evaporation; however, if this well-mixed air is subsaturated, $q<q^{\text {sat }}$, then evaporation of arbitrary intensity may happen in reality. A modified version which partially avoids these problems is assuming $\left(q^{\text {sat }}-q_{\mathrm{z}}\right)$ as the driving force of evaporation [18, 21, 59, 95 153-157]. This approach may be understood as a coarse graining of the parameterisation of Wüst (1920) [12], Sverdrup (1936) [13] and Albrecht (1940) [14] in two different ways, namely as either one of the "vapour-pressure jump", or one of the "vapour-pressure gradient" at land. The latter, however, does not describe evaporation directly but only indirectly via the intensity of the turbulent mixing close to the surface.

Already Knuspe (1977) had pointed to systematic errors in the estimation of the latent-heat flux by the BA method which result from assuming humidity saturation at the sea surface associated with a temperature sampled at 20-40 $\mathrm{cm}$ water depth ("subsurface water temperature"). The author emphasised that the sea surface is cooled down by evaporation and is colder than the bulk temperature of the near-surface water body. With reference to literature sources, Knuspe (1977) underlined the possibility that air immediately at the sea surface may be subsaturated. The determination of the latent-heat flux, carried out at the German Bight and the Baltic Sea, was based on measurements of fluctuations of the wind, of the temperature and of the atmospheric refractivity, as well as of the vertical differences of the specific humidity between the sea surface and a reference height of 10 metres, exploiting the measured bulk temperature of the nearsurface water body as well as the measured dry- and wet-bulb temperatures for the calculation of the relative humidity by means of a psychrometer. The BA formula for evaporation was fitted to the observed evaporation fluxes. The adjustment resulted in the existence of a residual term of evaporation of $-0.6 \mathrm{~mm} \mathrm{~d}^{-1}$ ("apparent negative moisture flux") at a vanishing vertical gradient of specific humidity. The residual term implies that the real evaporation flux disappears only if a certain, non-zero specific-humidity gradient is established [137]. This behaviour corresponds evidently to the physical deficiency of the BA approach discussed above. Without explicitly accounting for a negative residual evaporation, the application of the BA formula to the evaporation produces a significant systematic error in the heat flux 
of about $18 \mathrm{~W} \mathrm{~m}^{-2}$. On the basis of his data analysis, Kruspe (1977) [137] firmly stated: "Therefore we conclude that this finding is not merely a statistically accidental result."

The formulas used in diverse numerical models for the calculation of the latent-heat flux out of the ocean are suitably quantitatively defined as simple parameterisations that are on average consistent with available measured values of the present-day marine atmosphere. As physical models, however, they mostly fail already qualitatively under elementary plausibility tests. The reason for this lies in the circumstance that the exchange ansatz developed for the turbulent exchange of conservative and inert quantities does not account for any constraints regarding the thermodynamic (thermal, mechanical and chemical) equilibrium which controls the atmospheric water exchange.

"The ocean-atmosphere flux fields exhibit inconsistencies when evaluated separately for the individual sub-systems in independent, uncoupled mode equilibrium climate computations. In order to balance these inconsistencies a constant ocean-atmosphere flux correction field is introduced in the boundary conditions coupling the two sub-systems together" [158]. For the compensation of model artefacts or deficiencies of available parameterisations of subgrid-scaled fluxes, two basic versions of model adjustments are carried out in climate models:

(i) "Tuning": Adjustment of not directly measurable process parameters to warrant reasonable simulations of control runs (e.g., drag coefficient of the wind over land surfaces as a part of the parameterisation of subgrid-scaled processes), and

(ii) "Fudging": "Large-scale ad-hoc adjustment" to adapt the model climate to the real climate under the assumption that the adjustment itself is invariant with respect to climate change (e.g., correction of fluxes at the oceanatmosphere interface) [159].

The quantification of uncertainties resulting from the application of such adjustment techniques to climate models is subject to numerous investigations [86, 120, 160]. With respect to the latent heat flux, state-of-the-art climate models reveal a tendency of overestimating the seasonal amplitudes [160] as well as of overestimating the mean values in tropical regions [120].

One cannot expect of such models that they sufficiently precisely predict the sensitivity of climate with respect to changes of RH. If a model has previously been adjusted to a marine humidity of $80 \%$ rh, this model cannot subsequently offer an explanation why RH possesses just this value in nature and remains unchanged in the course of global warming. "Much of the systematic change in RH [in General Circulation Models] can be explained by Sherwood et al. (2010) [161] the gradients and trends each depend on a model's ability to resolve moisture transport". "Analysis of feedbacks in those models would be simplified by a methodology using relative rather than specific humidity as a state variable" [162]. State-of-the-art climate models show substantial deviations of simulated from observed seasonal cycles of RH. Simulated ensemble averages for the summer months underestimate the observed values by more than $20 \%$ rh [86].

In addition to the immense challenge to find the systematic error in the simulated heat fluxes, Zhang et al. (2018b) [120] raise the problem that the temperature coefficient of the observed specific humidity of $1.6 \% \mathrm{~K}^{-1}$ is significantly smaller than that of $7 \% \mathrm{~K}^{-1}$ resulting from the Clausius-Clapeyron (CC) equation, which in turn matches quite well the value of $7.6 \% \mathrm{~K}^{-1}$ obtained from ensemble simulations: "There are at least two aspects of this result worth discussing. On the one hand, we should acknowledge the large uncertainties in our observational data sources. For instance, surface humidity is usually derived from satellite-based total precipitable water content ... and/or brightness temperatures. Both the intrinsic limitations of those approaches and spread of modeling algorithms in various products could lead to significant uncertainties in observational $q_{\mathrm{a}}$. When considering trends with warming, these parameterisations in LHF [= latent heat flux] products may be somehow missing the compensatory increase in near-surface humidity as SSTs [= seasurface temperatures] increase. On the other hand, the plausibly well-constrained CC equation in the MME [= multimodel ensemble] indicates that the model output is favorably subordinated to model regulations. As stated in Levang \& Schmitt (2015) [163], however, 'the strength of the water cycle is governed by more complex processes than CC scaling'. It is quite likely that the strength of CC scaling is lower than theoretical prediction in the real world. Note that calculation error may also have a certain effect on the result, which is not discussed presently. A better understanding of how the $\mathrm{CC}$ equation/scaling behaves in the real world is essential for improving the accuracy of surface humidity in observations and needs continuous effort. It is worth noting that the very weak trend in LHF in all the models suggests that the LHF values are nearly conserved in the models. This discrepancy with respect to the observations may have an important impact on the energy budget in the models, and further studies are needed. The next generation of CMIP [= coupled model intercomparison project] is coming soon. This study is expected to provide constructive references for the evaluation of LHF in CMIP6 models. We will continue to focus on the performance of air-sea fluxes simulated in CMIP models and explore effective ways to improve them in the future" [120].

It should be noted at this point that the quotation, ,the strength of the water cycle is governed by more complex processes than CC scaling" in the upper excerpt, may be misunderstood as the CC equation can perhaps tell us something about the water content of the atmosphere, but not necessarily also something about its renewal rate, see Section 9. Because of the lack of sufficiently long time series of highly accurate humidity measurements it currently remains an 
open problem whether a potential trend in the latent heat flux, if it exists at all, will manifest itself in an associated trend of $\mathrm{RH}$ according to Equation 5, and whether the latter trend can be resolved significantly within the available measurement uncertainty of RH [82].

The exact physical reasons for the constancy of RH at the sea surface are not clear. While RH is determined by local processes on short time scales, its climatological values are the result of global processes. As soon as RH gets a bit smaller locally, the evaporation rate will increase due to Equation 3, and the moisture content of the air will increase again. At the same time the interface is cooling down (skin effect), and also this way the relative humidity is quickly increasing again, so that this negative feedback is stabilising the steady value against fluctuations. Assumingly, this local mechanism is acting on short time scales below one hour.

Feedback effects of global form, however, may be expected on climatological time scales of months, years or longer, but they are complicated and not fully understood yet. A simplified such feedback model is proposed by Randall (2012) [56]. As a starting point he considers a state of the atmosphere in which the atmospheric radiative cooling is balanced by the release of latent heat from condensing water vapour. What will happen as a result of a fluctuation during which the velocity of the hydrological cycle is higher?

(i) The atmosphere gets warmer because more latent heat is released per unit of time.

(ii) The high cloudiness grows due to additional water vapour, thereby reduces the radiative cooling of the atmosphere and heats up the atmosphere further (high clouds such as cirrus are very cold and emit less heat to above than they receive from below).

(iii) The enhanced evaporation cools down the sea surface and correspondingly also the thin air layer above, therefore increases RH there and reduces evaporation.

(iv) The additional release of latent heat in the upper troposphere warms up the air there, impedes the convection to form high-reaching clouds and strengthens in turn the radiative cooling.

The combination of these counter effects leads to a negative, stabilising feedback that attenuates the original fluctuation, as it is observed in nature. Randall adds that geographically, the distribution of radiative cooling and the release of latent heat are negatively correlated with a positive feedback between their fluctuations on the global average, so that they may also act destabilising.

Imagine our world with a tiny, hardly measurable reduction of RH under otherwise largely unchanged conditions. The evaporation rate from the ocean were higher, the ocean cooled down and the atmosphere received a stronger flux of water vapour. More clouds would form and more precipitation would fall. On the night hemisphere, clouds warm the Earth because they block thermal emission, while on the day side they cool by shadowing the sunlight. This striking difference between either clear or overcast nights and days can be described as a thermal moderation by clouds which all inhabitants of the mid-latitudes know very well from their own experience. The typical timescale of a cloud is only about an hour; to model the thermal effect of a cloud one cannot exploit its 24-h mean value. For example, many clouds form only under solar irradiation (thermal convection) and disappear soon again in the evening [164]. The day-night difference of the effect of cloudiness is quite significant; the global net cooling effect of $20 \mathrm{~W} \mathrm{~m}^{-2}$ of clouds [165] is the difference of strong warming by night-time clouds and strong cooling by daytime clouds. It would depend on various details like the local time of the day when the clouds are floating in the sky, with which sign the radiation balance of the ocean were climatologically affected by fluctuations of relative humidity. „The net effect [of clouds] depends on their appearance in time with respect to the seasonal and diurnal cycles" [92]. Whether a cloud is cooling or warming depends almost exclusively on whether it is in the sky at day or at night, and only insignificantly on its altitude and structure.

It is in particular the cloud dynamics with its short scales in time and space that poses a key problem to climate modelling which works on much larger scales [30,166,167]. Already the Swedish physicist and chemist Svante August Arrhenius $(* 1859, \uparrow 1927)$, the pioneer of simple climate modelling [168], hinted on the influence of clouds on the energy balance of the Earth [166]. With respect to the role of clouds in the climate system, Marshak \& Davis (2005) [166] explain that ,the short answer to the 'Why?' question is that clouds are the greatest unknown in all of physical climate modelling; they radically alter the distribution of radiant energy and latent heating in ways that have proven devilishly hard to capture in climate models since clouds reflect sunlight but preserve infrared radiation to the Earth (by radiating to space at a colder temperature than the surface they overlie) their solar and infrared radiation effects work against each other, and we had only theoretical calculations of which prevailed".

The speed of global warming as the response of a climate model with respect to a $\mathrm{CO}_{2}$ doubling depends strongly on the description of cloud feedbacks. The wide range of predicted global warming had led the above authors to the following statements: "Clouds hold the fate of the Earth in their hands, and we don't know which number they will pick, if either. They are indeed the lever sought by Archimedes, with which one could move the Earth - or at least the Earth's climate". "After all, clouds are a fast random component of the system, loosely analogous to the stochastic 'weather' term that was used in simple climate models of the 1970s, and thus clouds may prevent a perfectly deterministic solution to the climatic consequences of rising $\mathrm{CO}_{2}$. That is, the solution may never settle down to a predictable value that all 
models can agree upon because of the random jiggling of the clouds. Clouds may indeed be completely deterministic in an ideal Laplacian universe, but in any conceivable modeling framework they will always have unknown aspects which will have to be drawn from a probability distribution. This is already true now for any GCM [General Circulation Model] that uses 'random overlap' of clouds or any of its variants" [166].

The realistic description of how clouds modulate the radiation balance of the terrestrial surface is a still unsolved problem of climate modelling. In this regard, Marshak \& Davis (2005) [166] note: "Let's think about the nature of those 'modulations' for a moment. Without clouds, curves of solar and longwave surface radiation as a function of time look smooth and slowly varying. Clouds destroy that utterly. They make surface radiation 'turbulent', mirroring turbulence in the cloud themselves. This turbulence manifests itself as large vacillations in minute-to-minute measured surface fluxes and even second-to-second variations in the direct beam of the Sun." Using a conceptual model for the description of the radiation-convection equilibrium, Thomas and Stamnes (1999) [93] demonstrated that, depending on cloud-top altitude and cloud emissivity, the terrestrial surface temperature may either rise, or drop, or remain constant along with increasing cloud coverage. "Clouds have been of particular importance because of their value in understanding atmospheric circulation, particularly relating to atmospheric moisture and precipitation and their role in affecting the energy and water balances" [23].

State-of the-art climate models are still subject to systematic cloud-related model biases. For example, the fifth phase of the Coupled Model Intercomparison Project (CMIP5) revealed poor predictive power of tropical and subtropical stratocumulus layers prevailing over the eastern parts of ocean basins [169, 170]. This weakness is caused by a positive bias in the sea surface temperature (SST), which in turn is related to biases in surface humidity and cloudiness and reflects poor coupling of marine boundary layer (MBL) processes to the large-scale climate state [169, 170]. There are still great uncertainties in the simulated global mean equilibrium temperature change $\Delta T$ in response to the radiative forcing due to $\mathrm{CO}_{2}$ doubling, $\Delta F_{2 \mathrm{x}}$, and the radiative feedback parameter $\lambda(\Delta T=2.1$ to $4.7 \mathrm{~K}$ in $\mathrm{CMIP5}$ vs. $1.8-5.6 \mathrm{~K}$ in CMIP6; $\Delta F_{2 \mathrm{x}} \approx 2.5$ to $4.4 \mathrm{~W} \mathrm{~m}^{-2}$ in CMIP5 vs. $\approx 2.7$ to $4.2 \mathrm{~W} \mathrm{~m}^{-2}$ in CMIP6; cloud-related $\lambda_{\text {cloud }} \approx-0.25$ to $1.25 \mathrm{~W}$ $\mathrm{m}^{-2} \mathrm{~K}^{-1}$ in CMIP5 vs. -0.5 to $1.25 \mathrm{~W} \mathrm{~m}^{-2} \mathrm{~K}^{-1}$ in CMIP6 [171] $]^{*}$. For the low-cloud radiative feedback parameter the authors reported $0.09 \mathrm{~W} \mathrm{~m}^{-2} \mathrm{~K}^{-1}$ (CMIP 5) and $0.21 \mathrm{~W} \mathrm{~m}^{-2} \mathrm{~K}^{-1}$ (CMIP 6). Modelled cloud feedbacks depend sensitively on cloud parameterisation, e.g., the treatment of microphysics and the interrelation of cloud properties (low cloud cover, LWP, cloud water phase etc.) with the SST via MBL processes, in which atmospheric humidity plays an important role. For example, the cloud feedback strongly depends on the description of warm-rain processes [173]. The aggregation state of cloud water is expected to shift from ice and mixed-phase to liquid clouds in a warmer atmosphere [173]. Warm clouds, however, have a higher albedo and longer lifetime and reduce the shortwave radiation flux absorbed by the Earth's surface, which constitutes a negative radiative feedback [173]. This cooling feedback was found to decrease from CMIP5 to CMIP6, which increases the greenhouse warming in CMIP6. If cloud liquid water precipitates too quick, the cloud lifetime shortens and negative lifetime feedbacks of warm clouds will be underestimated [173]. The modification of the warm-rain probability alone is sufficient to increase the cloud lifetime feedback by a factor of three as compared to the default model [173].

"The treatment of clouds in climate models presents greater obstacles to quantitative analysis of climate sensitivity than does the treatment of water vapor. To model the relative humidity distribution and its response to global warming one requires a model of the atmospheric circulation. The complexity of the circulation makes it difficult to provide compelling intuitive arguments for how the relative humidity will change" [174]. "Using [ISCCP] data from 1983 to 1994, a globally increasing trend in monthly mean cloudiness reversed during the late 1980s and early 1990s. There now appears to be an overall trend toward reduced total cloud amounts over both land and ocean during this period" $[175,176]$. Similar to this finding, recent earthshine measurements [93] indicate a decline of global albedo by $0.5 \mathrm{~W} \mathrm{~m}$ ${ }^{2}$ between 1998 and 2017. However, between 2003 and 2015, while the uncertainty of satellite data on global cloud coverage could be reduced substantially, those do not exhibit any clearly discernible trend [82].

Of course there exists an immediate link between the humidity distribution in the atmosphere and cloudiness [98, 100, 177, 178]; a dry atmosphere cannot form water clouds, while a saturated one, however, does this very easily. Over

\footnotetext{
* The sensitivity of Earth's climate usually refers to the response of the energy balance at the top of the atmosphere (TOA) to a perturbation. The TOA energy imbalance is the sum of the radiative forcing and the radiative response of the system to a global surface temperature anomaly, $\Delta R=\Delta F+\lambda \Delta T$, where $\Delta R$ denotes the net TOA radiative flux anomaly, $\Delta F$ the radiative forcing ( $\Delta R>0$ and $\Delta F>0$ in downward direction), $\lambda$ the radiative feedback parameter (in units of $\mathrm{W} \mathrm{m}^{-2} \mathrm{~K}^{-1}$ ), and $\Delta T$ is the global mean surface air temperature [172]. Supposing an equilibrium state $(\Delta R=0)$, then a flux perturbation $\Delta F$ will lead to a relaxation of the system to a new equilibrium by a temperature change $\Delta T=-\Delta F / \lambda$. The climate equilibrium sensitivity, $\Delta T / \Delta F=-1 / \lambda$, describes the change in the global mean temperature at equilibrium in response to a radiative forcing [172]. For climate studies the climate forcing is usually taken to be the radiative forcing due to $\mathrm{CO}_{2}$ doubling, $\Delta F=\Delta F_{2 \mathrm{x}}$. While the forcing $\Delta F_{2 \mathrm{x}}$ is a measure of the external perturbation of the climate system, the radiative feedback parameter $\lambda$ is a measure of the response of the climate system to compensate this perturbation; "A climate system that more effectively radiates thermal energy to space or more strongly reflects sunlight back to space as it warms (larger magnitude $\lambda$ ) will require less warming to restore planetary energy balance in response to a positive radiative forcing, and vice versa" [171].
} 
India and the U.S., cloudiness anomalies and surface RH are positively correlated [84]. "Indeed one does find empirically that non-convective cloud amount, classed as low, middle, and high, is highly correlated with the average relative humidity in the respective layers" [177]. A simple correlation between cloud coverage $C$ and $R H$, for example;

$C=1-\sqrt{\frac{1-R H}{1-R H_{\text {crit }}}}$,

is employed for modelling cloud formation $[92,115,119,179]$. It is valid in the interval $1 \geq R H \geq R H_{\text {crit }}$ and defines cloud-free air $(C=0)$ otherwise. By cloud obstruction, short-wave radiation received at the sea surface may be estimated by an empirical reduction factor of $\left(1-0.614 C^{3}\right)$ [180].

In a simple conceptual model one may, without taking care in detail of the complicated small-scale processes, empirically assume that the observed constant values of marine RH of $80 \%$ rh and of global cloud cover of $C=60 \%$ represent a stable steady state of the climate system [82]. From the corresponding coupled system of equations for $R H$ and $C$, short relaxation times of only $32 \mathrm{~h}$ and $91 \mathrm{~h}$ can be derived for their fluctuations, which lie in the frequency range of weather processes [181] and indicate a high dynamical stability of this system [64]. Such a finding would be consistent with an expected high sensitivity of the climate system with respect to small changes of RH at the sea surface, see Section 6.

For its elliptically varying distance from the Sun, Earth receives $6.8 \%$ more irradiation on 1 January than on 1 July $[92,182]$; with respect to the mean oceanic absorption of $168 \mathrm{~W} \mathrm{~m}^{-2}$ [58], this amounts per ocean surface to $11 \mathrm{~W} \mathrm{~m}^{-2}$ more in boreal winter than in summer. Because the total illuminated ocean surface is larger in northern winter (77 \% of the global surface) than in northern summer $(66 \%)$, the marine fraction of the globally averaged solar forcing is seasonally oscillating between $134 \mathrm{~W} \mathrm{~m}^{-2}$ in January and $107 \mathrm{~W} \mathrm{~m}^{-2}$ in July. In the course of the astronomical Milanković cycles, this difference is currently at its maximum due to the actual correlation between axis tilt of the planet and eccentricity of its orbit [182]. By evaporation, the global influx of water vapour to the atmosphere should vary correspondingly strongly, however, these authors are unaware of related studies of such large amplitudes of the globally averaged marine relative humidity. The observed global cloud coverage varies seasonally by about $5 \%$ only, taking maximum cloudiness in the austral summer [183], being positively correlated with the global oceanic solar irradiation. Apparently, there exist sufficiently strong negative feedback loops which attenuate seasonal oscillations of $C$ and $R H$.

\section{Thermal Radiation of the Ocean: The Greenhouse Gases $\mathrm{H}_{2} \mathrm{O}$ and $\mathrm{CO}_{2}$}

Even without measuring instruments, the effect of water vapour $\left(\mathrm{H}_{2} \mathrm{O}\right)$ as a greenhouse gas can be experienced very impressively, as already Caecilie Seler-Sachs noted during her travel 1887-1897 across Mexico: "Since a couple of years, Tuxtla Gutierrez has been the seat of the government [of Chiapas]. For anyone who knows San Cristobal [de las Casas], the former capital of the state, the change is entirely beyond comprehension. Tuxtla is hot and has a flagging climate. In a two-days march one climbs up to the cool, clear altitude of San Cristobal"* [184]. In bioclimatology, this combined effect of temperature and humidity is often expressed in terms of equivalent temperature as a measure for heat content of the air by which statements about the perception of sultriness, comfortableness and chilliness may be quantified [185].

Similar differences exist between the extremely hot and humid Massawa at the Red Sea and the summerly-nippy Asmara in the Highland of Eritrea above. "Descending abruptly from an elevation of nearly $2400 \mathrm{~m}$ to sea-level, the climate becomes increasingly sultry and hot, and a burning wind, seemingly released from some gigantic oven, replaces the cool zephyrs of Asmara. At the end of the road is the Red Sea port of Massawa, where the average temperature throughout the year is $30^{\circ} \mathrm{C}$ " [186]. Whether between the towns of Tuxtla and San Cristobal in Mexico, or between Massawa and Asmara at the Red Sea, in the first ones the moist air prevents the tropical temperatures from getting cooler by radiation even in the starry night, while the latter places become noticeably chilly just after sunset. However, such conditions can hardly be transferred to the marine atmosphere without any mountains or dry places.

Among the various measures of the atmospheric content of water vapour, two are particularly important; the specific humidity, $q$, and the relative humidity, RH. The first one is the ratio of the mass of water vapour to the mass of humid air while the latter is the ratio of the number of moles of water vapour to that of saturated air (at the same temperature and pressure). For the greenhouse effect, the mass of water, $q$, is the key. In this context RH plays only a minor role by dictating the maximum value of $q$ at saturation (100\% $\mathrm{rh}$ ).

Water vapour in the troposphere may essentially amplify its own greenhouse effect. The feedback between $q$ and RH results in a kind of bistability, a Venus-Mars effect described by Komabayasi (1967) [187] and Ingersoll (1969, 2013) $[188,189]$. Along with rising temperature, the value of $q$ of a given air parcel remains unchanged while the saturation

\footnotetext{
* "Tuxtla Gutierrez ist seit einigen Jahren Sitz der Regierung [von Chiapas]. Wenn man San Cristobal [de las Casas], die frühere Hauptstadt des Staates, kennt, so scheint die Verlegung ganz unbegreiflich. Tuxtla ist heiß und hat ein erschlaffendes Klima. In zwei Tagesmärschen steigt man bis zur kühlen, klaren Höhe von San Cristobal hinan“
} 
value increases exponentially according to the Clausius-Clapeyron equation, and RH decreases accordingly strongly. If the air at a warm place is sufficiently humid, the resulting greenhouse effect may increase its temperature and in turn the saturation limit, so that $q$ may grow by evaporation and amplify the greenhouse effect even more. Vice versa, if the saturation value of $q$ is low at a cool place, then the greenhouse effect by $\mathrm{H}_{2} \mathrm{O}$ is weak. Under a clear sky the night temperatures my drop drastically, and falling dew or frost will reduce the specific humidity even further, and in turn the greenhouse effect, etc. In contrast to a moisture-induced Venus-Mars bistability, the terrestrial climate seems rather to be coined by a life-friendly stable homeostasis for which the constancy of RH apparently plays a certain role.

Water vapour in the troposphere may also amplify significantly a $\mathrm{CO}_{2}$-induced greenhouse effect [168]. "Water vapor, confessedly the greatest thermal absorbent in the atmosphere, is dependent on temperature for its amount, and if another agent, as $\mathrm{CO}_{2}$, not so dependent, raises the temperature of the surface, it calls into function a certain amount of water vapor which further absorbs heat, raises the temperature and calls forth more vapor" (T.C. Chamberlin 1905, quoted from Held \& Soden, 2000) [174]. "If changes in humidity and clouds produce between 66 and $85 \%$ of the temperature change induced by greenhouse gas emissions, then pinning down changes in humidity and clouds as a consequence of $\mathrm{CO}_{2}$ emissions is the crucial issue in predicting future climate change. The question how credible climate models are in making such predictions then revolves about how well they account for changes in humidity and cloudiness" [91, 190].

As a simple model for the feedback between water vapour and $\mathrm{CO}_{2}$, Held \& Soden (2000) [174] proposed an equation of the form;

$\frac{\mathrm{d} T}{\mathrm{~d} \log _{2}\left[\mathrm{CO}_{2}\right]}=\frac{a}{1-b-c}$,

in which $a \approx 1 \mathrm{~K}$ describes the direct reaction of the surface temperature $T$ to the $\mathrm{CO}_{2}$ content of the troposphere, $b \approx$ 0.4 (at fixed RH) the feedback via water vapour, and $c$ the change of the albedo due to melting snow and ice. An effect of these factors on the cloud coverage is not allowed for in the model (8).

Realistic radiation transport models in the atmosphere are mathematically and physically complicated [191-194]. In textbooks different statements may be found about water vapour as a greenhouse gas. So, Thomas \& Stamnes (1999) [93] write: "A species of key importance to terrestrial radiation, and thus to its heat balance, is the water vapor molecule $\left(\mathrm{H}_{2} \mathrm{O}\right)$. Although present in fractions of $1 \%$ by volume, it dominates the absorption of infrared radiation. Water vapor (along with several other minor species) has the dual properties of allowing relatively free passage of shortwave solar radiation while impeding the release to space of thermal infrared radiation."

"Irish physicist John Tyndall (1861) presented proof that water vapour and carbon dioxide $\left(\mathrm{CO}_{2}\right)$ were the most important atmospheric gases" [23]. Lutgens \& Tarbuck (2001) [195] explain: "Water vapor and carbon dioxide are the principal absorbing gases, with water vapor absorbing about $60 \%$ of the radiation emitted by Earth. Therefore, water vapor accounts (more than any other gas) for the warm temperatures of the lower troposphere". Also Rapp (2010) [92] emphasises: "Water vapor is by far the most important greenhouse gas, in the sense that it absorbs more irradiance from the Earth than all other greenhouse gases combined". Pierrehumbert (2010) [193], however, considers such statements as misleading: „One sometimes hears it remarked cavalierly that water vapor is the 'most important' greenhouse gas in the atmosphere. The misleading nature of such statements can be inferred directly from [the fact that] if water vapor were the only greenhouse gas in the Earth's atmosphere, the temperature would be a chilly $268 \mathrm{~K}$ ".

Thomas \& Stamnes (1999) [93] presented simple semi-empirical extrapolations of the so-called "greenhouse" factor based on the concept of the emission altitude (as the height in which the infrared cooling takes its maximum). Estimates of the global effects of various greenhouse gases by means of a detailed radiation model were published by Zhong and Haigh (2013) [196]. In order to quantitatively illustrate the specific role of the marine atmosphere, a rigorously simplified conceptual model will be discussed here, exploiting the absorption spectra of Zhong and Haigh (2013) [196].

The present-day atmosphere contains about $400 \mathrm{ppm} \mathrm{CO}_{2}$, equivalent to a partial pressure of $0.4 \mathrm{hPa}$ at sea level. As the related fraction of water vapour, we estimate a partial pressure $32 \mathrm{hPa}$, or $3.2 \%$ of the ambient pressure of 1013 $\mathrm{hPa}$, or $32000 \mathrm{ppm}$ volume fraction, from the vapour pressure of water of $40 \mathrm{hPa}$ at $300 \mathrm{~K}$ on the one hand, and an $\mathrm{RH}$ of $80 \%$ rh on the other hand. The ratio of these mole numbers, 32 000: $400=80: 1$, results in a mass ratio $\mathrm{H}_{2} \mathrm{O}: \mathrm{CO}_{2}$ of about 33: 1 or 1: 0.03 , using the molar masses of $\mathrm{H}_{2} \mathrm{O}\left(18 \mathrm{~g} \mathrm{~mol}^{-1}\right)$ and of $\mathrm{CO}_{2}\left(44 \mathrm{~g} \mathrm{~mol}^{-1}\right)$. For this mass ratio of the tropical marine atmosphere, the absorption curves of both in the infrared spectrum are displayed in Figure 5 (values taken from Zhong \& Haigh (2013) [196]). Considered formally, the blue curve for $\mathrm{CO}_{2}$ represents a mass absorption coefficient per $\mathrm{kg}$ of a mixture that consists of $0.97 \mathrm{~kg}$ of a transparent gas and $0.03 \mathrm{~kg} \mathrm{of} \mathrm{CO}_{2}$, in order to make the curves of $\mathrm{CO}_{2}$ and $\mathrm{H}_{2} \mathrm{O}$ more conveniently quantitatively comparable with their relative atmospheric impacts.

The total frequency range can be divided into five qualitatively different bands $\mathrm{A}-\mathrm{E}$, as displayed in Figure 5 and described in Table 1. The distribution of the thermal radiation energy of a black body (liquid water is in very good approximation opaque and black in the infrared) at $T=300 \mathrm{~K}$ possesses a maximum at a wavenumber of $k=$ $2 \pi / \lambda \approx 650 \mathrm{~cm}^{-1}$ with $\lambda$ being the wavelength. This follows from Wien's displacement law, $k_{\max }=2.168 \mathrm{~mm}^{-1} \times$ 
$(T / K)$. In band $\mathrm{A}, k<600 \mathrm{~cm}^{-1}$, at the long-wave flank of the radiation distribution, the absorption by $\mathrm{H}_{2} \mathrm{O}$ dominates About the maximum, in band $\mathrm{B}\left(600 \mathrm{~cm}^{-1}<k<800 \mathrm{~cm}^{-1}\right), \mathrm{CO}_{2}$ dominates as absorber. Radiation is still intense in band $\mathrm{C}\left(800 \mathrm{~cm}^{-1}<k<1200 \mathrm{~cm}^{-1}\right)$, the so-called atmospheric window, where neither $\mathrm{H}_{2} \mathrm{O}$ nor $\mathrm{CO}_{2}$ substantially impede the outgoing radiation. In the broad band $\mathrm{D}\left(1200 \mathrm{~cm}^{-1}<k<2000 \mathrm{~cm}^{-1}\right)$, again water vapour is blocking the heat export across the atmosphere, and in the short-wave band $\mathrm{E}, k>2000 \mathrm{~cm}^{-1}$, radiation is already weak enough to be ignored in our model for simplicity.

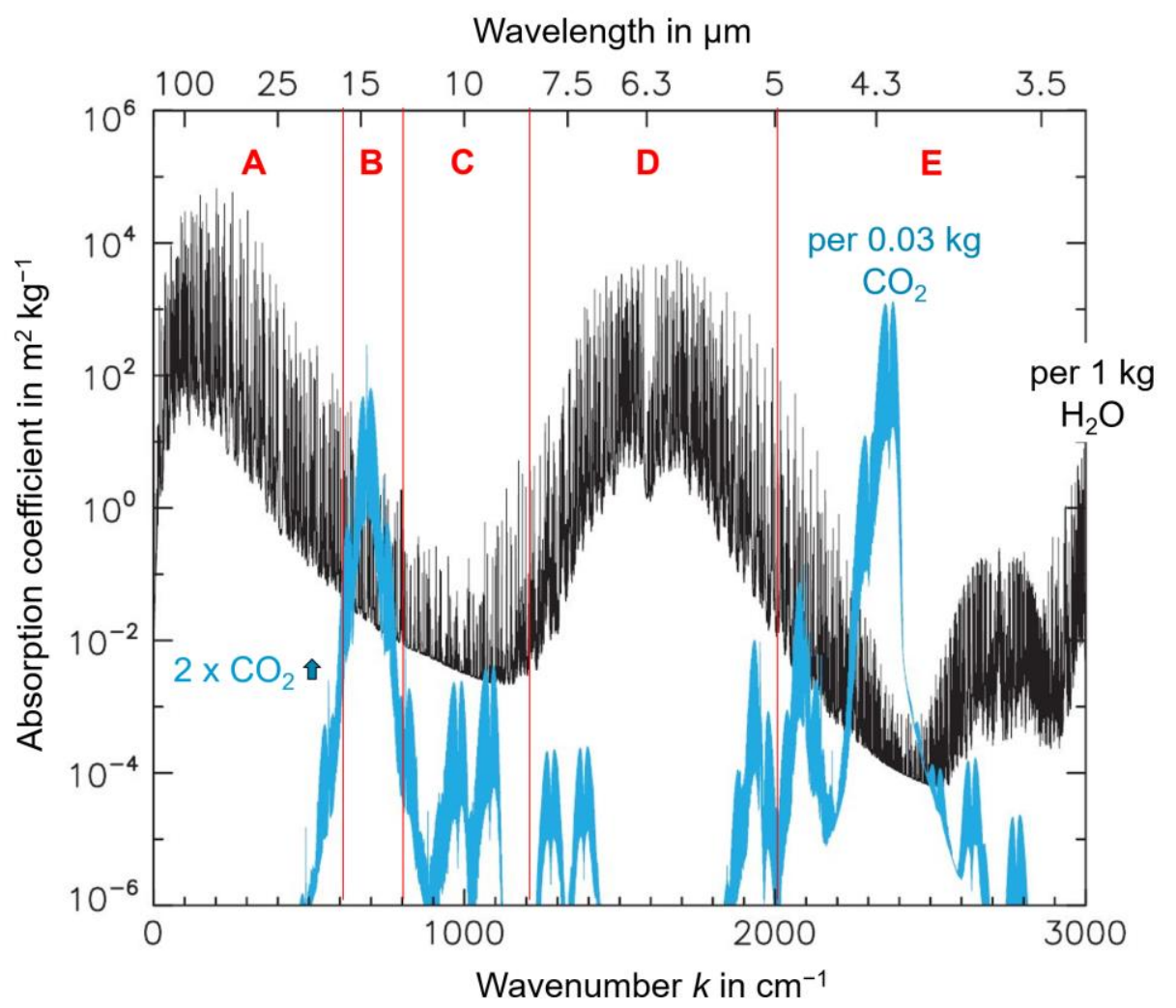

Figure 5. Infrared absorption spectra of water vapour $\left(\mathrm{H}_{2} \mathrm{O}\right.$, black curve). The corresponding spectrum of carbon dioxide $\left(\mathrm{CO}_{2}\right.$, blue curve) is drawn with a downward offset of $\log _{10}(33)=1.5$ units of the ordinate, so that it corresponds graphically to $\mathrm{H}_{2} \mathrm{O}$ with a mass ratio of $33: 1$ of the tropical marine atmosphere at $300 \mathrm{~K}$ and $80 \%$ rh as well as $400 \mathrm{ppm} \mathrm{CO}_{2}$. Original data were taken from the article of Zhong \& Haigh (2013) [196]. For the logarithmic scale of the ordinate, a doubling of the $\mathrm{CO}_{2}$ content would move its (blue) curve upward by $\log _{10}(2)=0.3$ units, as indicated by the short arrow " $2 \times \mathrm{CO}_{2}$ ". Thermal radiation at $300 \mathrm{~K}$ has its maximum at $k \approx 650 \mathrm{~cm}^{-1}$, near the boundary between the bands $A$ and $B$ (red). The properties of the bands $\mathrm{A}-\mathrm{E}$ are described in Table 1.

Table 1. Infrared spectral absorption properties (simplified) of $\mathrm{H}_{2} \mathrm{O}$ und $\mathrm{CO}_{2}$ with a mass ratio of 33:1, which corresponds to a tropical marine atmosphere at $300 \mathrm{~K}$ and $80 \% \mathrm{rh}$ as well as $400 \mathrm{ppm} \mathrm{CO}_{2}$, as shown in Figure 5. The radiation flux density of the particular bands A-E results from integrating Planck's radiation law [197] between the related band limits (rounded).

\begin{tabular}{|c|c|c|c|}
\hline Band & 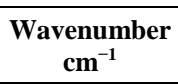 & $\begin{array}{l}\text { Radiation flux density at } 300 \mathrm{~K} \\
\qquad \mathrm{~W} \mathrm{~m}^{-2}\end{array}$ & Comment \\
\hline A & $<600$ & 150 & $\mathrm{H}_{2} \mathrm{O}$ dominates \\
\hline B & $600-800$ & 100 & $\mathrm{CO}_{2}$ dominates \\
\hline $\mathrm{C}$ & $800-1200$ & 130 & Radiation window \\
\hline $\mathrm{D}$ & $1200-2000$ & 70 & $\mathrm{H}_{2} \mathrm{O}$ dominates \\
\hline E & $>2000$ & 9 & neglected \\
\hline
\end{tabular}

During the past century, the atmospheric concentration of $\mathrm{CO}_{2}$ has increased from about $300 \mathrm{ppm}$ to about $400 \mathrm{ppm}$. As an illustration, during this time the (blue) $\mathrm{CO}_{2}$ curve in Figure 5 moved upward by an amount of $\log _{10}(400 / 300)=$ 0.125 units of the logarithmic $y$-axis, that is about $1 / 100$ of the total interval of 12 units visible in the graphic. This slight displacement with respect to the $\mathrm{H}_{2} \mathrm{O}$ curve represents the direct anthropogenic greenhouse effect on the tropical marine troposphere, of course without any changes of the absorption properties of the gas $\mathrm{CO}_{2}$ itself. Below the radiation maximum, in band $\mathrm{A}$, the effects are only minor as the absorption by $\mathrm{H}_{2} \mathrm{O}$ already present is merely strengthened. The major effect occurs at wavenumbers above the maximum; here the absorption band of $\mathrm{CO}_{2}$ is spreading at the cost of the atmospheric window $\mathrm{C}$, and less thermal radiation may pass the atmosphere. 
We estimate now separately the greenhouse effects of $\mathrm{H}_{2} \mathrm{O}$ and $\mathrm{CO}_{2}$, by simplifying the spectral absorption properties of Figure 5 to form a conceptual model with four 0/1 bands (without band E), that is, the black-body radiation at a given temperature is either absorbed completely or let passed completely in the particular band. This assumption permits a strongly simplified approximate partitioning of the infrared absorption with respect to the main absorbers water vapour

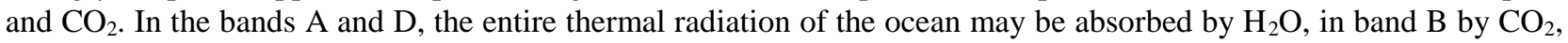
and band $\mathrm{C}$ may be fully transparent. The quantitative result is presented schematically in Figure 6.

The bottom row represents the tropical ocean which emits a total of $450 \mathrm{~W} \mathrm{~m}^{-2}$ in the spectral range between 0 and $2000 \mathrm{~cm}^{-1}$, according to its temperature of $300 \mathrm{~K}$. In the row above this radiation is taken as $100 \%$ and split into the bands. As given in Table 1, $130 \mathrm{~W} \mathrm{~m}^{-2}$ (corresponding to $29 \%$ ) pass band $\mathrm{C}$ without attenuation, bands $\mathrm{A}$ and $\mathrm{D}$ absorb $150 \mathrm{~W} \mathrm{~m}^{-2}$ resp. $70 \mathrm{~W} \mathrm{~m}^{-2}$ (together corresponding to $49 \%$ ) due to water vapour, while only band $\mathrm{B}$ depends on the $\mathrm{CO}_{2}$ content and absorbs $100 \mathrm{~W} \mathrm{~m}{ }^{-2}$ (corresponding to $22 \%$ ), about $1 / 4$ thereof as a result of the increase from 300 to $400 \mathrm{ppm}$. The radiation in the infrared window is of course additionally hampered by largely opaque clouds. Related to an average global cloud coverage of $60 \%$, the fraction of radiation in the infrared window absorbed by clouds is $60 \%$ $\times 29 \%=17 \%$ of the oceanic emission, as shown in the third row. As a result, uppermost row, only $12 \%$ of ocean's emission, or $54 \mathrm{~W} \mathrm{~m}^{-2}$, are directly released to the outer space. Of the radiation emitted by the ocean, $88 \%$ are absorbed by atmospheric water (in vapour and condensed phase) together with $\mathrm{CO}_{2}$. If the greenhouse effect of the two major absorbers is set to $100 \%$, a share of $3 / 4$ of the total effect is due to water vapour in the troposphere, only $1 / 4$ is due to $\mathrm{CO}_{2}$, and in turn only $1 / 4$ of the latter is caused by economic processes. The exclusive role of $\mathrm{CO}_{2}$ among the greenhouse gases results solely from the fact that its total mass in the atmosphere is a changing quantity which continuously increases [198] by the progressing anthropogenic mobilisation of the global fossil carbon reservoir, as does, as a consequence, also that of water vapour. This way small but systematic and momentous perturbations of terrestrial energy balance take place.

Of course, various arguments may be raised against the drastic simplifications of this conceptual model, but the results in Figure 6 are sufficiently similar to the accurate model calculations of Zhong \& Haigh (2013) [196], so that one may well consider the first ones as simple, plausible "rule-of-thumb" estimates of the radiation conditions over the tropical ocean. In particular it is important to emphasise that despite its high content of water vapour the marine troposphere is by no means "radiation saturated" in the infrared, that means, opaque like a bank of fog, so that additional $\mathrm{CO}_{2}$ cannot add any additional greenhouse effect. The residual transparency remaining despite the $\mathrm{H}_{2} \mathrm{O}$ abundance is the consequence of the existence of a suitable spectral atmospheric window. Otherwise, for instance, by modelling a spectrally homogeneous, "grey" troposphere [193, 199, 200], such analyses lead to unrealistic conclusions because they substantially underestimate the effect of $\mathrm{CO}_{2}$ in humid air.

\section{Tropical Marine Atmosphere (300 K, $80 \%$ rh)}

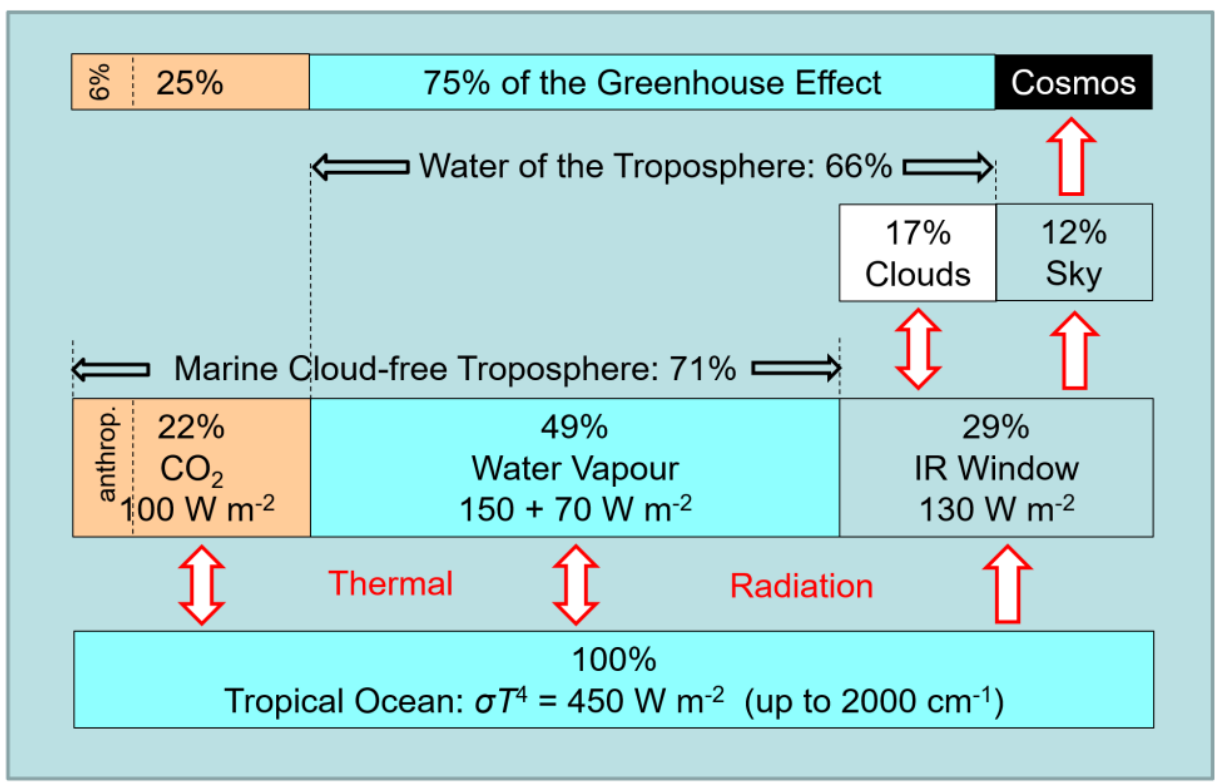

Figure 6. Conceptual spectral-band model of the tropical marine greenhouse effect. The thermal radiation at $300 \mathrm{~K}$ and 80 \%rh amounts to $450 \mathrm{~W} \mathrm{~m}^{-2}$ (lowest box). According to Table 1, $100 \mathrm{~W} \mathrm{~m}^{-2}$ thereof are absorbed by $\mathrm{CO}_{2}$ in band $\mathrm{B}$ (anthropogenic part $25 \mathrm{~W} \mathrm{~m}^{-2}$ ) and $(150+70) \mathrm{W} \mathrm{m}^{-2}=220 \mathrm{~W} \mathrm{~m}^{-2}$ by water vapour in bands $A$ and $D$. The rest of $130 \mathrm{~W} \mathrm{~m}^{-2}$ in the radiation window $D$ is blocked to $60 \%$ by clouds and only the remaining $130 \mathrm{~W} \mathrm{~m}^{-2} \times 40 \%=52 \mathrm{~W} \mathrm{~m}^{-2}$ are directly emitted from the sea surface to the cosmic space. Anthropogenic $\mathrm{CO}_{2}$ has narrowed the window by $25 \mathrm{~W} \mathrm{~m}^{-2}$ and, therefore, the emission without clouds by $10 \mathrm{~W} \mathrm{~m} \mathrm{~m}^{-2}$. Water in the form of vapour and clouds is responsible for $75 \%$ of the total greenhouse effect in the troposphere. 
The strong infrared radiation exchange between sea surface and troposphere causes a quick mutual equilibration of temperatures, typically on a time scale of hours, depending on the intensity of turbulent processes and the heat capacities of the water and air masses involved. Generally, the temperature difference between the two sides of the interface is small [201]. Strong evaporation is cooling the water surface ("skin effect" [202, 203]) and reduces the net heat export from the ocean by radiation, or even inverts it.

\section{Thermal Relaxation of the Ocean: What Seasons Tell Us}

On the climatological average, the terrestrial climate may be considered as a stable steady state if we refrain from phenomena such as global warming or ice ages. Then, the behaviour of small temperature fluctuations, $\delta T$, about this state is described by a simple linear dynamic equation:

$\frac{\mathrm{d}}{\mathrm{d} t} \delta T=-\gamma \delta T$

Here, $\gamma$ is the so-called Lyapunov coefficient which denotes quantitatively the strength of the restoring forces and this way the degree of stability; its reciprocal $\tau=1 / \gamma$ is the characteristic decay time or lifetime of a fluctuation, or its relaxation time. Schwartz (2007) [204] estimated from the autocorrelation of the mean global surface temperature 18802004 that this relaxation time of the Earth is about 5 years. This time is determined by the ocean to $85 \%$ and only to 15 $\%$ by the land. A similar result is obtained from the radiation balance of the ocean at a temperature of $18{ }^{\circ} \mathrm{C}$ and with an isobaric heat capacity of $C_{p} \approx 800 \mathrm{MJ} \mathrm{K}^{-1} \mathrm{~m}^{-2}$ per surface area of the mixed layer down to $200 \mathrm{~m}$ depth, with no atmosphere above it [146].

$\tau=\frac{C_{p}}{4 \sigma_{\mathrm{SB}} T^{3}} \approx 5 \mathrm{yr}$.

After critical discussion, Schwartz subsequently extended his estimate to even 8 years [92, 205]. In contrast to this value, Frankignoul \& Hasselmann (1977) [206] found a significantly shorter typical lifetime of only 6 months of oceanic sea-surface temperature anomalies, and the analysis of seasonal data by Prescott \& Collins (1951) [207] suggests even times of merely 2-3 months (Figure 7).

How to explain such substantial discrepancies? It is helpful to know the effect of the decay time on periodic variations such as seasons. Equation 9, modified for this purpose by including a periodic forcing term with an amplitude $a$ and the angular frequency $\omega=2 \pi /(1 \mathrm{yr})$;

$\frac{\mathrm{d}}{\mathrm{d} t} \delta T+\gamma \delta T=a \cos \omega t$

may describe the effect of seasonal oscillations of the solar intensity. Given the variation $\Delta I$ (in $\mathrm{W} \mathrm{m}{ }^{-2}$ ) of the irradiation and the isobaric heat capacity $C_{p}$ per area of a periodically heated water column, the amplitude of the perturbation is $a=\Delta I / C_{p}$. A suitable solution of the differential Equation 11 for the function $\delta T(t)$ reads;

$\delta T(t)=A \cos (\omega t-\varphi)$.

By inserting Equation 12 into 11 it is easily verified that the phase shift $\varphi$ between astronomical solar irradiation and temperature follows from the equation;

$\tan \varphi=\omega \tau$.

The decay time of 5 years (Equation 8) results in a phase angle of $\varphi=88^{\circ}$, corresponding to a time lag of the seasonal temperature curve by 89 days. Quite fundamentally, the relation (13) implies that the phase difference must always be less than $90^{\circ}$, and that the delay of the temperature signal cannot exceed 91 days, even for arbitrarily long relaxation times. Observed lags of nearly 3 months in climate data therefore hardly permit any conclusion regarding the radiationcontrolled lifetime of thermal fluctuations, except that it is significantly longer than just those 3 months [146]. Regionally between the Tropics in Atlantic and Pacific, Prescott \& Collins (1951) [207] found delays of up to 110 days, as visible in Figure 7 for the austral spring. In such cases the primitive model (11) is evidently too simple because it neglects influences such as that of the atmosphere, of ocean currents, of the strength of turbulent mixing and of the double transit of the overhead sun position.

The amplitude of the seasonal temperature signal (12) follows to be;

$A=\frac{a \tau}{\sqrt{1+(\omega \tau)^{2}}}=a \tau \cos \varphi$

As the asymptotic limiting value for long decay times, $\tau \gg 1 / \omega \approx 2$ months we find $A=a / \omega$. For St. Helena Island located at $16^{\circ} \mathrm{S}$, the well-known astronomical solar irradiation varies between summer and winter by about $\Delta I \approx$ $\pm 80 \mathrm{~W} \mathrm{~m}^{-2}[56,208]$. Resulting from the model (11), a seasonal temperature amplitude of only $A=0.5^{\circ} \mathrm{C}[146]$ would result, which needed to be halved once more if the real irradiation at the sea surface beneath the atmosphere were allowed 
for. This value is at least by a factor of 5 less than the seasonal cycle (Figure 7) observed in reality, if the island's air temperature is taken as a proxy for that of the surrounding ocean. A difference between summer and winter of less than $1{ }^{\circ} \mathrm{C}$ were hardly be perceptible anymore, would the subtropical Atlantic solely be cooled by thermal radiation. There remains only one plausible process for the real cooling mechanism which should be responsible for the additional at least $80 \%$ of the thermal seasonal cycle, and this is the export of latent heat from the ocean to the atmosphere by evaporation from the sea surface.

The marine climate, as we may conclude from the seasonal cycle of temperature at St. Helena Island, is not dominated by the thermal radiation of the ocean. Water vapour in the atmosphere and its formation rate can be assumed to be the governing control quantities, as Heinrich Hertz did already back in 1885. Opposite to thermal radiation, latent heat transport is affected at most indirectly by the presence of other greenhouse gases. Latent heat is generated by evaporation and is released as thermal radiation only after condensation in clouds at high altitudes above which the greenhouse effect is only minor. Latent heat passes the dense lower troposphere and its "greenhouse", so to say, by a "tunnel effect" by means of thermal convection and large-scale circulation.

As an aside, it may be mentioned in this context that, strictly speaking, the widespread use of the term "greenhouse" is physically misleading. The greenhouse effect of a glasshouse or in a botanical garden is not caused by radiation as it is in the atmosphere due to absorber gases, but is a consequence of suppressing the convective transport of sensible and latent heat. By opening or closing of control windows, the convective air current may be increased or reduced, and the temperature in the interior of the greenhouse be regulated mechanically.

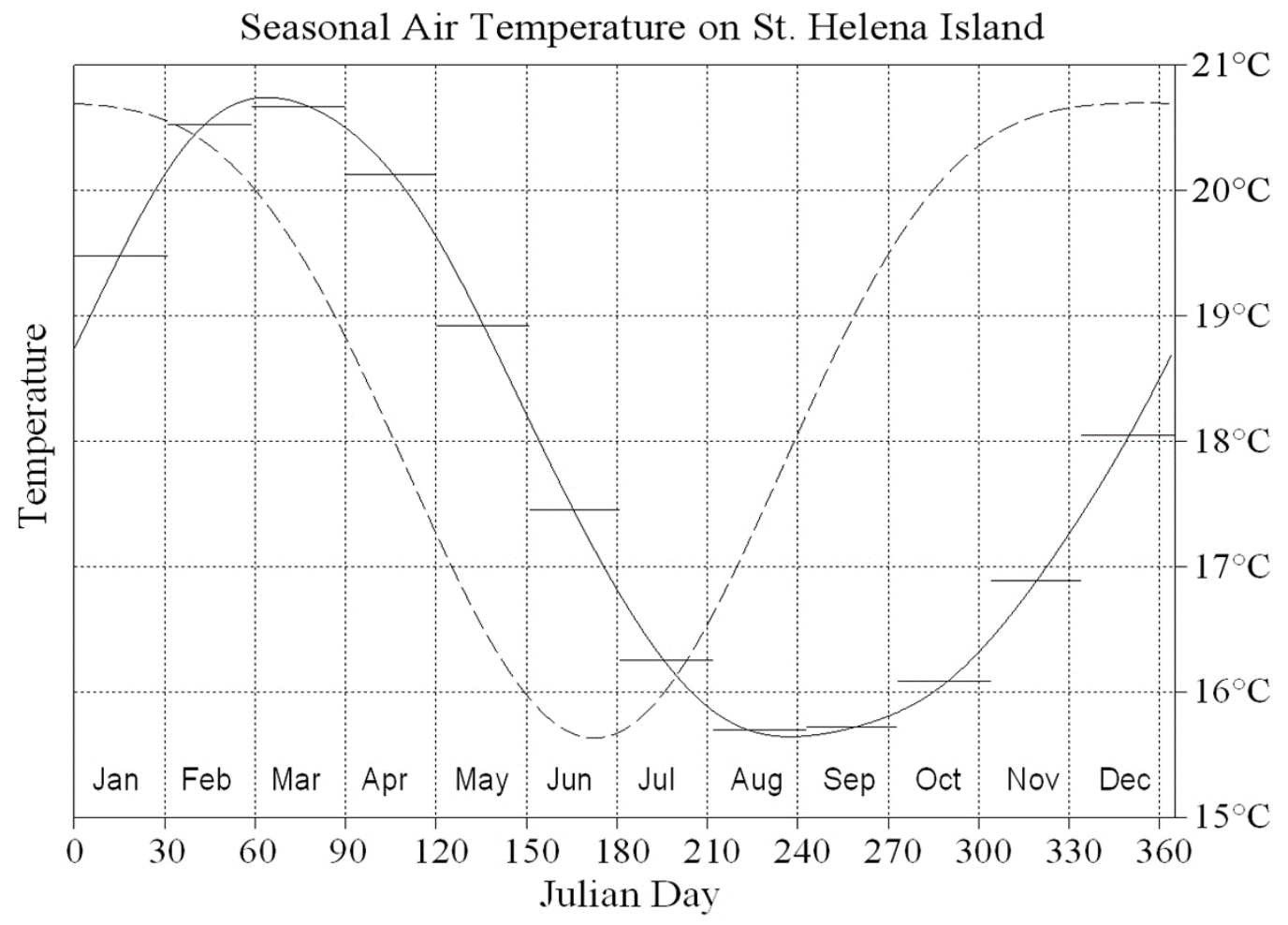

Figure 7. Climatological seasonal cycle 1893-1999 of the air temperature at St. Helena Island in the South Atlantic, converted to sea level [65]. Horizontal steps show the monthly mean values; the smooth curve is a daily interpolation of those values. Dashed is a phase-true daily astronomical solar irradiation, scaled to the temperature range. The average delay between the two curves is 78 days. The extended radiation maximum from November until January result from the double passage of the solar overhead position between the Tropics of Cancer and Capricorn.

\section{The Warming Air and Sea: How Much Heat Energy is Detoured?}

In the course of the last century, the surface temperatures have noticeably risen on Earth; this is evident from many long measurement series such as that on St. Helena Island in the South Atlantic [65]. The record of the air temperature [209], Figure 8, which is essentially influenced by the surrounding ocean, reveals an irregular but systematic increase. Over the last 40 years there was no month any more with a temperature below $15^{\circ} \mathrm{C}$, in contrast to the decades before.

On the global average, between 1979 and 2010 the surface temperature rose by $0.17{ }^{\circ} \mathrm{C}$ per decade [210]. Assuming for simplicity that the entire mass of air, which is about $10000 \mathrm{~kg} \mathrm{~m}^{-2}$ with a specific heat capacity of about 1000 $\mathrm{J} \mathrm{kg}^{-1} \mathrm{~K}^{-1}$, is affected by that warming, then the heat flux required is only as little as $0.005 \mathrm{~W} \mathrm{~m}^{-2}$, extended over the long time interval. This is a tiny figure compared to various other energy fluxes at the terrestrial surface (see Section 7). 
For example, of the ca. $300 \mathrm{~W} \mathrm{~m}^{-2}$ that the planetary surface receives from the sun, approximately $2.3 \mathrm{~W} \mathrm{~m}^{-2}$ are spent for the generation of "potentially available kinetic energy" as the maximum energy that is available for isentropic movements of the baroclinic atmosphere in order to achieve horizontally oriented pressure surfaces of a hydrostatic equilibrium. The energy flux density for the conversion of potentially available potential energy to the potential energy of mean and turbulent currents is about $2.0 \mathrm{~W} \mathrm{~m}^{-2}$ [211].

Considered energetically, the greenhouse effect of the atmosphere is very small and may originate from various different heat sources. Observational data and climate models suffer from too large uncertainties to permit a statistically significant resolution of the responsible transport processes. Despite the dramatic consequences suspected for life on Earth as a consequence of the warming, the fact persists that still today the relevant causal chains are insufficiently well known quantitatively. Other processes, in particular ones in which water in the atmosphere is participating, are characterised by significantly larger energy transfers, and their possible changes, perhaps unforeseen by models, may easily accelerate global warming by several times, or turn it into its opposite. For demonstration, several important energy fluxes are compared in Section 7. Two simple examples may illustrate this statement.

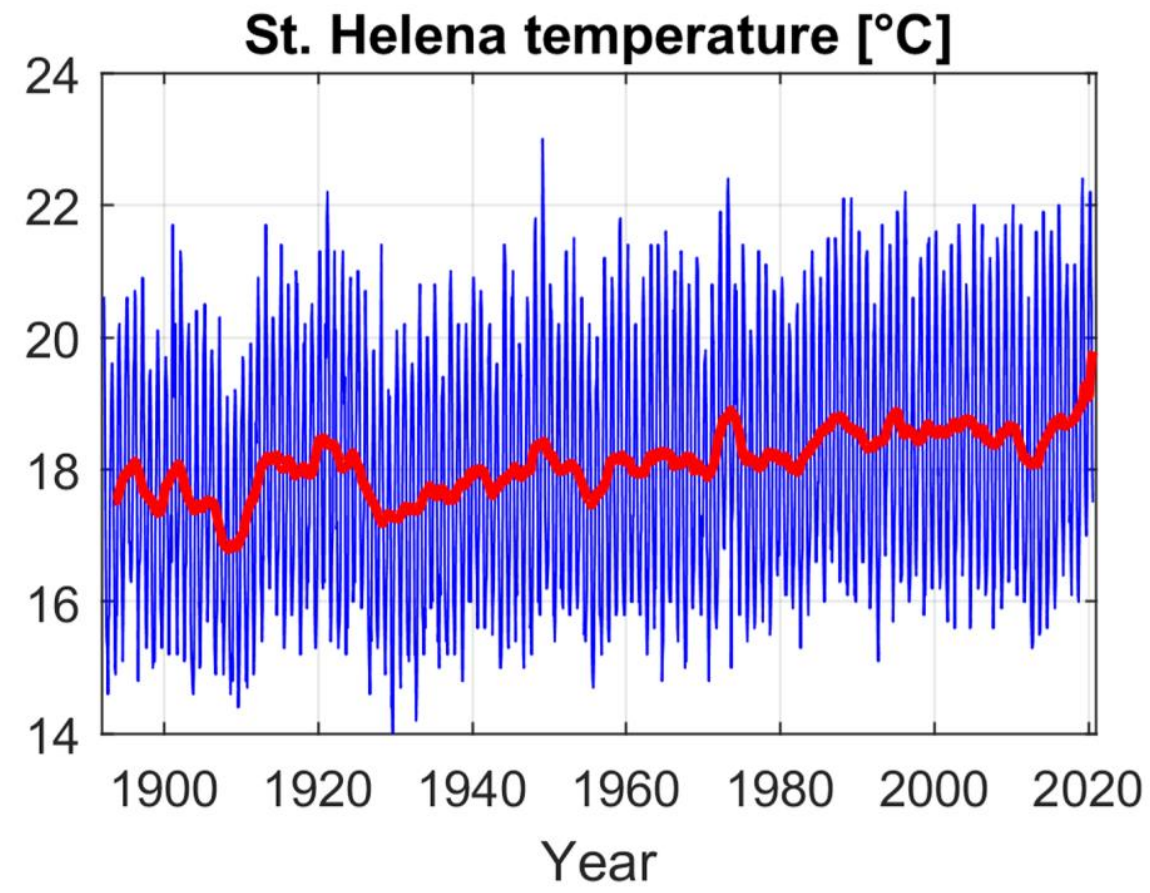

Figure 8. Monthly mean values of the air temperature at St. Helena Island in the South Atlantic [65]; after appearance of the publication the time series has been extended [209]. The bold curve shows the moving average over 3 years. The trend of this local warming amounts to $0.9^{\circ} \mathrm{C}$ per century.

\section{Example 1 - Fossil Fuels}

Per year, the fraction of atmospheric $\mathrm{CO}_{2}$ is increasing by $2 \mathrm{ppm}$ as a result of burning fossil energy carriers in power plants, heaters or cars. We can roughly estimate how much heat is released by this combustion, ignoring for simplicity all $\mathrm{CO}_{2}$ that is stored or bound elsewhere in similar amounts [198]. The molecular weight of dry air is about $30 \mathrm{~g} \mathrm{~mol}^{-1}$. The air column with a mass of $10000 \mathrm{~kg} \mathrm{~m}^{-2}$ contains approximately $330000 \mathrm{~mol} \mathrm{~m}^{-2}$ air molecules. Thereof, a volume fraction of $2 \mathrm{ppm}$ corresponds to $0.66 \mathrm{~mol} \mathrm{~m}^{-2}$ of $\mathrm{CO}_{2}$. The formation enthalpy of gaseous $\mathrm{CO}_{2}$ from solid carbon is about $400 \mathrm{~kJ} \mathrm{~mol}^{-1}$. Along with a production of $0.66 \mathrm{~mol} \mathrm{~m}^{-2}$ of $\mathrm{CO}_{2}$, energy is released at a rate of $\approx 260 \mathrm{~kJ} \mathrm{~m}^{-2}$ per year, which is, converted to seconds, a power of $\approx 0.008 \mathrm{~W} \mathrm{~m}^{-2}$. The waste heat of our technical devices clearly exceeds the heating power requisite for global warming, and may, theoretically, well be a candidate for its cause. However, see further below, the technical heat does not at all suffice to explain also the measured warming of the ocean.

\section{Example 2 - Accelerated Water Cycle}

Per year, the ocean evaporates about $1000 \mathrm{~mm}$ of water, see Section 2, whose latent heat is later released in the atmosphere during the formation of clouds. An inconsiderably small increase in annual evaporation by just $0.06 \mathrm{~mm}$ per year would correspond to an excess heat flux of $\approx 0.005 \mathrm{~W} \mathrm{~m}^{-2}$, which virtually resulted in a doubling of the global warming observed so far. If, however, the evaporation had reduced by $0.06 \mathrm{~mm}$ per year, the warming of the air would simply stall. No observation or model exists that may safely predict or exclude a future change of annual evaporation by $0.06 \mathrm{~mm}$ in whatever direction. The substantial uncertainty in our knowledge of the global evaporation rate (Figure 3) practically does not allow reliable predictions of its variation by a few hundredth $\mathrm{mm}$ per year, that is, by several orders of magnitude below the uncertainty limits. An intensification of the hydrological cycle, of evaporation and 
precipitation, is concluded from available data in several scientific papers, see Section 9. An estimated increase in absolute humidity (more precisely, in integral water content) of the troposphere by $0.4 \mathrm{~kg} \mathrm{~m}^{-2}$ per year [90] requires an additional evaporation rate of $0.4 \mathrm{~mm} \mathrm{yr}^{-1}$. This extra evaporation flux ebbs away in the troposphere where it piles up the integral water content, but it does not affect the global precipitation flux, and so it does not constitute an amplification of the full hydrological cycle. The associated export of latent heat from the ocean is about 7 times larger than the energy flux required for the measured global warming of the air. Therefore, the increase of the tropospheric water-vapour content is significantly more energy-intensive than that of the temperature so vehemently discussed in the public. During the condensation of the additional water vapour in clouds, consequently, significantly more latent heat is released in excess than is necessary for the observed global warming of the atmosphere.

Together with the atmosphere, also land and ocean are warming up and ice masses are melting. 10 years ago is was relatively uncertain whether at all or to what extent the ocean is warming [212]. Meanwhile more and better data have improved the knowledge [213]. According to that, since 1987 the heat content of the upper $2000 \mathrm{~m}$ of the world ocean has risen at a rate of $0.67 \mathrm{~W} \mathrm{~m}^{-2}$ or $0.47 \mathrm{~W} \mathrm{~m}^{-2}$, respectively, if referred to the sea or to the global surface. Considered only energetically, the warming of the sea is about 100 times as strong as that of the atmosphere. The related amounts of energy are clearly beyond our technical possibilities. A similar quantity of heat would be released if per day about 100 of the largest H-bombs fictitiously detonated in the ocean.

For us as land inhabitants, the subjective impression appears easily that during the daytime the Sun is heating up our surrounding and that this heat "under the greenhouse roof" cannot escape fast enough anymore, as we know it from the little glasshouse in the own garden in spring. This way our air would get warmer and warmer, and only the cold water of the seas may moderate these effects a bit, as it virtually seems. The physical facts, however, do not support this heavily simplified picture. Heating up the air requires only $1 \%$ of the energy that is warming our oceans. The increase of temperature felt by us and recognised as dominating turns out to be objectively only a small side effect of the global oceanic warming. "So, the much disputed 'global warming' concerns in fact mostly the temperature rise in the ocean"* [214].

The main energy reservoir is the ocean, and the exchange of energy between the atmosphere and ocean is ubiquitous, so that heat once sequestered can resurface at a later time to affect weather and climate on a global scale. ... Increasing concentrations of carbon dioxide and other greenhouse gases have led to a post-2000 imbalance at the top-of-atmosphere (TOA) of $0.9 \pm 0.5 \mathrm{~W} \mathrm{~m}^{-2}$ that produces 'global warming'. Over the past 50 years, the oceans have absorbed about 90 $\%$ of the total heat added to the climate system while the rest goes to melting sea and land ice, and heating the land surface and atmosphere. While the planetary imbalance at TOA is too small to measure directly from satellites, instruments are far more stable than they are absolutely accurate with calibration stability $<0.3 \mathrm{~W} \mathrm{~m}^{-2}$ per decade $(95 \%$ confidence) $[215,216]$.

\section{Uncertainty at the Ocean-Atmosphere Interface: Is the Causality Significant?}

As David Hume had analysed already in 1748, observation may indicate correlations between certain events but cannot rigorously prove mutual causal relations between them [217], and his conclusion was confirmed in 1787 by Immanuel Kant (1956) [218]. This problem is particularly grave in the case of the reasons for climate change [4, 146, $219,220]$, especially because the criterion of repeatability is not applicable. Models which rely on such causality assumptions provide convincing arguments for their correctness if and only if they permit successful and significant predictions for situations whose data had not been exploited for the construction of the model. Quantitative predictions which do not exceed the uncertainty level of the model do not fall into the category of significant predictions. An extreme example for a causal chain for a correct but insignificant prognosis within the uncertainty range is the ironic weather proverb "If the rooster crows on the dung pile, the weather will change, or stay as is for a while"

Therefore, the analysis of uncertainties of climate observations and models is indispensable for the interpretation of their results and predictions. As is visible from Table 2, for the global warming of the atmosphere only a tiny part of $0.005 \mathrm{~W} \mathrm{~m}^{-2}$ is detoured from the total solar irradiation of $341 \mathrm{~W} \mathrm{~m}^{-2}+$ geothermal + fossil energy sources. There is hardly any property in geosciences, however, which is known to within an extremely small uncertainty of only $1 \mathrm{ppm}$.

Global climate models suffer from technical problems of correctly closing the energy balance between ocean and atmosphere as soon as they simulate both subsystems together. Heat fluxes through the sea surface exhibit imbalances there of at least $10 \mathrm{~W} \mathrm{~m}^{-2}$, occasionally even of $30 \mathrm{~W} \mathrm{~m}^{-2}$, and different models may deviate from one another on the order of $50 \mathrm{~W} \mathrm{~m}^{-2}$ [59]. It is the ambitious aim for the coming decade to reduce on the global scale the systematic errors of observations below $5 \mathrm{~W} \mathrm{~m}^{-2}$ and the random uncertainties below $15 \mathrm{~W} \mathrm{~m}^{-2}$ [143]. Yet, however, such error ranges are typical for the lower end of Table 2 and will exceed the typical effects of global warming by several orders of magnitude.

\footnotetext{
* "Die viel diskutierte ,globale Erwärmung" betrifft also in Wahrheit vorrangig dem Temperaturanstieg im Ozean".

$\dagger$ "Kräht der Hahn auf dem Mist, ändert sich das Wetter oder bleibt, wie es ist".
} 
In the beginning of the $80 \mathrm{~s}$, with the advance of essentially improved measurement methods and devices for the determination of turbulent energy fluxes ("eddy-correlation" method), the problem of the "mismatched energy balance" became more and more obvious $[52,139]$. Currently considered as mainly responsible are mesoscale circulation patterns due to the heterogeneity of the substratum which are less relevant over the ocean than over land [221, 222]. Further error sources were identified to be:

(i) The measurement of longwave radiation fluxes and the resulting errors in the radiation balance,

(ii) The measurement of latent heat fluxes, as well as,

(iii) The measurement of energy-balance quantities at different altitudes and above different substrata regions (heterogeneity of the substratum) (ibid.)

According to Foken (1998) [52], the biggest difficulties of investigations at land arise from the experimental validation of ground moisture and, strongly coupled to it, the latent heat flow. Today, knowledge about this phenomenon is largely restricted to a small group of experimenters. Critically the author notes that the relevance of this expert knowledge is hardly recognised by modellers, although scientific needs such as those for model validation with measurement data, for the quantitative determination of the water cycle, and for questions regarding environmental policy, should have urged a rapid solution of the problem. Measurement of the latent heat flux is characterised as one of the most complicated metrological problems. Foken (1998) [52] estimates the relative error of the latent heat flux for closing the energy balance of the ground to 5-20\% and the related uncertainty to $20-50 \mathrm{~W} \mathrm{~m}^{-2}$ [52]. Similar values are reported by Laubach (1996) [139].

Foken (1998) [52] and Laubach (1996) [139] argue that despite the care exercised, during the last years experimenters were unable to explain the residuum of the energy-balance closing by deficiencies of the determination of turbulent fluxes exclusively. Even the progress achieved is considered as insignificant. An important question remains without answer: Why does the terrestrial surface apparently receive more energy by irradiation during daytime than it may get lost in the form of turbulent fluxes in the atmosphere (and as mostly molecular flux into the ground)?

Foken (1998) [52] found indications for a problem of averaging that is rather typical in meteorology: "It turned out that unsteady conditions on a temporal scale of about 5 minutes during heat storage in the ground may explain a part of the energy imbalance. Turbulence eruptions are similar, however, the temporal scale in this case is sometimes $<1$ minute. If the two events do not appear regularly during the measurement period of 30 minutes for eddy-correlation measurements, they are identified by the quality check only as disturbances. If they occur regularly, the frequency of their appearance is virtually assigned to a flux, however, the energy of the single events can be quantified only by special investigations, such as by wavelet analysis."*

Laubach (1996) [139] argues in a similar way: "The summary of all results lets appear another, common cause to be more plausible, namely that the assumption of vanishing vertical winds at periods beyond the chosen average interval $\tau$ is often critical. In other words: there exist 'convective' or 'mesoscale' vertical motions which may, as a consequence of the selected value of $\tau$, contribute only to [the mean vertical velocities] $\bar{w}$ rather than to [their fluctuations] $w^{\text {'. } . " ~}$ Foken (1998 [52], see also Kracher et al., 2009 [223]), finally, directs warning words to the address of atmosphere modelling by saying: "Despite a certain success it must still be stated that the modellers among my colleagues are not yet aware of the severity of the problem. As a rule, they work with energy-balance equations whose coefficients had been verified by measurements, while their latent-heat fluxes are mostly determined as the remaining left-over term, which therefore received the residual as an additive. This has implications for the surface temperature that is important for most of the models, and in particular for the water-vapour flux"

It is referred here to the monograph of Schmugge and André (1991) [224] for a deepening of the problems discussed here, of the theoretical foundations of the latent-heat-flux parameterisation in multi-scale atmospheric models for

\footnotetext{
* "Es zeigte sich, daß instationäre Bedingungen in einem zeitlichen Maßstab von ca. 5 Minuten bei der Wärmespeicherung im Boden einen Teil der Nicht-Schließung der Energiebilanz erklären können. Analoges gilt für Turbulenzausbrüche, jedoch ist hier der zeitliche Maßstab z. T. $<1$ Minute. Treten beide Ereignisse nicht regelmäßig während der 30 minütigen Meßdauer der eddycorrelation-Messungen auf, werden sie bei einem Qualitätstest nur als Störung identifiziert. Treten sie regelmäßig auf, wird zwar die Frequenz des Auftretens scheinbar einem Fluß zugeordnet, die Energie der Einzelereignisse kann aber erst durch spezielle Bearbeitungen, z. B. mittels Wavelet-Analyse, quantitativ ermittelt werden.“

$\dagger$ “Die Zusammenschau aller Ergebnisse läßt jedoch eine andere, gemeinsame Ursache plausibler erscheinen, und zwar die, dass die Voraussetzung verschwindender Vertikalwindanteile bei Perioden oberhalb der gewählten Mittelungszeit $\tau$ oft kritisch ist. Mit anderen Worten: es existieren ,konvektive“ oder ,mesoskalige‘ Vertikalbewegungen, die als Folge der Wahl von $\tau$ nur zu [den

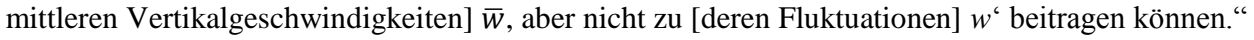

$\$$ “Trotz mancher Erfolge muß jedoch weiterhin konstatiert werden, daß die Tragweite der Problematik insbesondere den Modellierern unter den Fachkollegen noch nicht bewußt ist. Sie arbeiten in der Regel mit Energiebilanzgleichungen, deren Koeffizienten durch Messungen verifiziert worden sind, bei denen der latente Wärmestrom meist als Restglied bestimmt wurde und somit den Zuschlag durch das Residuum erhielt. Dies hat Auswirkungen auf die für die meisten Modelle wichtige Oberflächentemperatur und insbesondere den Wasserdampffluß.“
} 
different applications (climate modelling, weather forecast, hydrological predictions), as well as for the understanding of the practice and of the challenges of in-situ techniques, of ground-based as well as air- and space-borne remotesensing methods for the determination of the latent-heat flux as well of its determining physical parameters.

Violations of the physical conservation laws are not restricted to numerical models but appear also along with the objective analysis of observational data which enter numerical predictions or serve as a basis for model validation and verification. In this context, Trenberth et al. (1995) [247] mention errors in the heat and momentum balance, but also unclosed mass balances of the operational global objective analysis of dry air as well as of trace gases such as water vapour, $\mathrm{CO}_{2}$ or ozone.

Table 2. Estimates of globally averaged energy forcings* of selected processes, see also Hupfer (1991) [246]

\begin{tabular}{|c|c|c|}
\hline Process (*values not averaged globally) & Flux in $\mathrm{W} \mathrm{m}^{-2}$ & Reference \\
\hline Ocean model heat flux uncertainty & 0.0003 & McDougall et al. (2021) [225] \\
\hline Ice melt of Antarctica per year 2003-2019 & 0.0024 & Smith et al. (2020) \\
\hline Human electric power consumption & 0.004 & Lu et al. (2009) [227] \\
\hline Ice melt, globally per year 1992-2011 & 0.004 & Feistel (2017) [228] \\
\hline Ice melt of Greenland per year 2003-2019 & 0.004 & Smith et al. (2020) [226] \\
\hline Global warming of the atmosphere & 0.005 & Feistel (2015) [229] \\
\hline Rise by $2 \mathrm{ppm} \mathrm{CO}$ per year in the air & 0.008 & Example 1 Section 6 \\
\hline Anthropogenic power consumption & 0.02 & Lu et al. (2009) [227] \\
\hline Latent heat of rising humidity & 0.03 & Trenberth et al. (2005) [90] \\
\hline Geothermal heat, locally for Antarctica* & 0.05 & Maule et al. (2005) [230] \\
\hline $1 \mathrm{~mm}$ per year of world-ocean evaporation & 0.057 & Section 2 \\
\hline Geothermal heat, globally averaged & 0.087 & Pollack et al. (1993) [231] \\
\hline Geothermal heat, locally for Antarctica* & 0.115 & Lösing et al. (2020) [232] \\
\hline Warming of the oceanic surface layer & 0.13 & Flohn et al. (1992) [6] \\
\hline Sunspot cycle of 11 years & \pm 0.3 & Pallé et al. (2004) [233] \\
\hline Uncertainty of the solar constant & 0.4 & Schmutz et al. (2009) [234] \\
\hline Global radiation imbalance & 0.42 & Bernhardt (2014) [235] \\
\hline Warming ocean (upper $2000 \mathrm{~m}$ ) & 0.47 & Cheng et al. (2020) [213] \\
\hline Uncertainty of the terrestrial energy balance & 0.5 & Trenberth and Fasullo (2010) [216] \\
\hline Earth's albedo decline 1998-2017 & 0.5 & Goode et al. (2021) [236] \\
\hline Reduction of the $\mathrm{AMOC}^{\dagger} 2009-2010$ & 0.63 & Bryden et al. (2014) [237] \\
\hline Milanković cycles ( $0.2 \%$ of the solar constant) & \pm 0.7 & Laskar et al. (2011) [238] \\
\hline Little Ice Age 1645-1715 (Maunder Minimum) & -0.9 & Steinhilber et al. (2009) [239] \\
\hline Global radiation imbalance & 0.9 & Trenberth and Fasullo (2010) [216] \\
\hline $\mathrm{CO}_{2}$ radiation forcing (last 230000 years) & \pm 1 & Pausata et al. (2020) [240] \\
\hline Greenhouse effect of methane $\mathrm{CH}_{4}$ & 1.7 & Zhong and Haigh (2013) [196] \\
\hline Greenhouse effect of laughing gas $\mathrm{N}_{2} \mathrm{O}$ & 1.8 & Zhong and Haigh (2013) [196] \\
\hline Mechanical energy of the atmosphere & 2 & Peixoto and Oort (1992) [67] \\
\hline Anthropogenic radiation forcing & 2.3 & Bernhardt (2014) [235] \\
\hline Uncertainty of evaporation due to $1 \%$ rh & 3.6 & Eq. (15) \\
\hline Kinetic energy of the atmosphere & 4 & Monin (1982) [241] \\
\hline Estimates of increase since Maunder Minimum & $1 \ldots 6$ & Haigh and Cargill (2015) [182] \\
\hline Greenhouse effect of ozone $\mathrm{O}_{3}$ & 7.0 & Zhong and Haigh (2013) [196] \\
\hline Uncertainty of celestial thermal radiation & 7.2 & Ahmet et al. (2020) [242] \\
\hline Elliptical orbit of the Earth & \pm 12 & Peixoto and Oort (1992) [67] \\
\hline Cloud cooling & 20 & Mitchell (1994) [243] \\
\hline Uncertainty of the ocean-atmosphere heat flux & 20 & Josey et al. (2013) [59] \\
\hline Uncertainty of the meridional heat flux & 25 & Lindzen (1997) [244] \\
\hline Greenhouse effect of carbon dioxide $\mathrm{CO}_{2}$ & 25.5 & Zhong and Haigh (2013) [196] \\
\hline Greenhouse effect of water vapour $\mathrm{H}_{2} \mathrm{O}$ & 70.6 & Zhong and Haigh (2013) [196] \\
\hline Solar constant, globally averaged & 341 & Tobiska and Nusinov (2006) [245] \\
\hline
\end{tabular}

* Climatic forcing: „A climate forcing is an imposed perturbation of Earth's energy balance, measured in watts per square meter $\left(\mathrm{Wm}^{-2}\right)$ averaged over the planet" [249].

$\dagger$ AMOC: Atlantic Meridional Overturning Circulation (heat transport of the Gulf Stream in the North Atlantic). 
Errors in the mass balance of dry air propagate into the balances of climate-effective trace gases as a consequence of the fact that trace-gas concentrations are typically expressed as mass (or volume) ratios of the respective substance to that of moist or dry air. Errors alone in the mass balance of dry air may cause fictitious excess fluxes in the vertically integrated heat balance of $100 \mathrm{~W} \mathrm{~m}^{-2}$ locally [248]. Without specific investigations it cannot simply be assumed that such excess fluxes "average out" as randomly distributed in long-term integrations, and that they may not cause any systematic data bias.

The exchange of latent heat through the ocean-atmosphere interface is determined by the evaporation rate $E$ which is driven by the difference (3) of the chemical potentials [104]. For the purpose of a simple uncertainty estimate we replace that equation by its approximation for ideal gases:

$E=r\left(\frac{\mu_{\mathrm{W}}^{\mathrm{W}}}{R T}-\frac{\mu_{\mathrm{V}}^{\mathrm{AV}}}{R T}\right) \approx-r \ln R H$.

Here, $r$ is an effective empirical Onsager coefficient that decribes the proportionality between thermodynamic force ( - ln $R H$ ) and associated flux $(E)$. From the climatological values of the latent heat flux, $E \approx 95 \mathrm{~W} \mathrm{~m}^{-2}$, and the marine $R H=$ $80 \%$ rh, $r$ can be estimated [146] to:

$r=-\frac{E}{\ln R H} \approx 430 \mathrm{~W} \mathrm{~m}^{-2}$.

Meteorological measurements are not more accurate than 1 \%rh. Replacing in Equation 15 now $80 \%$ rh by $79 \%$ rh, we may estimate the sensitivity of the heat flux across the ocean surface with respect to small variations of RH:

$-r \ln 0.79 \approx 100 \mathrm{~W} \mathrm{~m}^{-2}$.

With respect to the surface of the world ocean, the estimated uncertainty of the latent heat flux caused by RH measurement therefore amounts to $\Delta E \approx 100 \mathrm{~W} \mathrm{~m}^{-2}-95 \mathrm{~W} \mathrm{~m}^{-2}=5 \mathrm{~W} \mathrm{~m}^{-2}$, or $3.6 \mathrm{~W} \mathrm{~m}^{-2}$ if referred to the total global surface area (Table 2). Hence, the global energy balance depends extremely sensitively on changes of the marine RH, significantly stronger than the accuracy with which RH is known. The global warming of the air could be maintained already by a hypothetical additional latent heat flux of $\Delta E=0.005 \mathrm{~W} \mathrm{~m}^{-2}$,

$\Delta E=-r \ln \frac{R H+\Delta R H}{R H} \approx-r \frac{\Delta R H}{R H}$,

if the average $\mathrm{RH}$ were reduced by merely $\Delta R H \approx-0.001 \% \mathrm{rh}$. Measurements or model predictions with such a resolution are far beyond our current technical and scientific capabilities; corresponding to this uncertainty, changes of this magnitude in the latent heat fluxes through the ocean-atmosphere interface can neither be detected nor predicted with metrological significance. Therefore, the role of those heat fluxes within causal climate models cannot be considered as ultimately clarified.

\section{Relative Fugacity: Toward a Thermodynamic Definition of Relative Humidity}

Phase transitions of water at the sea surface and in clouds control the huge energetic forcing of the "steam engine climate". These processes obey the fundamental laws of thermodynamics; energy and mass is conserved, entropy is produced. Climate models, however, do not strictly conform to those laws, neither separately in the atmosphere nor in the ocean, and even less at the interface between the two, see also Section 7.

"Unfortunately, it is not always possible to maintain the exact conservation laws and symmetries in the [discretized model] equations" [250]. "Model drift in time-integrated ocean heat and freshwater flux, net top-of-the-atmosphere radiation (netTOA) and moisture flux into the atmosphere (evaporation minus precipitation) is indicating a substantial leakage of mass and energy in the simulated climate system. This non-closure of the global mass and energy budgets arises due to small inconsistencies in the model treatment of energy and/or water" [251]. "Inspecting commonly used parametrizations for subgrid fluxes, we find that some of them obey the second law of thermodynamics and some do not" [252]. "Exchanges of heat, water, and momentum across the air-sea interface play major roles in driving the circulation of the ocean and atmosphere on timescales ranging from less than a day to millennia. The long-standing problem of obtaining closure of the ocean heat budget remains to be adequately resolved" [59].

To the various technical reasons for the violation of physical laws by numerical climate models also the fact belongs that prior to 2010 no standard equations existed at all for the computation of energy, entropy, enthalpy and of the chemical potentials of the particular phases and mixtures such as seawater, humid air or ice. For example, during the development of the 1980 seawater standard the Joint Panel on Oceanographic Tables and Standards (JPOTS) merely noted under the headline "Entropy of Seawater" that "as little time was available and extensive data sets were lacking, the panel could not discuss this matter in detail" [253]. In meteorology [78], no standard is defined for the entropy of humid air. "A key issue when discussing the isentropic circulation lies in that the entropy of moist air is not uniquely defined" [254]. Only since the adoption of the international seawater standard TEOS-10, these thermal and chemical quantities have become available to the geosciences with high accuracy and perfect internal consistency, and are gradually implemented in oceanographic circulation models [148, 225, 255-257]. Applications to meteorology are only at the beginning $[258,259]$. 


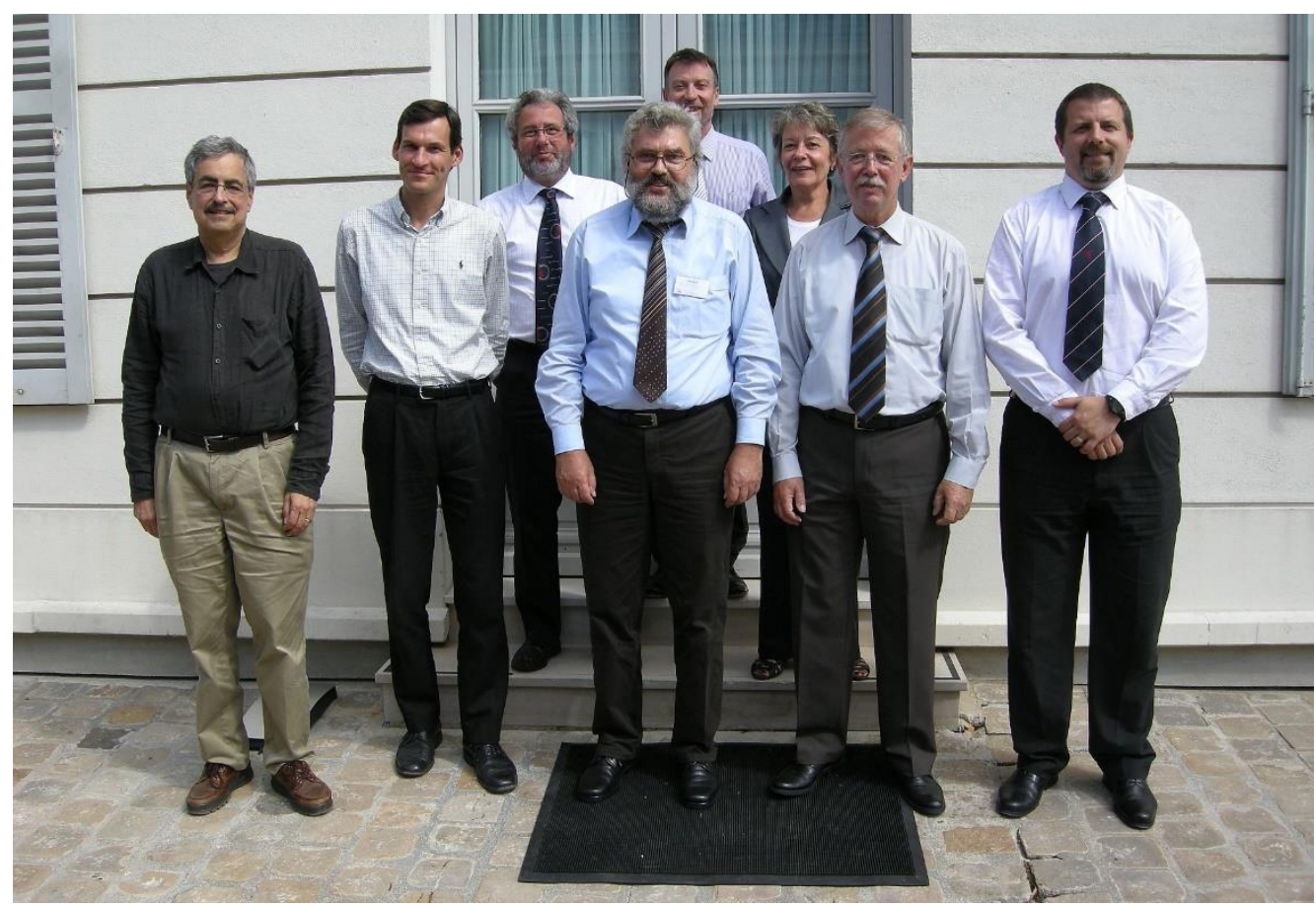

Figure 9. Initial meeting of the cooperation between BIPM and IAPWS at the Pavillon de Breteuil, Sèvres, 30 August 2011. From left to right: Richard Davis, Michael Stock, Alain Picard ${ }^{\dagger}$, Rainer Feistel, Andy Henson, Claudine Thomas, Michael Kühne, Robert Wielgosz.

For the exceptionally high quality and accuracy of the equations of TEOS-10, the close cooperation between geoscientists and the experts of the International Association for the Properties of Water and Steam (IAPWS) was vital. During the development of the seawater standard it became obvious that further fundamental problems exist which may be addressed only in cooperation with other international bodies, among those a uniform, physically based definition of relative humidity [77, 148, 260-262]. These activities commenced in 2011 after a first meeting at the International Bureau of Weights and Measures (BIPM) [55] at Sèvres near Paris (Figure 9) and have been coordinated since 2012 by the IAPSO ${ }^{*} / \mathrm{SCOR}^{\dagger} / \mathrm{IAPWS}$ Joint Committee on the Properties of Seawater (JCS) [263].

In TEOS-10, energies and entropies are defined relative to arbitrarily specified, metrologically advantageous reference states [148, 264]. The claim that these definitions lead to incorrect results in atmosphere models [265], and a resulting call for a related revision of TEOS-10 are, however, empirically ill-founded [266]. The "arbitrary additive constant [of the entropy has] no physical meaning and may be omitted at will" [267]. "That these additive terms, if considered absolutely, have no physical relevance at all is related to the fact that during processes in nature always exclusively differences of energy, entropy, free energy etc. between different states of a substance play a role, and that those additional terms compensate each other upon forming the differences"§ (Planck, 1911 [268]). Absolute values of the entropy are available only from mathematical models of statistical thermodynamics; they cannot be determined from empirical measurements [266].

"The seawater properties entropy, internal energy, enthalpy, and particularly potential enthalpy were not available [before TEOS-10] but are central to accurately calculating the air-sea heat flux in the coupled climate system" [24]. In this context the consistency of the TEOS-10 equations means, for example, that seawater in the ocean loses exactly the same amount of energy as the humid air above gains when a certain mass of water evaporates. If the air pressure is constant during the process, the total enthalpy (the thermodynamic measure for the heat constant, also expressed as "conservative temperature" [24]) remains the same:

$m_{\mathrm{SW}} h^{\mathrm{SW}}+m_{\mathrm{AV}} h^{\mathrm{AV}}=$ const.

Here, $m$ are the masses involved, $h$ their specific enthalpies, and the sub- and superscripts attached indicate seawater (SW) and humid air (AV). From the conservation Equation 19 an exact formula;

\footnotetext{
* IAPSO: International Association for the Physical Sciences of the Oceans

$\dagger$ SCOR: Scientific Committee on Oceanic Research

$\$$ "willkürliche additive Konstante [der Entropie hat] keine physikalische Bedeutung und kann nach Belieben fortgelassen werden".

$\S$ “Daß diese additiven Zusatzglieder absolut genommen gar keine physikalische Bedeutung haben, hängt damit zusammen, daß bei den Vorgängen in der Natur immer nur Differenzen der Energie, der Entropie, der freien Energie usw. in verschiedenen Zuständen einer Substanz eine Rolle spielen, bei deren Bildung jene Zusatzglieder sich gegenseitig kompensieren“.
} 
$L=h^{\mathrm{AV}}-A \frac{\partial h^{\mathrm{AV}}}{\partial A}-h^{\mathrm{SW}}+S \frac{\partial h^{\mathrm{SW}}}{\partial S}$

can be derived for the specific latent heat of water at the transition from seawater with an absolute salinity $S$ to humid air with a mass fraction $A$ of day air [147]. The evaluation of this equation is implemented in the TEOS-10 open source code library [269] and results, for instance, in the curves presented in Figure 10.

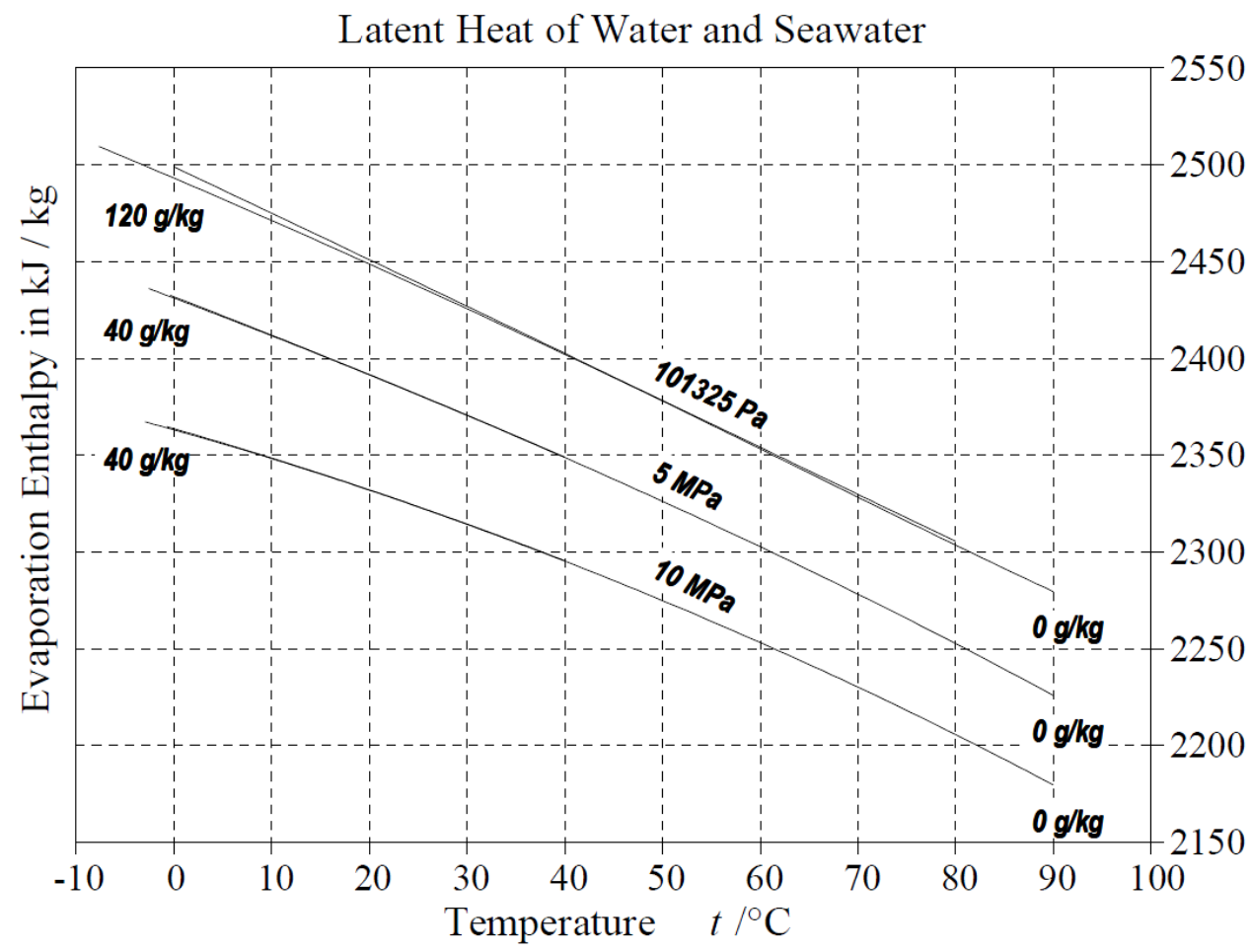

Figure 10. Latent heat of evaporation of seawater, calculated from Equation 20 with the source-code library of TEOS-10 for salinities between 0 and $120 \mathrm{~g} \mathrm{~kg}^{-1}$ at a surface pressure of $1013.25 \mathrm{hPa}$, and up to $40 \mathrm{~g} \mathrm{~kg}^{-1}$ for higher pressures between 5 and $10 \mathrm{MPa}$.

In practical approximation, humid air was and is often treated as an ideal gas [77], with accordingly simple equations of state [270, 271]. For higher accuracies, corrections turned out to be indispensable; in particular the so-called "enhancement factor" (EF) had been introduced which described deviations of saturated humid air from the ideal-gas properties [78]. Relative humidity (RH) is defined in meteorology as a ratio of partial pressures of water vapour [77], that is, of quantities which possess a clear physical meaning only for ideal gases. By correction using the EF it is provisionally achieved that the relative humidity is also correct for non-ideal gases at least at $\mathrm{RH}=0$ (dry air) and $\mathrm{RH}$ $=100 \%$ rh (saturated air). The values in between, for example those of the marine atmosphere at $80 \%$ rh, are still interpolated between the two endpoints following the rules of ideal gases, and exhibit related systematic errors. The evaporation of water from the ocean is driven by the difference of the chemical potentials, Equation 15, of water (in seawater) and water vapour (in humid air). In unsaturated air this is an irreversible process which produces entropy proportional to the square of this difference [272]. For the global ocean this production amounts to about $0.004 \mathrm{~W} \mathrm{~m}^{-2}$ $\mathrm{K}^{-1}$ and contributes $0.4 \%$ to the total entropy export of the Earth [146, 266]. In irreversible thermodynamics, partial pressures are not considered as reasonable physical description quantities of real gases.

The difference of the chemical potentials may correctly be described also by related quantities such as the activity, $a$, or the fugacity, $f_{V}$, of water, as introduced by Lewis (1901) [105] more than a century ago. The fugacity of an ideal gas turns out to equal the partial pressure; for this simple reason the latter, easily calculable quantity has been established in the practical work of meteorologists also for real gases. In contrast, no standard equations for the computation of chemical potentials was available. This situation has changed only recently with the introduction of the seawater standard TEOS-10 by Unesco/IOC in 2010 and IUGG in 2011 [148, 258, 256]. "The great advantage of this new quantity lies ... in the fact that the approximate equations, which contain the vapour pressure and were strictly speaking only developed under the assumption that the vapour pressure obeys the [ideal] gas laws, can be replaced by exact equations of the same form and the same simplicity by replacing the vapour pressure by the fugacity"* [105].

\footnotetext{
* "Der grosse Nutzen dieser neuen Grösse liegt ... in der Thatsache, dass die angenäherten Gleichungen, welche den Dampfdruck enthalten, und die streng genommen nur unter der Annahme entwickelt wurden, dass der Dampfdruck den [idealen] Gasgesetzen gehorche, durch exakte Gleichungen von derselben Form oder von gleicher Einfachheit ersetzt werden können, indem sie die Fugazität anstatt des Dampfdruckes enthalten“.
} 


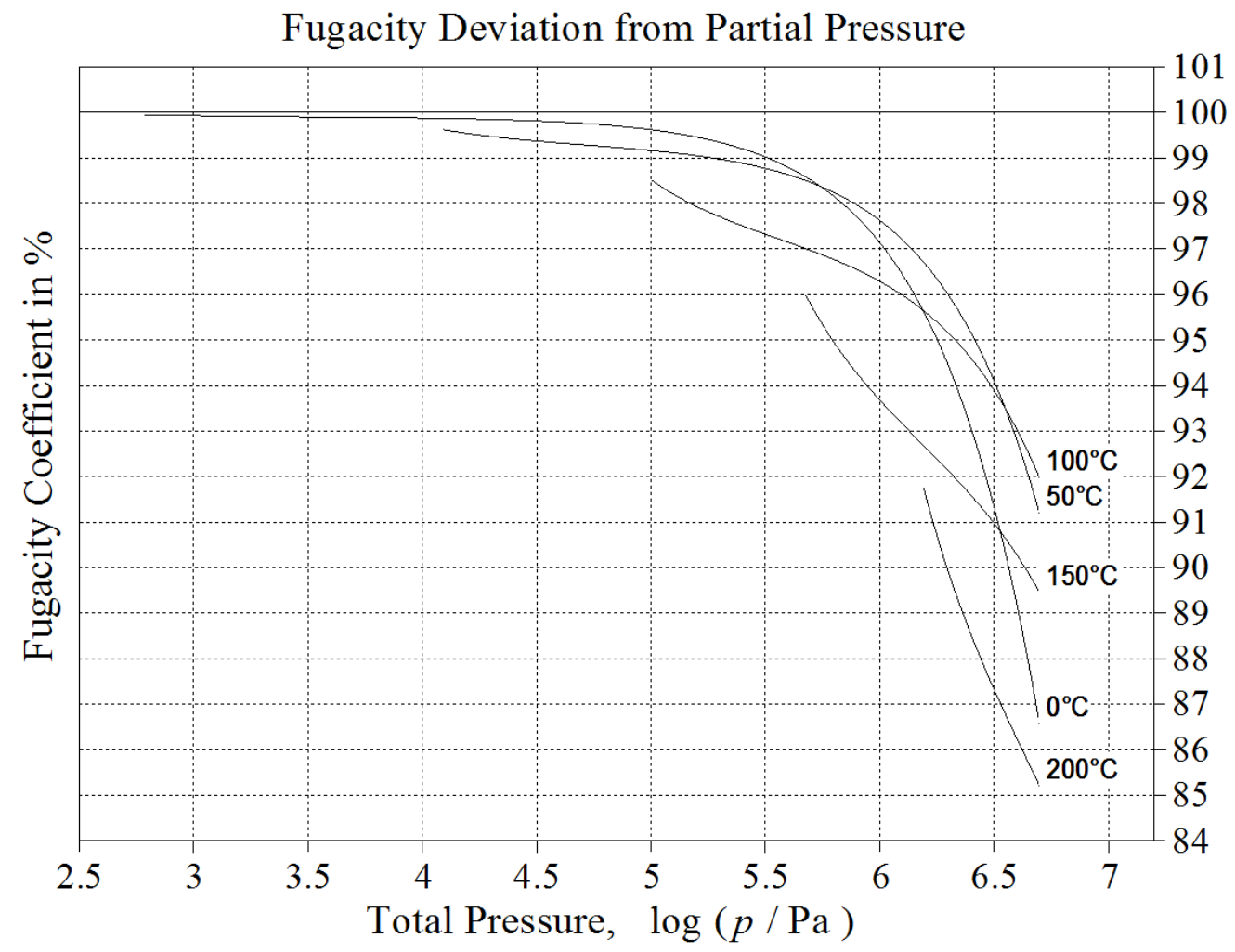

Figure 11. The fugacity coefficient, Equation 22, of water vapour in saturated air at different temperatures and pressures, calculated using a virial expansion of the TEOS-10 [273]. The value of $100 \%$ corresponds to the ideal-gas approximation. Under meteorological conditions, $\log _{10}(\mathrm{p} / \mathrm{Pa}) \leq 5, t \leq 50{ }^{\circ} \mathrm{C}$, deviations from the ideal-gas behaviour remain below $1 \%$.

In fact, TEOS-10 permits an exact quantitative calculation of the jump of the chemical potentials, Equation 15, at the sea surface [80, 147, 148, 256, 273]. Fully in the sense of the original works of Wüst (1920) [12], Sverdrup (1937) [13] and Albrecht (1940) [14], the current, relatively arbitrary parameterisation of the evaporation rate in terms of vertical gradients of the specific humidity in numerical climate models could be put on an improved physical basis (see Section 3 ). This concerns the thermodynamically correct allowance of the oceanic salinity as well as the highly variable relative humidity that dominates the evaporation.

Easy access to fast computation facilities today permits permanent and convenient availability of highly accurate descriptions of substance properties. The continued exploitation of less accurate historical standards based on the approximation of ideal gases is mostly caused by tradition, habit and subjective preferences of users, but also by efforts and error risks involved in fundamental changes of internationally established computation methods. Actually, such risks would be minor for a potential transition from a conventional definition of $\mathrm{RH}$ to the relative fugacity, as the uncertainties of many of today's measurement techniques are larger than the differences between the particular formulae. A similar argumentation, by the way, was used for the successful fundamental transition to the current "new SI" [55].

The suggested new definition of relative humidity by the relative fugacity or the relative activity of water vapour in humid air [77, 80, 147, 273, 274] replaces the meteorological definition of RH, Equation 1, by the thermodynamically correct difference of the chemical potentials (3) in the form;

$\psi_{f}(x, T, p)=\frac{a}{a^{\text {sat }}(T, p)}=\frac{f_{v}}{f_{v}^{\text {sat }}(T, p)}$.

Here, the reference state of the activity is defined as saturated air, $a^{\mathrm{sat}}(T, p) \equiv 1$, so that the relative fugacity of water vapour equals the activity of water in that gas mixture. The relation of the fugacity to the partial pressure, the fugacity coefficient;

$\varphi_{v}=\frac{f_{v}}{x p}$

equals unity for ideal gases. For air at the sea surface it deviates by about $0.5-1 \%$ (Figure 11). Considering the high sensitivity of latent heat fluxes with respect to small changes of the marine RH, Equation 18, see Sections 3 and 6 , it should be necessary to correctly describe the acting thermodynamic forces as in Equation 3, even if this may improve only a minor part of the complex problem of the evaporation process. This is an important argument supporting a new definition of RH that is thermodynamically better founded and in detail already available, given that only minor effects may be expected yet on the measurement values in the current meteorological practice. 


\section{Global Warming: Is the Hydrological Cycle Accelerating?}

Relatively frequently, mutually similar statements about an "acceleration of the global water cycle" are found in the literature about climate change. Some of those examples may be quoted literally here to demonstrate this.

- "On average, [from 1963 till 1975] the heat loss of the world ocean increased by $11 \%$ " [17].

- "In the last decades, an increase of evaporation (about $15 \%$ ) was observed over the tropical oceans. This confirms an acceleration of the hydrological cycle"* [6].

- "Since the transition [1977-78], the global oceanic evaporation has been up about $11 \mathrm{~cm} \mathrm{yr}^{-1}(\sim 10 \%)$, from a low at $103 \mathrm{~cm} \mathrm{yr}^{-1}$ in 1977 to a peak at $114 \mathrm{~cm} \mathrm{yr}^{-1}$ in 2003" [156].

- "Salinity increases at the sea surface are found in evaporation-dominated regions and freshening in precipitationdominated regions with the spatial pattern of change strongly resembling that of the mean salinity field, consistent with an amplification of the global hydrological cycle" [275].

- "The globally averaged precipitation rate is also expected to increase as the Earth warms. The increased surface warming 'enables' more surface evaporation. The hydrological cycle speeds up accordingly. This implies a decrease in the convective mass flux, and also a slowing of the large-scale atmospheric circulation, as the climate warms. The overall strength of the Hadley-Walker circulation decreases in a warmer climate" [56].

- "New information suggests that the global water cycle is rapidly intensifying" [276].

- "Intensification of the hydrologic cycle is a key dimension of climate change, with substantial impacts on human and natural systems" [277].

- "In the climate simulation, the hydrological cycle increases" [259].

- "The hydrological cycle is intensifying as the climate warms, with global mean precipitation increasing by 1 to $3 \%$ per degree rise of surface air temperature, in balance with the atmospheric energy budget" [278].

From the only fact that the mass of water vapour in the troposphere is slowly increasing with the temperature one can only conclude that the global difference $(E-P)$ between evaporation $E$ and precipitation $P$ is slightly positive. This does not imply anything about the temporal change $\mathrm{d} E / \mathrm{d} t$ nor about $\mathrm{d} P / \mathrm{d} t$, as long as no additional information is available. Without reference to supporting data, however, Randall (2012) [56] 'expects' an acceleration of the water cycle with increasing precipitation, $\mathrm{d} P / \mathrm{d} t>0$, along with $\mathrm{d} E / \mathrm{d} t>0$ because of $E>P$. The water volume in a garden hose depends on the size of the hose but is independent of how wide the tap is open. A longer hose will contain more water even without more water flowing through the hose per unit of time, as is mistakenly argued sometimes with respect to the atmosphere. Because of the mutual dependency $r=m / \tau$ between the mass $m$ of water in the troposphere, its turnover rate $r$ and residence time $\tau$, a rigorous relation between two of these quantities exists only under the assumption that the remaining third quantity can be taken as constant. An intensification of the turnover rate is by no means a compelling conclusion from the increasing water mass in the troposphere as long as a possible parallel change of the residence time is unknown. In fact, the global precipitation 1981-2020 does not show any significant trend [82], in contrast to the integral water content of the troposphere.

The model results for trends in the latent-heat flow are uncertain, as the following examples may illustrate. On the basis of ensemble simulations with 14 climate models ("multi-model ensemble"), Cao et al. (2015) [160] derived a linear trend of the latent heat flux of $0.037 \mathrm{~W} \mathrm{~m}^{-2} \mathrm{yr}^{-1}$ which is significantly smaller than the empirical value of $0.296 \mathrm{~W} \mathrm{~m}^{-2}$ $\mathrm{yr}^{-1}$ obtained from objective-analysis studies. For the specific humidity those authors report a simulated trend of von $0.016 \mathrm{~g} \mathrm{~kg}^{-1} \mathrm{yr}^{-1}$ which clearly exceeds the figure of $0.006 \mathrm{~g} \mathrm{~kg}^{-1} \mathrm{yr}^{-1}$ from objective analysis. For the sea-surface

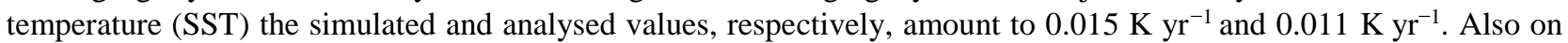
the basis of ensemble simulations, this time with 30 climate models, Zhang et al. (2018b) [120] estimated a value of $(87.4 \pm 4.9) \mathrm{W} \mathrm{m}^{-2}$ (model range between $79.0 \mathrm{~W} \mathrm{~m}^{-2}$ and $96.1 \mathrm{~W} \mathrm{~m}^{-2}$ ) for the globally averaged oceanic latent heat flux. This figure is overestimated by $5.9 \mathrm{~W} \mathrm{~m}^{-2}$ (or $7.2 \%$ ) compared to the objective-analysis result of $81.5 \mathrm{~W} \mathrm{~m}^{-2}$. These simulations show a strong seasonal variation of the latent heat flux with a maximum amplitude, averaged over the meridians, of $\approx 40 \mathrm{~W} \mathrm{~m}^{-2}$ at $40{ }^{\circ} \mathrm{N}$ and local maxima in the Kuroshio region (Western Pazific, $30-40{ }^{\circ} \mathrm{N}: \approx 80$ $\mathrm{W} \mathrm{m}^{-2}$ ) as well as in the Gulf Stream region (Western Atlantic, $30-40{ }^{\circ} \mathrm{N}: \approx 70 \mathrm{~W} \mathrm{~m}^{-2}$ ) [120]. For the trend of the latent heat flow those authors report a simulated value of $0.0333 \mathrm{~W} \mathrm{~m}^{-2} \mathrm{yr}^{-1}$ (model range between $0.0054 \mathrm{~W} \mathrm{~m}^{-2} \mathrm{yr}^{-1}$ and $0.0502 \mathrm{~W} \mathrm{~m}^{-2} \mathrm{yr}^{-1}$ ) which appears too small if compared to the objective-analysis value of $0.2856 \mathrm{~W} \mathrm{~m}^{-2} \mathrm{yr}^{-1}$. For comparison, the values of the simulated and observed trends, respectively, are also given here for the specific humidity as $0.0101 \mathrm{vs} .0 .0017 \mathrm{~g} \mathrm{~kg}^{-1} \mathrm{yr}^{-1}$, and for the SST as $0.0137 \mathrm{vs} .0 .0112 \mathrm{~K} \mathrm{yr}^{-1}$. As a reason for the too small ratio between simulated and observed trends of the latent heat flux, Zhang et al. (2018b) [120] discuss the neglect of subgrid-scale variations of turbulent exchange coefficients due to fluctuation of the stratification stability, of the wave height and of the wind's gustiness intensity.

\footnotetext{
* "Über den tropischen Ozeanen wurde in den letzten Jahrzehnten eine Zunahme der Verdunstung (ungefähr $+15 \%$ ) beobachtet. Dies belegt eine Beschleunigung des hydrologischen Zyklus“"
} 
Most precipitation is falling over the sea without topographic obstacles such as mountain ranges like the Alps or the German Upper Harz at land. Marine precipitation is the result of only the dynamics of air movement and cloud formation over the ocean, which in turn is driven by temperature and humidity in the troposphere in a complex manner. No models exist yet with sufficiently small uncertainties in order to safely predict a dry summer or an intense hurricane season, neither for a special case nor for the climatic trend. The willingly claimed acceleration of the hydrological cycle must therefore remain a mere hypothesis. "By now it has not been possible to make unambiguous statements on a modified water cycle as a result of climate change"* [279]. Even two decades later, IAPSO is still rather cautious regarding putative trends: "Without the precision of salinity measurements, the detection of subtle basin-wide changes as indicators of changes in the earth's hydrological cycle would not be possible" [24].

Rather, the warming of the ocean is suggesting a reduction of evaporation and of the associated latent energy export, although by no means compellingly, and in turn also a decrease of precipitation on the global average. Also polar warming which is weakening the driving force of the global wind system by diminishing the temperature differences between higher and lower latitudes, is rather an argument in favour of a slowing down of the water cycle. In the fictitious theoretical extreme case that the air were saturated everywhere and in a spatially isothermal equilibrium, that no wind blew and a stably stratified, dense cloud cover absorbed all the sunlight, the water cycle would completely stall despite a maximum of water stored in the atmosphere.

The estimates of global evaporation depicted in Figure 3 suggest an initially rapidly increasing trend during the last century. However, there are good reasons to believe that a trend of this magnitude may be only virtual, regional or temporary, and that the quotations made above warrant a more detailed quantitative consideration. Here are a few arguments:

(i) A strengthened evaporation by as little as $8 \mathrm{~mm}$ per year would extract enough latent heat from the ocean to let stagnate its current temperature rise; stronger evaporation would even turn its warming into cooling. Theoretically, significant enhancement of evaporation, as occasionally suspected, should therefore be accompanied by a clearly measurable lowering of the water temperatures. Strengthening evaporation by $10-15$ $\%$ as quoted above would imply an additional export of latent heat of $10-15 \mathrm{~W} \mathrm{~m}^{-2}$ from the ocean to the atmosphere; the related cooling of the oceans were by an order of magnitude larger (and with opposite sign) than the really observed ocean warming by $0.67 \mathrm{~W} \mathrm{~m}^{-2}$ [213].

(ii) "It will be substantially harder to quantify the range of possible changes in the hydrologic cycle than in globalmean temperature, both because the observations are less complete and because the physical constraints are weaker" [280].

(iii) The measured increase by $0.4 \mathrm{~kg} \mathrm{~m}^{-2}$ per year [90] of the integral water-vapour content of the troposphere requires additional evaporation of $0.4 \mathrm{~mm} \mathrm{yr}^{-1}$, which is a minor intensification by $0.004 \%$ of the normal rate and is deeply within the uncertainty of observations (Figure 3).

(iv) Amplification of evaporation by $10-15 \%$ as quoted before would imply an additional export of $10-15 \mathrm{~W} \mathrm{~m} \mathrm{~m}^{-2}$ of latent heat from the ocean to the atmosphere; the related heating of the atmosphere were by a factor of 2000 higher than the warming of $0.006 \mathrm{~W} \mathrm{~m}^{-2}$ observed in reality, and would hardly remain unnoticed.

(v) Significantly intensified evaporation should cause a stronger formation of high clouds [56]. Such observations are unknown, however.

(vi) Significantly intensified evaporation should cause a stronger warming of the upper troposphere [56]. Such observations are unknown, however.

(vii) Significantly intensified evaporation by $10-15 \%$ could be the result of a reduced marine RH by about 2-3\%rh. Such observations are unknown, however.

(viii) Substantial increase in evaporation would enhance global precipitation with a tendency of growing glaciers, lakes and rivers. Observations seem to suggest the opposite [82, 281].

The strengthening of lateral contrasts in the sea-surface salinity quoted initially [275, 276] is by no means compellingly connected with a general amplification of the hydrological cycle, as those authors conclude from their data. Rather, it is sufficient that the average evaporation remains unaltered while only its regional distribution is changing, that is, evaporations gets stronger where it is already strong at the same time gets weaker where it is already weak ("wet gets wetter, dry gets drier" [48]). It may be misleading to talk somewhat sloppily of "amplification" or "intensification" while perhaps suggesting just a spatial redistribution with steeper lateral gradients. Without necessarily being associated with a substantial increase in the mean global evaporation and precipitation rate, such a marine contrast sharpening, as reflected in the salinity patterns, would well be consistent with the more frequent appearance of locally and temporally focused weather extremes at land [282, 283] with longer lasting draught phases between heavier rain events but similar integral overall precipitation.

\footnotetext{
* "Bis heute ist es nicht gelungen, zu eindeutigen Aussagen über die Veränderung des Wasserkreislaufs infolge von Klimaänderungen zu kommen".
} 


\section{Summary and Conclusions}

Powered mainly by sunlight absorbed in a thick surface mixed layer of ocean water, the hydrological cycle is energetically the dominant component of the Earth's climate system, once termed "steam engine" by Heinrich Hertz. In turn, the dominant part of the ocean's energy export is the latent heat of evaporation, as compared to thermal radiation or sensible heat flux. Ocean evaporation occurs invisibly and almost unnoticed by humans living on land; this may be a reason why this gigantic energy transfer process is hardly recognised in the public perception of climate change.

For illustration, in approximate figures averaged over all oceans, the water absorbs $120 \mathrm{~W} \mathrm{~m}^{-2}$ of solar irradiation and releases $100 \mathrm{~W} \mathrm{~m}^{-2}$ of latent heat by evaporation (globally averaged over sea plus land, this is about $70 \mathrm{~W} \mathrm{~m}^{-2}$ ). The total wind energy of the atmosphere is only a small fraction of $2-4 \mathrm{~W} \mathrm{~m}^{-2}$ of this amount, and in turn, the global human electric power consumption, if supplied by only wind generation, required only a tiny share of $0.004 \mathrm{~W} \mathrm{~m}^{-2}$.

Global warming requires heat that is diverted from the total solar power flux. The observed rate of rising air temperature, together with the total mass and the heat capacity of the atmosphere, requires a power supply of only 0.005 $\mathrm{W} \mathrm{m}^{-2}$, a figure very close to the heat released by human electrical devices and machines. To the best of our knowledge, recently added greenhouse gases such as $\mathrm{H}_{2} \mathrm{O}$ and $\mathrm{CO}_{2}$ hold back this small fraction of infrared surface radiation energy. Those gases have only minor effects, however, on the latent heat transport by ascending humid air to the altitude where high clouds emit this energy to the cosmic background. In other words, very small fluctuations of the oceanic evaporation rate, namely by $\pm 0.005 \mathrm{~W} \mathrm{~m}^{-2}$ of $70 \mathrm{~W} \mathrm{~m}^{-2}$, would theoretically suffice to either compensate or double the atmospheric greenhouse warming.

Can we predict changes in the marine evaporation flux to the required accuracy? Observations and models are estimated to be reliable to within an uncertainty of about $20 \mathrm{~W} \mathrm{~m}^{-2}$ which exceeds the atmospheric warming rate by a noise-to-signal ratio of 4000:1. Likely more severely but less obviously than the warming atmosphere, also the ocean (down to $2 \mathrm{~km}$ depth) is warming, but at a rate of $0.5 \mathrm{~W} \mathrm{~m}^{-2}, 100$ times stronger than the air. Assuming that greenhouse gases are causing this, it is manifest that just a little increase by $<1 \%$ of marine evaporation from $70 \mathrm{~W} \mathrm{~m} \mathrm{~m}^{-2}$ to $70.5 \mathrm{~W}$ $\mathrm{m}^{-2}$ could theoretically counterbalance this effect. But also such a change would again be disguised by the excessively large uncertainty of available evaporation rate predictions.

The irreversible transfer of water from seawater to humid air is driven by the difference of the chemical potentials of water in the two mixtures. A century ago, oceanographers parameterised the evaporation rate in terms of this difference, approximated in a simple way as the "vapour pressure jump" at the sea surface. Today this difference is very precisely available from equations of the current international seawater standard TEOS-10, the "Thermodynamic Equation of Seawater - 2010", which consistently describes all thermodynamic properties of seawater, ice and humid air in the form of algorithms verified and adopted by the International Association for the Properties of Water and Steam (IAPWS) and recommended by the International Union of Geodesy and Geophysics (IUGG). Regrettably, climate models ignore this available option so far.

When the first numerical weather models were implemented, they were applied to situations at land. Evaporation rates from the solid ground, possibly covered by plants, have traditionally been estimated by the vertical gradient of specific humidity above the surface, similar to a diffusion process. When those models were later extended to cover also ocean surfaces, the same crude parameterisation was also used there, perhaps because the modellers were not aware of the physically much better justified equations that had been developed before by oceanographers. Here we recommend to return to those old parameterisations in terms of "vapour pressure jumps", now even improved by latest international property equations of the geophysical fluids.

The chemical potential of water in a fluid mixture can equivalently be expressed by thermodynamic activities or fugacities. Relative fugacity of water vapour has recently been proposed to substitute the traditional meteorological standard measure of relative humidity (RH), in order to properly account for irreversible fluxes and equilibria between humid air and liquid mixtures or moist solids. In the ideal-gas approximation, relative fugacity asymptotically agrees with conventional RH. The possibility of such a strategic redefinition is currently under investigation by the Consultative Committee for Thermometry (CCT) of the International Bureau of Weights and Measures (BIPM) [55].

The sensitivity of the hydrological cycle with respect to changes of the marine surface RH can be estimated to about $6 \mathrm{~W} \mathrm{~m}^{-2}$ per $1 \% \mathrm{rh}$. Accordingly, as the atmospheric global warming rate of $0.005 \mathrm{~W} \mathrm{~m}^{-2}$ suggests, self-organisation of the climate system is capable of naturally adjusting RH to stable values well within a tolerance range of $0.001 \%$ rh. Trends of this magnitude cannot be resolved, neither by observation with typical uncertainties $>1 \%$ rh, nor by climate models. Some of the latter consider RH as an externally adjustable parameter and fix it at values that permit reproducing the present climate conditions. Frequently posted statements that the atmospheric specific humidity is increasing with temperature in accord with Clausius-Clapeyron saturation humidity are silently based on the empirical assumption of constant RH. The question of whether RH possesses a trend along with global warming, and, as a consequence, of whether the hydrological cycle becomes amplified, still poses a key scientific challenge. 


\section{Declarations}

\subsection{Author Contributions}

Conceptualization, R.F.; methodology, R.F. and O.H.; investigation, R.F. and O.H.; resources, O.H.; data curation, R.F.; writing — original draft preparation, R.F. and O.H.; writing - review and editing, R.F. and O.H. All authors have read and agreed to the published version of the manuscript.

\subsection{Data Availability Statement}

Data sharing is not applicable to this article.

\subsection{Funding}

The authors received no financial support for the research, authorship, and/or publication of this article.

\subsection{Acknowledgements}

The authors are very grateful to Joachim Pelkowski, Bogota, for essential references, to Volker Mohrholz, Warnemünde, for providing the temperature curve in Figure 8, as well as to Robert Mars, Warnemünde, for making available the data of the IOW station "Darss Sill“ in Figure 4. Further, the authors are much obliged to Thomas Foken, Bayreuth, and to Werner Ebeling, for helpful suggestions and discussions. The contribution of O. Hellmuth was provided within the framework of the research theme 1 "Aerosols: Process studies at small temporal and spatial scales" of Leibniz Institute for Tropospheric Research (TROPOS), Leipzig and is part of the TROPOS activities within the framework of the EU project "Aerosol, Clouds and Trace gases Research InfraStructure" (ACTRIS). This work contributes to the tasks of the IAPSO/SCOR/IAPWS Joint Committee on the Properties of Seawater (JCS).

\subsection{Institutional Review Board Statement}

Not applicable.

\subsection{Informed Consent Statement}

Not applicable.

\subsection{Declaration of Competing Interest}

The authors declare that there is no conflict of interests regarding the publication of this manuscript. In addition, the ethical issues, including plagiarism, informed consent, misconduct, data fabrication and/or falsification, double publication and/or submission, and redundancies have been completely observed by the authors.

\section{References}

[1] Mulligan, J.F., Hertz, G.G. (1997): An unpublished lecture by Heinrich Hertz: "On the energy balance of the Earth". American Journal of Physics 65, 36-45. doi:10.1119/1.18565.

[2] Hoepke, K.-P. (2007): Geschichte der Fridericiana: Stationen in der Geschichte der Universität Karlsruhe (TH) von der Gründung 1825 bis zum Jahr 2000 (Veröffentlichungen aus dem Universitätsarchiv Karlsruhe). Universitätsverlag Karlsruhe, Karlsruhe.

[3] AGU (1995): Water Vapor in the Climate System. Special Report. December 1995. American Geophysical Union, Washington, DC, ISBN 0-87590-865-9, Available online: https://www.eso.org/gen-fac/pubs/astclim/espas/pwv/mockler.html (accessed on February 2021).

[4] Ebeling, W., Feistel, R. (1994): Chaos und Kosmos. Spektrum-Verlag, Heidelberg, Germany.

[5] IAMAS (1994). Cloud-Radiation Interactions and their Parameterization in Climate Models. International Association of Meteorology and Atmospheric Sciences, WCRP-86, WMO/TD 648, Geneva, Switzerland.

[6] Flohn, H., Kapala, A., Knoche, H.R., Mächel, H. (1992): Water vapour as an amplifier of the greenhouse effect: new aspects. Meteorol. Zeitschrift, N.F. 1, 120-138. doi:10.1127/metz/1/1992/122.

[7] Hagedorn, H. (1998): Hermann Flohn 19.2.1912 - 23.6.1997. Nachruf der Bayerischen Akademie der Wissenschaften, Available online: https://badw.de/fileadmin/nachrufe/Flohn\%20Hermann.pdf (accessed on February 2021).

[8] Hupfer, P. (2020): Klimaforschung - Grundlage der Klimapolitik. Naturwissenschaftliche Rundschau 73(2), 61-70.

[9] Lenoble, J. (1993): Atmospheric Radiative Transfer. A. Deepak Publishing, Hampton, Virginia, United States.

[10] Rosbjerg, D., Rodda, J. (2019): IAHS: a brief history of hydrology. Hist. Geo Space Sci., 10, 109-118. doi:10.5194/hgss-10109-2019. 
[11] Schmidt, W. (1915): Sonnenstrahlung und Verdunstung an freien Wasserflächen; ein Beitrag zum Wärmehaushalt des Weltmeeres und zum Wasserhaushalt der Erde. Annalen der Hydrographie und maritimen Meteorologie 43, 11-178.

[12] Wüst, G. (1920): Die Verdunstung auf dem Meere. Veröffentlichungen des Instituts für Meereskunde an der Universität Berlin. A. Geographisch-naturwissenschaftliche Reihe 6, 1-95.

[13] Sverdrup, H.U. (1936): Das maritime Verdunstungsproblem. Annalen der Hydrographie und maritimen Meteorologie 64, 41-47.

[14] Albrecht, F. (1940). Untersuchungen über den Wärmehaushalt der Erdoberfläche in verschiedenen Klimagebieten. doi:10.1007/978-3-662-42530-5.

[15] Budyko, M.I. (1948): Izpareniye v Estestvennykh Usloviayakh. Gidrometeoizdat, Leningrad, Russia.

[16] Budyko, M.I. (1963): Evaporation under Natural Conditions. Office of Technical Services, U.S. Dept. of Commerce, Washington, United States.

[17] Budyko, M.I., Berlyand, T.G., Efimova, N.A., Zubenok, L.I., Strokina, L.A. (1978): Teplovoi Balans Zemli. Gidrometeoizdat, Leningrad, Russia.

[18] Budyko, M.I. (1984): Evolyutsiya Biosfery. Gidrometeoizdat, Leningrad, Russia.

[19] Budyko, M.I. (1956): Teplovoi Balans Zemnoi Poverkhnosti. Gidrometeoizdat, Leningrad, Russia.

[20] Budyko, M.I. (1958): The Heat Balance of the Earth's Surface. Office of Technical Services, U.S. Dept. of Commerce, Washington.

[21] Sellers, W.D. (1965): Physical Climatology. University of Chicago Press, Chicago, United States.

[22] Schimming, R. (2014): Theories on the Earth System. Vernadskij, Lovelock and beyond. Sitzungsberichte der Leibniz-Sozietät 120, 171-176. Available online: http://leibnizsozietaet.de/wp-content/uploads/2012/10/Gesamtdatei-SB-120-2014.pdf (accessed on March 2021).

[23] MacCracken, M.C., Volkert, H. (2019): IAMAS: a century of international cooperation in atmospheric sciences. Hist. Geo Space Sci., 10, 119-136. doi:10.5194/hgss-10-119-2019.

[24] Smythe-Wright, D., Gould, W.J., McDougall, T.J., Sparnocchia, S., Woodworth, P.L. (2019): IAPSO: tales from the ocean frontier. Hist. Geo Space Sci., 10, 137-150. doi:10.5194/hgss-10-137-2019.

[25] Kim, Y., Garcia, M., Morillas, L., Weber, U., Black, T.A., Johnson, M.S. (2021): Relative humidity gradients as a key constraint on terrestrial water and energy fluxes. Hydrol. Earth Syst. Sci. 25, 5175-5191. doi:10.5194/hess-25-5175-2021.

[26] Smagorinsky, J. (1969): Numerical simulation of the global atmosphere. In Corby, G.A. (ed.): The Global Circulation of the Atmosphere. Royal Meteorological Society, London, S. 24-41

[27] Lorenz, E.N. (1969): The nature of the global circulation of the atmosphere: a present view. In Corby, G.A. (ed.): The Global Circulation of the Atmosphere. Royal Meteorological Society, London, United Kingdom.

[28] Hasselmann, K. (2002): Is Climate Predictable? In: Bunde, A., Kropp, J., Schellnhuber, H.J. (eds): The Science of Disasters. Springer, Berlin/Heidelberg, pp. 140-169. doi:10.1007/978-3-642-56257-0_4.

[29] Milz, M. (2003): Untersuchungen zur Messung von Wasserdampf in der tropischen Tropopausenregion mit MIPAS/Envisat. Forschungszentrum Karlsruhe in der Helmholtz-Gemeinschaft. Wissenschaftliche Berichte FZKA 67772.

[30] Tollefsen, J. (2012): Climate forecasting: a break in the clouds. Nature 485, 164-166. doi:10.1038/485164a.

[31] GCOS-171 (2013): WIGOS WMO Integrated Global Observation System. The GCOS Reference Upper-Air Network (GRUAN) Guide, Tech. rep., World Meteorological Organization, Geneva, Switzerland, WIGOS Technical Report No. 2013-03, GCOS171, Version 1.1.0.3, Available online: https://www.gruan.org/gruan/editor/documents/gcos/gcos-171.pdf (accessed on March 2021).

[32] Bony, S., Stevens, B., Frierson, D.M.W., Jakob, C., Kageyama, M., Pincus, R., Shepherd, T.G., Sherwood, S.C., Siebesma, A.P., Sobel, A.H., Watanabe, M., Webb, M.J. (2015): Clouds, circulation and climate sensitivity. Nature Geoscience 8, 261-268. doi:10.1038/ngeo2398.

[33] Schiermeier, Q. (2015): Physicists, your planet needs you. Nature 520, 140-141. doi:10.1038/520140a.

[34] Eicker, A. (2020): JG04 Geodesy for Atmospheric and Hydrospheric Climate Research (IAG, IAMAS, IACS, IAPSO). Zeitschrift für Geodäsie, Geoinformation und Landmanagement 145, 12-13. doi:10.12902/zfv-0286-2019.

[35] Voosen, P. (2020): Why does the weather stall? New theories explain enigmatic 'blocks' in the jet stream. Science 367. doi:10.1126/science.abb5843.

[36] Kolditz, L. (1995): Zur Chemie des Fluors. Sitzungsberichte der Leibniz-Sozietät 7, 5-23. Available online: https://leibnizsozietaet.de/wp-content/uploads/2012/10/Gesamtdatei-SB-007-1995.pdf (accessed on March 2021).

[37] Möller, D. (2003): Luft - Chemie • Physik • Biologie • Reinhaltung • Recht. Walter de Gruyter, New York, United States. 
[38]Möller, D. (2006): Das atmosphärische Wasserstoffperoxid. Sitzungsberichte der Leibniz-Sozietät 83, 167-188, Available online: https://leibnizsozietaet.de/wp-content/uploads/2012/10/Gesamtband-SB-083-2006.pdf (accessed on March 2021).

[39] Solomon, S., Rosenlof, K.H., Portmann, R.W., Daniel, J.S., Davis, S.M., Sanford, T.J., Plattner, G.-K. (2010): Contributions of Stratospheric Water Vapor to Decadal Changes in the Rate of Global Warming, Science, 327, 1219-1223. doi:10.1126/science.1182488.

[40] Reiner, P.M. (2004): Einfluss der Vertikalverteilung des Wasserdampfes auf den Lebenszyklus intrasaisonaler Konvektionsschwankungen über dem tropischen Indopazifik. Mitteilungen aus dem Institut für Geophysik und Meteorologie der Universität zu Köln, Heft 158, Köln.

[41] Mohr, S. (2013): Änderung des Gewitter- und Hagelpotentials im Klimawandel. Wissenschaftliche Berichte des Instituts für Meteorologie und Klimaforschung des Karlsruher Instituts für Technologie (KIT), Band 58, Institut für Meteorologie und Klimaforschung am Karlsruher Institut für Technologie Karlsruhe. KIT Scientific Publishing. doi:10.5445/KSP/1000033828.

[42] Mahlke, H. (2017): Mechanismen der Auslösung hochreichender Konvektion im südwestdeutschen Mittelgebirgsraum. Wissenschaftliche Berichte des Instituts für Meteorologie und Klimaforschung des Karlsruher Instituts für Technologie (KIT) Band 65. Institut für Meteorologie und Klimaforschung am Karlsruher Institut für Technologie (KIT) Karlsruhe. KIT Scientific Publishing. doi:10.5445/KSP/1000040122.

[43] Piper, D. A. (2017): Untersuchung der Gewitteraktivität und der relevanten großräumigen Steuerungsmechanismen über Mittelund Westeuropa. Wissenschaftliche Berichte des Instituts für Meteorologie und Klimaforschung des Karlsruher Instituts für Technologie (KIT) Band 73, Institut für Meteorologie und Klimaforschung am Karlsruher Institut für Technologie (KIT), Karlsruhe, KIT Scientific Publishing. doi:10.5445/KSP/1000072089.

[44] Caldas-Alvarez, A. (2019): Atmospheric Moisture Effects on Deep Convection in the Western Mediterranean. Wissenschaftliche Berichte des Instituts für Meteorologie und Klimaforschung des Karlsruher Instituts für Technologie (KIT) Band 81, Institut für Meteorologie und Klimaforschung am Karlsruher Institut für Technologie (KIT) Karlsruhe. KIT Scientific Publishing. doi: $10.5445 / \mathrm{KSP} / 1000097100$.

[45] Sasse, R. (2012): Analyse des regionalen atmosphärischen Wasserhaushalts unter Verwendung von COSMO-Simulationen und GPS-Beobachtungen. Wissenschaftliche Berichte des Instituts für Meteorologie und Klimaforschung des Karlsruher Instituts für Technologie (KIT) Band 54. Institut für Meteorologie und Klimaforschung am Karlsruher Institut für Technologie Karlsruhe. KIT Scientific Publishing. doi:10.5445/KSP/1000024938.

[46] Hoffmann, G. (1999): Die Bedeutung der diabatischen Heizung für die synoptische Störungsaktivität der Nordhemisphäre im heutigen und in einem zukünftigen Klima. Mitteilungen aus dem Institut für Geophysik und Meteorologie der Universität zu Köln, Heft 126, Köln.

[47] Riemer, M. (2011): Außertropische Umwandlung tropischer Wirbelstürme. Einfluss auf das Strömungsmuster in den mittleren Breiten. Wissenschaftliche Berichte des Instituts für Meteorologie und Klimaforschung des Karlsruher Instituts für Technologie (KIT) Band 45. Institut für Meteorologie und Klimaforschung am Karlsruher Institut für Technologie (KIT) Karlsruhe. KIT Scientific Publishing. doi:10.5445/KSP/1000024930.

[48] Wills, R. C., Byrne, M. P., Schneider, T. (2016): Thermodynamic and dynamic controls on changes in the zonally anomalous hydrological cycle. Geophys. Res. Lett. 43, 4640-4649. doi:10.1002/2016GL068418.

[49] Bernhardt, K.-.HH. (1987): Aufgaben der Klimadiagnostik in der Klimaforschung. Gerl. Beitr. zur Geophys. 96, $113-126$.

[50] Bernhardt, K.-H. (2016a): Komplexität und Einfachheit im Klimasystem der Erde. Sitzungsberichte der Leibniz-Sozietät, 125/126, 25-47. Available online: https://leibnizsozietaet.de/wp-content/uploads/2012/10/Band-125-126-Gesamtdatei-neu.pdf (accessed on January 2021).

[51] Clayson, C.A., Rutgersson, A., Ward, B., de Souze, R.B., Edson, J., Gleckler, P., Heil, P., Ichii, K., Jung, M., Miralles, D., Mathieu, P.-P., P. Stackhouse, P. (2019): WCRP Surface Flux Task Team. A white paper outlining the need for a coordinated high-level approach to improving our understanding of surface-atmosphere fluxes. World Climate Research Programme, World Meteorological Organization, Geneva, Switzerland, Available online: https://www.wcrpclimate.org/JSC40/12.1(a).\%20WDAC\%20SurfaceFluxWhitePaper.pdf (accessed on January 2021).

[52] Foken, Th. (1998): Die scheinbar ungeschlossene Energibilanz am Erdboden - eine Herausforderung an die Experimentelle Meteorologie. Sitzungsberichte der Leibniz-Sozietät 24, 131-150. Available online: https://leibnizsozietaet.de/wpcontent/uploads/2012/10/Gesamtdatei-SB-24-1998.pdf (accessed on January 2021).

[53] WCRP (2012): Action Plan for WCRP Research Activities on Surface Fluxes. World Climate Research Programme, World Meteorological Organization, Geneva, Switzerland, WCRP Informal/Series Report No.01/2012. Available online: https://www.wcrp-climate.org/documents/woap_fluxes_report_01_2012.pdf (accessed on March 2021).

[54] Woeikoff, Al. (1886): Studie über die Temperatur der Meere und die Aenderungen der Erdtemperatur. Naturwiss. Rundschau $1(21), 178-180$.

[55] BIPM (2019): The International System of Units (SI). 9th edition of the SI Brochure, available from the BIPM. Available online: https://www.bipm.org/en/publications/si-brochure (accessed on February 2021). 
[56] Randall, D.A. (2012): Atmosphere, Clouds, and Climate. Princeton University Press, Princeton, New Jersey, United States.

[57] Gimeno L., Nieto R., Drumond A., Durán-Quesada A.M. (2013): Ocean Evaporation and Precipitation. In: Orcutt J. (ed.): Earth System Monitoring: Selected Entries from the Encyclopedia of Sustainability Science and Technology. Springer, New York. doi:10.1007/978-1-4614-5684-1_13.

[58]Pierce, D.W., Barnett, T.P., Gleckler, P.J. (2011): Ocean Circulations, Heat Budgets, and Future Commitment to Climate Change. Annual Review of Environment and Resources 36, 27-43. doi:10.1146/annurev-environ-022610-112928.

[59] Josey, S.A., Gulev, S., Yu, L. (2013): Exchanges through the ocean surface. In: Siedler, G., Griffies, S.M., Gould, J., Church, J.A. (eds): Ocean Circulation and Climate. A 21st Century Perspective. Elsevier, Amsterdam, S. 115-140. doi:10.1016/B978-012-391851-2.00005-2.

[60] Houghton, J.T. (2015): Global Warming, The complete Briefing. Cambridge University Press, Cambridge, United Kingdom.

[61] Peters-Lidard, C.D., Hossain, F., Leung, L.R., McDowell, N., Rodell, M., Tapiadore, F.J., Turk, F.J., Wood, A. (2019): 100 Years of Progress in Hydrology. American Meteorological Society. doi:10.1175/AMSMONOGRAPHS-D-18-0019.1.

[62] Foken, T. (2008a): Micrometeorology. Springer, Berlin, Heidelberg, Germany.

[63] Brückner, E. (1905): Die Bilanz des Kreislaufs des Wassers auf der Erde. Geogr. Zeitschr, Leipzig, 11, $436-445$.

[64] Feistel, R. (2013): Water, steam and climate. Proc. 16th Int. Conf. on the Properties of Water and Steam (Greenwich, UK, 1-5 September 2013). doi:10.13140/2.1.3855.9043.

[65] Feistel, R., Hagen, E., Grant, K. (2003): Climate changes in the subtropical Southeast Atlantic: The St. Helena Island Climate Index (1893-1999). Progress in Oceanography 59, 321-337. doi:10.1016/j.pocean.2003.07.002.

[66] Baumgartner, A., Reichel, E. (1975): The World Water Balance. R. Oldenbourg Verlag, München, Germany.

[67] Peixoto, J.P., Oort, A.H. (1992): Physics of Climate. American Institute of Physics, New York, United States.

[68] Feistel, R., Feistel, S. (2006): Die Ostsee als thermodynamisches System. In: L. Schimansky-Geier, H. Malchow, T. Pöschel (Hrsg.), Irreversible Prozesse und Selbstorganisation, Logos-Verlag, Berlin, p. 247-264. doi:10.13140/RG.2.1.1351.8883.

[69] Yan, Y., Gan, Z., Qi, Y. (2004): Entropy budget of the ocean system. Geophysical Research Letters, 31, L14311, 1-4. doi:10.1029/2004GL019921.

[70] Hunt, J.D., Nascimento, A., Diuana, F.A., de Assis Brasil Weber, N., Malta Castro, G., Chaves, A.C., Amarante Mesquita, A.L., Viviani Colling, A., Smith Schneider, P. (2019): Cooling down the world oceans and the earth by enhancing the North Atlantic Ocean current. Springer Nature Applied Sciences 2, 15. doi:10.1007/s42452-019-1755-y.

[71] Matveev, L.T. (1981): Dinamika Oblakov. Gidrometeoizdat, Leningrad, Russia.

[72] Vietinghoff, H. (2002): Die Verdunstung freier Wasserflächen. UFO Atelier für Gestaltung \& Verlag, Allensbach, Germany.

[73] Quante, M. (2011): Verteilung und Transport des Wassers in der Atmosphäre. In: J. L. Lozán, H. Graß1, P. Hupfer, L. Karbe, C.-D. Schönwiese (Hrsg.): WARNSIGNAL KLIMA: Genug Wasser für alle? 3. Auflage. CSC Climate Service Center, Helmholtz-Zentrum Geesthacht, 399 pp.

[74] Liang, J. (2013): Chemical Modeling for Air Resources. Academic Press, New York, pp 143-161. doi:10.1016/B978-0-12408135-2.00007-0.

[75] Greenwald, T.J. Stephens, G.L. (1995): Satellite Microwave Sensing of Oceanic Cloud Liquid Water: Application to the Earth Radiation Budget and Climate. Atmospheric Science Paper No. 572, Department of Atmospheric Science, Colorado State University, Fort Collins, CO.

[76] Katsaros, K. (2001): Evaporation and Humidity. In: Thorpe, A.S., Turekian, K.K. (eds.): Encyclopedia of Ocean Sciences, Academic Press, S. 870-877. doi:10.1006/rwos.2001.0068.

[77] Lovell-Smith, J.W., Feistel, R., Harvey, A.H., Hellmuth, O., Bell, S.A., Heinonen, M., Cooper, J.R. (2016): Metrological challenges for measurements of key climatological observables. Part 4: atmospheric relative humidity. Metrologia 53, R40-R59. doi:10.1088/0026-1394/53/1/R40.

[78] WMO (2017): WMO Guide to Meteorological Instruments and Methods of Observation. World Meteorological Organization, Genf. https://www.wmo.int/pages/prog/www/IMOP/CIMO-Guide.html.

[79] Wells, N.C. (2012): The Atmosphere and Ocean. Wiley-Blackwell, Oxford, United States.

[80] Feistel, R., Lovell-Smith, J.W. (2017): Defining relative humidity in terms of water activity. Part 1: definition. Metrologia 54, 566-576. doi:10.1088/1681-7575/aa7083.

[81] Mahmud, S. Bhuiyan, M.A.M., Sarmin, N., Elahee, S. (2020): Study of wind speed and relative humidity using stochastic technique in a semi-arid climate region. AIMS Environmental Science 7, 156-173. doi:10.3934/environsci.2020010. 
[82] Blunden, J., Arndt, D.S. (2020): State of the Climate in 2019. Bull. Amer. Meteor. Soc. 101 (8), Si-S429. doi:10.1175/2020BAMSStateoftheClimate.1, Special Online Supplement to the Bulletin of the American Meteorological Society, Vol. 101, No. 8, August, 2020

[83] Hocke, K., Martin, L., Kämpfer, N. (2013): Survey of intercomparisons of water vapour measurements. In: Kämpfer, N. (ed): Monitoring Atmospheric Water. Springer, Berlin, S. 243-288.

[84] Dai, A. (2006): Recent Climatology, Variability, and Trends in Global Surface Humidity. J. Climate 19, 3589-3606. doi:10.1175/JCLI3816.1.

[85] Gerding, M., Weisheimer, A., Dethloff, K., Neuber, R. (2002): Ground-based GPS: Benefit in the data sparse Arctic region. Proceedings of the COST Action 716 Workshop: Exploitation of ground-based GPS for meteorology. Potsdam, Germany. Available online: https://epic.awi.de/id/eprint/5750/1/Ger2002m.pdf (accessed on March 2021).

[86] Zhang, C., Xie, S., Klein, S.A., Ma, H.-Y., Tang, S., Van Weverberg, K., Morcrette, C.J., Petch, J. (2018a): CAUSES: Diagnosis of the Summertime Warm Bias in CMIP5 Climate Models at the ARM Southern Great Plains Site. J. Geophys. Res. Atmos. 123, 2968-2992. doi:10.1002/2017JD027200.

[87] Hagen, E., Feistel, R. (2008): Baltic Climate Change. In: Feistel, R., Nausch, G., Wasmund, N. (eds.): State and Evolution of the Baltic Sea 1952-2005. John Wiley and Sons, Hoboken, NJ, S. 93-120. doi:10.1002/9780470283134.ch5.

[88] Hellmuth, O. (2006b): Columnar modelling of nucleation burst evolution in the convective boundary layer - first results from a feasibility study. Part II: Meteorological characterisation. Atmos. Chem. Phys. 6, 4215-4230. doi:10.5194/acp-6-4215-2006.

[89] Stull, R.B. (1997): An Introduction to Boundary Layer Meteorology. Kluwer Academic Publishers, Dordrecht, Netherlands.

[90] Trenberth, K.E., Fasullo, J., Smith, L. (2005): Trends and variability in column-integrated atmospheric water vapor. Climate Dynamics 24, 741-758. doi:10.1007/s00382-005-0017-4.

[91] Rapp, D. (2014): Assessing Climate Change: Temperatures, Solar Radiation and Heat Balance. 3rd edition, Springer, Cham Heidelberg New York, United States.

[92] Rapp, D. (2010): Assessing Climate Change: Temperatures, Solar Radiation, and Heat Balance. 2nd edition, Praxis Publishing, Chichester, UK.

[93] Thomas, G. E., Stamnes. K. (1999): Radiative Transfer in the Atmosphere and Ocean. Cambridge University Press, Cambridge.

[94] Liou, K.N. (2002): An Introduction to Atmospheric Radiation. Second Edition. International Geophysics Series, Vol. 84. Academic Press, New York

[95] Frankignoul, C. (1985): Sea Surface Temperature Anomalies, Planetary Waves, and Air-Sea Feedback in the Middle Latitudes. Rev. Geophys. 23, 357-390. doi:10.1029/RG023i004p00357.

[96] Manabe, S., Wetherald, R.T. (1967): Thermal Equilibrium of the Atmosphere with a Given Distribution of Relative Humidity. J. Atm. Sci. 24, 241-259. doi:10.1175/1520-0469(1967)024<0241:TEOTAW>2.0.CO;2.

[97] Möller, F. (1963): On the influence of changes in CO2 concentration in air on the radiation balance of Earth's surface and on climate. J. Geophys. Res. 68, 3877-3886. doi:10.1029/JZ068i013p03877.

[98] Rieck, M., Nuijens, L., Stevens, B. (2012): Marine Boundary Layer Cloud Feedbacks in a Constant Relative Humidity Atmosphere. J. Atm. Sci. 69, 2538-2550. doi:10.1175/JAS-D-11-0203.1.

[99] Wentz, F.J., Ricciardulli, L., Hilburn, K., Mears, C. (2007): How Much More Rain Will Global Warming Bring? Science 317, 233-235. doi:10.1126/science.1140746.

[100] Peixoto, J.P., Oort, A.H. (1996): The climatology of relative humidity in the atmosphere. Journal of Climate 9, 3443-3463. doi:10.1175/1520-0442(1996)009<3443:TCORHI >2.0.CO;2

[101] Wentz, F.J., Schabel, M. (2000): Precise climate monitoring using complementary satellite data sets. Nature, 403, 414-416. doi:10.1038/35000184.

[102] Wright, P.B. (1988): An Atlas Based on the 'COADS' Data Set: Fields of Mean Wind, Cloudiness and Humidity at the Surface of the Global Ocean. Report No. 14, Max-Planck-Institut für Meteorologie, Hamburg.

[103] Willett, K.M., Dunn, R.J.H., Thorne, P.W., Bell, S., de Podesta, M., Parker, D.E., Jones, P.D., Williams Jr., C.N. (2014): HadISDH land surface multi-variable humidity and temperature record for climate monitoring. Clim. Past 10, 1983-2006. doi:10.5194/cp-10-1983-2014.

[104] Kraus, E.B., Businger, J.A. (1994): Atmosphere-Ocean Interaction. Oxford University Press, Clarendon Press, Oxford, New York, United States.

[105] Lewis, G.N. (1901): Das Gesetz physiko-chemischer Vorgänge. Z. Phys. Chem., Lpz. 38, 205-226; The Law of PhysicoChemical Change. Proceedings of the American Academy of Arts and Sciences 37, 49-69. doi:10.2307/20021635. 
[106] Malinin, V.N., Gordeeva, S.M. (2017): Variability of Evaporation and Precipitation over the Ocean from Satellite Data Izvestiya, Atmospheric and Oceanic Physics 53, 934-944. doi:10.1134/S0001433817090195.

[107] Thurnherr, I., Kozachek, A., Graf, P., Weng, Y., Bolshiyanov, D., Landwehr, S., Pfahl, S., Schmale, J., Sodemann, H., SteenLarsen, H.C., Toffoli, A., Wernli, H., Aemisegger, F. (2020): Meridional and vertical variations of the water vapour isotopic composition in the marine boundary layer over the Atlantic and Southern Ocean. Atmos. Chem. Phys. 20, 5811-5835. doi:10.5194/acp-20-5811-2020.

[108] Guggenheim, E.A. (1949): Thermodynamics. North-Holland, Amsterdam, Netherlands.

[109] Prausnitz, J.M., Lichtenthaler, R.N., Gomes de Azevedo, E. (1999): Molecular Thermodynamics of Fluid-Phase Equilibria, 3rd edn. Prentice Hall, New Jersey, United States.

[110] Trabert, W. (1896): Neuere Beobachtungen über die Verdampfungsgeschwindigkeit. Meteorologische Zeitschrift 13, 261-263.

[111] Debski, K. (1966): Continental Hydrology, Volume 2: Physics of Water, Atmospheric Precipitation, and Evaporation. Scientific Publications Foreign Cooperation Center of the Central Institute, Warsaw, Poland.

[112] Brutsaert, W. (1982): Evaporation into the Atmosphere: Theory, History and Applications. Springer, Dordrecht, Germany.

[113] Bunker, A.F. (1976): Computation of Surface Energy Flux and Annual Air-Sea Interaction Cycles of the North Atlantic Ocean. Monthly Weather Review 104, 1122-1140. doi:10.1175/1520-0493(1976)104<1122:COSEFA>2.0.CO;2.

[114] Liu, W.T., Katsaros, K.B., Businger, J.A. (1979): Bulk Parameterization of Air-Sea Exchanges of Heat and Water Vapor Including the Molecular Constraints at the Interface. Journal of Atmospheric Sciences 36, 1722-1735. doi:10.1175/15200469(1979)036<1722:BPOASE >2.0.CO;2.

[115] Liou, K.-N., Zheng, Q. (1984): A numerical experiment on the interactions of radiation, clouds and dynamic processes in a general circulation model. J. Atmos. Sci. 41, 1513-1535.

[116] Doney, S.C. (1995): Irreversible thermodynamics and air-sea exchange. J. Geophys. Res. 100, 8541-8553. doi:10.1029/95JC00685.

[117] Roeckner, E., Arpe, K., Bengtsson, L., Christoph, M.; Claussen M., Dümenil, L., Esch, M., Giorgetta, M., Schlese, U., Schulzweida, U. (1996): The atmospheric general circulation model ECHAM-4: model description and simulation of presentday climate. Max-Planck-Institut für Meteorologie, REPORT No. 218. Available online: https://pure.mpg.de/rest/items/item_1781494/component/file_1786328/content (accessed on March 2021).

[118] Fairall, C.W., Bradley, E.F., Hare, J.E., Grachev, A.A., Edson, J.B. (2003): Bulk Parameterization of Air-Sea Fluxes: Updates and Verification for the COARE Algorithm. J. Climate 16, 571-591. doi:10.1175/15200442(2003)016<0571:BPOASF>2.0.CO;2.

[119] Stevens, B., Giorgetta, M., Esch, M., Mauritsen, T., Crueger, T., Rast, S., Salzmann, M., Schmidt, H., Bader, J., Block, K., Brokopf, R., Fast, I., Kinne, S., Kornblueh, L., Lohmann, U., Pincus, R., Reichler, T., E. Roeckner, E. (2013): Atmospheric component of the MPI-M Earth System Model: ECHAM6. Journal of Advances in Modeling Earth Systems 5, 146-172. doi:10.1002/jame.20015.

[120] Zhang, R., Wang, X., Wang, C. (2018b): On the Simulations of Global Oceanic Latent Heat Flux in the CMIP5 Multimodel Ensemble. J. Climate 31, 7111-7127. doi:10.1175/JCLI-D-17-0713.1.

[121] Thornthwaite, C.W., Holzman, B. (1939): The determination of evaporation from land and water surfaces. Mon. Wea. Rev. 67, 4-11. doi:10.1175/1520-0493(1939)67<4:TDOEFL>2.0.CO;2.

[122] Hasse, L. (1971): The Sea Surface Temperature Deviation and the Heat Flow at the Sea-Air-Interface. Boundary-Layer Meteorology 1, 368-379. doi:10.1007/BF02186037.

[123] Wunderlich, W.O. (1972): Heat and Mass Transfer Between a Water Surface and the Atmosphere. Report No. 0-6803, Tennessee Valley Authority, Illinois, United States.

[124] Thompson, O.E., Pinker, R.T. (1981): An error analysis of the Thornthwaite-Holzmann equations for estimating sensible and latent heat fluxes over crop and forest canopies. J. Appl. Metorol. 20, 250-254. doi:10.1175/15200450(1981)020<0250:AEAOTT>2.0.CO;2.

[125] Prandtl, L. (1925): Bericht über Untersuchungen zur ausgebildeten Turbulenz. Zeitschrift für Angewandte Mathematik und Mechanik (ZAMM) 5, 136-139.

[126] Prandtl, L. (1932): Meteorologische Anwendung der Strömungslehre. Beiträge zur Physik der freien Atmosphäre (BjerknesFestschrift) 19, 188-202.

[127] Logwinow, K.T. (1955): Dynamische Meteorologie. VEB Deutscher Verlag der Wissenschaften, Berlin, Germany. 
[128] Albert, H.-F. (1988): Modelle zur Berechnung des Windprofils in einer planetarischen Grenzschicht unter Verwendung von Ansätzen für den Turbulenzkoeffizienten. In: Grenzschichtmodellierung und Klimaforschung, Abh. Meteorol. Dienstes DDR Nr. 140, Akademie-Verlag Berlin, 21-26.

[129] Albert, H.-F., Bernhardt, K., Mix, W. (1988): Ergebnisse und Erfahrungen bei der halbempirischen Modellierung der Vertikalprofile von Wind und Turbulenzkoeffizient in der planetarischen Grenzschicht. In: Grenzschichtmodellierung und Klimaforschung, Abh. Meteorol. Dienstes DDR Nr. 140, Akademie-Verlag Berlin, 7-20.

[130] Albert, H.-F., Bernhardt, K., Vogler, P. (1982): Ein quasigeotriptisches integrales Grenzschichtmodell. In: Untersuchungen zur Meteorologie der Grenzschicht und zur Analyse klimatologischer Zeitreihen, Abh. Meteorol. Dienstes DDR Nr. 128, Akademie-Verlag Berlin, 7-29.

[131] Albert, H.-F., Mix, W. (1988): Vergleiche berechneter und empirisch ermittelter Vertikalprofile in der planetarischen Grenzschicht. In: Grenzschichtmodellierung und Klimaforschung, Abh. Meteorol. Dienstes DDR Nr. 140, Akademie-Verlag Berlin, 27-32.

[132] Bernhardt, K., Klose, B., Pethe H. (1982): Grenzschichthöhen und Windprofile nach Radiosondendaten. In: Untersuchungen zur Meteorologie der Grenzschicht und zur Analyse klimatologischer Zeitreihen, Abh. Meteorol. Dienstes DDR Nr. 128, Akademie-Verlag Berlin, 41-51.

[133] Detering, H. W. (1985): Mischungsweg und turbulenter Diffusionskoeffizient in atmosphärischen Simulationsmodellen. Berichte des Instituts für Meteorologie und Klimatologie der Universität Hannover Nr. 25, Hannover, Germany.

[134] Mix, W. (1982): Über die vertikale Verteilung des horizontalen Windvektors und des Turbulenzkoeffizienten in einer planetarischen Grenzschicht mit eingelagerter Inversionsschicht. In: Untersuchungen zur Meteorologie der Grenzschicht und zur Analyse klimatologischer Zeitreihen, Abh. Meteorol. Dienstes DDR Nr. 128, Akademie-Verlag Berlin, 53-73.

[135] Mix, W. (1988): Qualitative Erfassung von Beschleunigungseinflüssen in der planetarischen Grenzschicht. In: Grenzschichtmodellierung und Klimaforschung, Abh. Meteorol. Dienstes DDR Nr. 140, Akademie-Verlag Berlin, 33-41.

[136] Kondo, J. (1975): Air-sea bulk transfer coefficients in diabatic conditions. Boundary-Layer Meteorology 9, 91-112. doi:10.1007/BF00232256.

[137] Kruspe, G. (1977): On moisture flux parameterization. Boundary-Layer Meteorology 11, 55-63. doi:10.1007/BF00221824.

[138] Foken, T. (1990): Turbulenter Energieaustausch zwischen Atmosphäre und Unterlage. Methoden, meßtechnische Realisierung sowie ihre Grenzen und Anwendungsmöglichkeiten. Berichte DWD Nr. 180, Selbstverlag des DWD, Offenbach a.M.

[139] Laubach, J. (1996): Charakterisierung des turbulenten Austausches von Wärme, Wasserdampf und Kohlendioxid über niedriger Vegetation anhand von Eddy-Korrelations-Messungen. Wissenschaftliche Mitteilungen aus dem Institut für Meteorologie der Universität Leipzig und dem Institut für Troposphärenforschung e.V. Leipzig Band 3, Leipzig, Germany.

[140] Enriquez, A.G., Friehe, C.A. (1997): Bulk parameterization of momentum, heat, and moisture fluxes over a coastal upwelling area. J. Geophys. Res. 102(C3), 5781- 5798. doi:10.1029/96JC02952.

[141] Hellmuth, O. (2006a): Columnar modelling of nucleation burst evolution in the convective boundary layer - first results from a feasibility study. Part I: Modelling approach. Atmos. Chem. Phys. 6, 4175-4214. doi:10.5194/acp-6-4175-2006.

[142] Doms, G., Förstner, J., Heise, E., Herzog, H.-J., Mironov, D., Raschendorfer, M., Reinhardt, T., Ritter, B., Schrodin, R., Schulz, J.-P., Vogel, G. (2013): A Description of the Nonhydrostatic Regional COSMO-Model. Part II: Physical Parameterizations, COSMO 5.00, November 2013. Deutscher Wetterdienst, Offenbach. doi:10.5676/DWD_pub/nwv/cosmo-doc_5.00_II.

[143] Cronin, M. F., Gentemann, C. L., Edson, J., Ueki, I., Bourassa, M., Brown, S., ... Zhang, D. (2019). Air-Sea Fluxes with a Focus on Heat and Momentum. Frontiers in Marine Science, 6. doi:10.3389/fmars.2019.00430.

[144] Fortak, H.G. (1979): Entropy and climate. In: Bach, W., Pankrath, J., Kellogg, W. (eds.), Developments in atmospheric science, Vol. 10, Man's impact on climate. Elsevier Sci., New York, p. 1-14.

[145] Ebeling, W., Feistel, R. (1982): Physik der Selbstorganisation und Evolution. Akademie-Verlag, Berlin, Germany.

[146] Feistel, R., Ebeling, W. (2011): Physics of Self-Organization and Evolution. Wiley-VCH, Weinheim, Germany.

[147] Feistel, R., Wright, D.G., Kretzschmar, H.-J., Hagen, E., Herrmann, S., Span, R. (2010): Thermodynamic properties of sea air. Ocean Sci. 6, 91-141. doi:10.5194/os-6-91-2010.

[148] Feistel, R. (2018): Thermodynamic properties of seawater, ice and humid air: TEOS-10, before and beyond. Ocean Sci. 14, 471-502. doi:10.5194/os-14-471-2018.

[149] Landau, L.D., Lifschitz, I.M. (1974): Lehrbuch der Theoretischen Physik VI, Hydrodynamik. Akademie-Verlag, Berlin, Germany.

[150] Hasse, L. (1963): On the cooling of the sea surface by evaporation and heat exchange. Tellus 15, 363-366. doi:10.1111/j.21533490.1963.tb01399.x. 
[151] Reeves Eyre, J.E.J., Zeng, X., Zhang, K. (2021): Ocean Surface Flux Algorithm Effects on Earth System Model Energy and Water Cycles. Frontiers in Marine Science 8, 642804. doi:10.3389/fmars.2021.642804.

[152] Foken, T., Hupfer, P. (2009): Interaction between the Atmosphere and the Underlying Surface. Berichte zur Polar- und Meeresforschung 588, 40-51.

[153] Oberhuber, J.M. (1988): An atlas based on the 'COADS' data set : The budgets of heat, buoyancy and turbulent kinetic energy at the surface of the global ocean. Report No. 15, Max-Planck-Institut für Meteorologie, Hamburg, Germany.

[154] Boer, G.J. (1993): Climate change and the regulation of the surface moisture and energy budgets. Climate Dynamics 8, 225239. doi:10.1007/BF00198617

[155] Olbers, D. (2001): A gallery of simple models from climate physics. In: Imkeller P., von Storch, J.S. (eds): Stochastic Climate Models. Progress in Probability, vol 49. Birkhäuser, Basel. doi:10.1007/978-3-0348-8287-3_1.

[156] Yu, L. (2007): Global Variations in Oceanic Evaporation (1958-2005): The Role of the Changing Wind Speed. J. Climate 20, 5376-5390. doi:10.1175/2007JCLI1714.1.

[157] Liu, W.T., Xie, X. (2014): Ocean-Atmosphere Water Flux and Evaporation. In: Njoku E.G. (ed.): Encyclopedia of Remote Sensing. Encyclopedia of Earth Sciences Series, Springer, New York, pp. 480-489. doi:10.1007/978-0-387-36699-9_122.

[158] Sausen, R., Barthel, K., Hasselmann, K. (1988): Coupled ocean-atmosphere models with flux correction. Climate Dynamics 2 , 145-163. doi:10.1007/BF01053472.

[159] CENR (1992): Global climate change: hearings before the Committee on Energy and Natural Resources (CENR), United States Senate, One Hundred Second Congress, second session, on the science and energy policy implications of global climate change and international agreements. United States. Congress. Senate. Committee on Energy and Natural Resources. Washington: U.S. G.P.O.: Washington, United States.

[160] Cao, N., Ren, B., Zheng, J. (2015): Evaluation of CMIP5 Climate Models in Simulating 1979-2005 Oceanic Latent Heat Flux over the Pacific. Advances in Atmospheric Sciences 32, 1603-1616. doi:10.1007/s00376-015-5016-8.

[161] Sherwood, S.C., Ingram, W., Tsushima, Y., Satoh, M., Roberts, M., Vidale, P.L., O’Gorman, P.A. (2010): Relative humidity changes in a warmer climate. J. Geophys. Res., 115, D09104. doi:10.1029/2009JD012585.

[162] Held, I.M., Soden, B.J. (2012): Using Relative Humidity as a State Variable in Climate Feedback Analysis. J. Climate 25, 2578-2582. doi:10.1175/JCLI-D-11-00721.1.

[163] Levang, S.J., Schmitt, R.W. (2015): Centennial changes of the global water cycle in CMIP5 models. J. Climate, 28 , 6489-6502. doi:10.1175/JCLI-D-15-0143.1.

[164] Pfeifroth, U., Hollmann, R., Ahrens, B. (2012): Cloud Cover Diurnal Cycles in Satellite Data and Regional Climate Model Simulations. Meteorologische Zeitschrift 21, 551-560. doi:10.1127/0941-2948/2012/0423.

[165] King, M.D., Platnick, S., Menzel, W.P., Ackerman, S.A., Hubanks, P.A., (2013): Spatial and Temporal Distribution of Clouds Observed by MODIS Onboard the Terra and Aqua Satellites. IEEE Trans. Geosci. Remote Sensing 51, 3826-3852. doi:10.1109/TGRS.2012.2227333.

[166] Marshak, A., Davis, A.B. (2005): 3D Radiative Transfer in Cloudy Atmospheres. Springer-Verlag Berlin, Germany.

[167] Matus, A.V., L'Ecuyer, T.S. (2017): The role of cloud phase in Earth's radiation budget, J. Geophys. Res. Atmos., 122, 25592578. doi:10.1002/2016JD025951.

[168] Arrhenius, S. (1896): On the Influence of Carbonic Acid in the Air upon the Temperature of the Ground. London, Edinburgh, and Dublin. Philosophical Magazine and Journal of Science 41, 237-275. doi:10.1080/14786449608620846.

[169] Dong, Y., Armour, K.C., Zelinka, M.D., Proistosescu, C., Battisti, D.S., Zhou, C., Andrews, T. (2020): Intermodel spread in the pattern effect and its contribution to climate sensitivity in CMIP5 and CMIP6 models. Journal of Climate 33, 7755 - 7775. doi:10.1175/JCLI-D-19-1011.1.

[170] Stouffer, R.J., Eyring, V., Meehl, G.A., Bony, S., Senior, C., Stevens, B., Taylor, K.E. (2017): CMIP5 scientific gaps and recommendations for CMIP6. Bulletin of the American Meteorological Society 98, 95-105. doi:10.1175/BAMS-D-15-00013.1.

[171] Zelinka, M. D., Myers, T.A., McCoy, D.T., Po-Chedley, S., Caldwell, P.M., Ceppi, P., Klein, S.A., Taylor, K.E. (2020): Causes of higher climate sensitivity in CMIP6 models. Geophysical Research Letters 47, e2019GL085782. doi:10.1029/2019GL085782.

[172] Goosse, H., Barriat, P., Lefebvre, W., Loutre, M., Zunz, V. (2008-2010): Introduction to climate dynamics and climate modeling (2008-2010). UCL Université catholique de Louvain, Online textbook.

[173] Mülmenstädt, J., Salzmann, M., Kay, J.E., Zelinka, M.D., Ma, P.-L., Nam, C., Kretzschmar, J., Hörnig, S., Quaas, J. (2021): An underestimated negative cloud feedback from cloud lifetime changes. Nature Climate Change 11, 508-513. doi:10.1038/s41558-021-01038-1. 
[174] Held, I.M., Soden, B.J. (2000): Water Vapor Feedback and Global Warming. Annual Review of Energy and the Environment 25, 441-475. doi:10.1146/annurev.energy.25.1.441.

[175] Folland, C.K., Karl, T.R., Christy, J.R., Clarke, R.A., Gruza, G.V., Jouzel, J., Mann, M.E., Oerlemans, J., Salinger, M.J., Wang, S.-W. (2001): Observed Climate Variability and Change. In: Climate Change 2001: The scientific basis. Contribution of Working Group I to the Third Assessment Report of the IPCC. Cambridge University Press, Cambridge, UK. Chapter 2, pp. 99-181. Available online: https://www.ipcc.ch/report/ar3/wg1 (accessed on March 2021).

[176] Burrows, W.J. (2003): Weather Cycles, Second Edition: Real or Imaginary? Cambridge University Press, Cambridge, UK.

[177] Smagorinsky, J. (1960): On the Dynamical Prediction of Large-Scale Condensation by Numerical Methods. In: Weickmann, H. (ed.): Physics of Precipitation: Proceedings of the Cloud Physics Conference, Woods Hole, Massachusetts, June 3-5, 1959. American Geophysical Union, S. 71-78. doi:10.1029/GM005p0071.

[178] Xu, K.-M, Randall, A.A. (1996): A Semiempirical Cloudiness Parameterization for Use in Climate Models. J, Atm. Sci 53, 3084-3102. doi:10.1175/1520-0469(1996)053<3084:ASCPFU>2.0.CO;2.

[179] Klaus, D., Dorn, W., Dethloff, K., Rinke, A., Mielke, M. (2012): Atmosphere 2012, 419-450. doi:10.3390/atmos3030419.

[180] Faizal, M., Ahmed, M.R. (2011): On the ocean heat budget and ocean thermal energy conversion. Int. J. Energy Resaerch 35, 1119-1144. doi:10.1002/er.1885.

[181] Wippermann, F. (1971): Die "Scales" als ein erstes Ordnungsprinzip für alle Turbulenzvorgänge der Atmosphäre. Promet Meteorologische Fortbildung. Mikro-und Maktroturbulenz 1971, 1/2, 16-20, Available online: https://www.dwd.de/DE/leistungen/pbfb_verlag_promet/pdf_promethefte/1_1_2_pdf.pdf?_blob=publicationFile\&v=3 (accessed on March 2021).

[182] Haigh, J.D., Cargill, P. (2015): The Sun's Influence on Climate. Princeton University Press, New Jersey, United States.

[183] Schepanski, K. (2006): Natürliche Variabilität der Wolken im Klimamodell. Diplomarbeit, Leibniz-Institut für Meereswissenschaften, Kiel, Germany.

[184] Scurla, H. (1984): Durch das Land der Azteken. Berichte deutscher Reisender des 19. Jahrhunderts aus Mexiko und Guatemala. Verlag der Nation, Berlin, Germany.

[185] Heyer, E. (1979): Witterung und Klima. Eine allgemeine Klimatologie. BSB B. G. Teubner Verlagsgesellschaft, Leipzig.

[186] Hancock, G., Pankhurst, R., Willetts, D. (1983): Under Ethiopian Skies. H\&L Communications, London, Germany.

[187] Komabayasi, M. (1967): Discrete equilibrium temperatures of a hypothetical planet with the atmosphere and the hydrosphere of one component-two phase system under constant solar radiation. J. Meteorol. Soc. Japan 45, 137-138. doi:10.2151/jmsj1965.45.1_137.

[188] Ingersoll, A.P. (1969): The runaway greenhouse: a history of water on Venus. J. Atmos. Sci. 26, 1191-1198. doi:10.1175/15200469(1969)026<1191:TRGAHO>2.0.CO;2.

[189] Ingersoll, A.P. (2013): Planetary Climates. Princeton University Press, Princeton, New Jersey, United States.

[190] Bülow, M. (2020): Anthropogener Klimawandel? - Rückkopplungen und Fallgruben. Leibniz Online 39. Available online: https://leibnizsozietaet.de/wp-content/uploads/2020/02/Portfolio-LO-39-2020.pdf (accessed on March 2021).

[191] Pelkowski, J. (1995): Entropieerzeugung eines strahlenden Planeten: Studien zu ihrer Rolle in der Klimatheorie. Verlag Harry Deutsch, Thun, Frankfurt am Main, Germany.

[192] Pelkowski, J. (2014): On the Clausius-Duhem Inequality and Maximum Entropy Production in a Simple Radiating System. Entropy 16, 2291-2308. doi:10.3390/e16042291.

[193] Pierrehumbert, R.T. (2010): Principles of Planetary Climate. Cambridge University Press, Cambridge, UK.

[194] Rothman, L. S., Jacquemart, D., Barbe, A., Chris Benner, D., Birk, M., Brown, L. R., ... Wagner, G. (2005). The HITRAN 2004 molecular spectroscopic database. Journal of Quantitative Spectroscopy and Radiative Transfer, 96(2), 139-204. doi:10.1016/j.jqsrt.2004.10.008.

[195] Lutgens, F.G., Tarbuck, E.J. (2001): The Atmosphere. Prentice Hall, Upper Saddle River, New Jersey, United States.

[196] Zhong, W., Haigh, J.D. (2013): The greenhouse effect and carbon dioxide. Weather 68, 100-105. doi:10.1002/wea.2072.

[197] Czerny, M. (1954): Zur Integration des Planckschen Strahlungsgesetzes. Zeitschrift für Physik, 139, 302-308.

[198] Le Quéré, C., Andrew, R. M., Friedlingstein, P., Sitch, S., Hauck, J., Pongratz, J., .. Canadell, J. G. (2018). Global Carbon Budget 2018. Earth System Science Data, 10(4), 2141-2194. doi:10.5194/essd-10-2141-2018.

[199] Emden, R. (1913): Über Strahlungsgleichgewicht und atmosphärische Strahlung. Sitzungsberichte der mathematischphysikalischen Klasse der Königlich Bayerischen Akademie der Wissenschaften zu München 1913, 55-142. 
[200] Feistel, R. (2011): Radiative entropy balance and vertical stability of a gray atmosphere. Eur. Phys. J. B 82, $197-206$. doi:10.1140/epjb/e2011-20328-2.

[201] Kara, A.B., Hurlburt, H.E., Loh, W.-Y. (2007): Which near-surface atmospheric variable drives air-sea temperature differences over the global ocean? J. Geophys. Res.-Ocean 112, C05020. doi:10.1029/2006JC003833.

[202] Saunders, P.M. (1967): The temperature at the ocean-air interface. J. Atmos. Sci. 24, 269-273. doi:10.1175/15200469(1967)024<0269:TTATOA>2.0.CO;2.

[203] Schluessel, P., Emery, W.J., Grassl, H., Mammen, T. (1990): On the bulk-skin temperature difference and its impact on satellite remote sensing of sea surface temperature. J. Geophys. Res. 95, 13341-13356. doi:10.1029/JC095iC08p13341.

[204] Schwartz, S.E. (2007): Heat capacity, time constant, and sensitivity of Earth's climate system. Journal of Geophysical Research 112, D24S05. doi:10.1029/2007JD008746.

[205] Foster, G., Annan, J.D., Schmidt, G.A., Mann, M.E. (2008): Comment on "Heat capacity, time constant, and sensitivity of Earth's climate system" by S. E. Schwartz. Journal of Geophysical Research Atmospheres 113, D15102. doi:10.1029/2007JD009373.

[206] Frankignoul, C., Hasselmann, K. (1977): Stochastic climate models, Part II. Application to sea-surface temperature anomalies and thermocline variability. Tellus 29, 298-305. doi:10.1111/j.2153-3490.1977.tb00740.x.

[207] Prescott, J.A., Collins, J.A. (1951): The lag of temperature behind solar radiation. Quarterly Journal of the Royal Meteorological Society 77, 121-126. doi:10.1002/qj.49707733112.

[208] Hupfer, P. (1998): Klima und Klimasystem. In: Lozan, J.E., Graß1, H., Hupfer, P. (1998): Warnsignal Klima. Wissenschaftliche Auswertungen, Hamburg, S. 17-24.

[209] IOW (2020): HIX - St. Helena Island Climate Index. Available online: https://www.io-warnemuende.de/hix-st-helena-islandclimate-index.html (accessed on December 2020).

[210] Morice, C.P., Kennedy, J.J., Rayner, N.A., Jones, P.D. (2012): Quantifying uncertainties in global and regional temperature change using an ensemble of observational estimates: The HadCRUT4 data set. J. Geophys. Res. 117, D08101. doi:10.1029/2011JD017187.

[211] Deland, R. (1968): Energetics of Atmospheric Motions. Institut für Theoretische Meteorologie der FU Berlin, Berlin, Germany.

[212] Trenberth, K. (2010): The ocean is warming, isn't it? Nature 465, 304. doi:10.1038/465304a.

[213] Cheng, L., Abraham, J., Zhu, J., Trenberth, K.E., Fasullo, J., Boyer, T., Locarnini, R., Zhang, B., Yu, F., Wan, L., Chen, X., Song, X., Liu, Y., Mann (2020): Record-Setting Ocean Warmth Continued in 2019. Advances in Atmospheric Sciences 37, 137-142. doi:10.1007/s00376-020-9283-7.

[214] Bernhardt, K.-H. (2020): Alexander von Humboldts Wirken für die Klimatologie aus heutiger Sicht. Sitzungsberichte der Leibniz-Sozietät 143, 63-81. Available online: https://leibnizsozietaet.de/wp-content/uploads/2020/09/Gesamtdatei-SB-1432020.pdf (accessed on March 2021).

[215] Loeb, N.G., Wielicki, B.A., Doellingast, D.R., Smith, G.L., Keyes, D.F., Kato, S., Manalo-Smith, N., Wong, T. (2009): Toward Optimal Closure of the Earth's Top-of-Atmosphere Radiation Budget. J. Climate 22, 748-766. doi:10.1175/2008JCLI2637.1.

[216] Trenberth, K.E., Fasullo, J.T. (2010): Tracking Earth's Energy. Science 328, 316-317. doi:10.1126/science.1187272.

[217] Hume, D. (2015): Eine Untersuchung über den menschlichen Verstand. Felix Meiner Verlag, Hamburg, Germany.

[218] Kant, I. (1956): Kritik der reinen Vernunft. 2nd edition of 1787. Felix Meiner, Hamburg, Germany.

[219] Sugihara, G., May, R., Ye, H., Hsieh, C.-H., Deyle, E., Fogarty, M., Munch, S. (2012): Detecting causality in complex ecosystems. Science 338, 496-500. doi:10.1126/science.1227079.

[220] Stips, A., Macias, D., Coughlan, D., Garcia-Gorriz, E., San Liang, X. (2016): On the causal structure between CO2 and global temperature. Scientific Reports 6, 21691. doi:10.1038/srep21691.

[221] Foken, T. (2008b): The energy balance closure problem - An overview. Ecolog. Appl. 18, 1351-1367. doi:10.1890/06-0922.1.

[222] Mauder, M., Foken, T. Cuxart, J. (2020): Surface Energy Balance Closure over Land: A Review. Boundary-Layer Meteorol. doi:10.1007/s10546-020-00529-6.

[223] Kracher, D., Mengelkamp, H.-T., Foken, T. (2009): The residual of the energy balance closure and its influence on the results of three SVAT models. Meteorologische Zeitschrift 18, 647-661. doi:10.1127/0941-2948/2009/0412.

[224] Schmugge, T.J., André, J.-C. (Hrsg.) (1991): Land Surface Evaporation. Measurement and Parameterization. Springer-Verlag New York, United Kingdom.

[225] McDougall, T.J., Barker, P.M., Holmes, R.M., Pawlowicz, R., Griffies, S.M., Durack, P.J. (2021): The interpretation of temperature and salinity variables in numerical ocean model output and the calculation of heat fluxes and heat content. Geoscientific Model Development 14, 6445-6466. doi:10.5194/gmd-14-6445-2021. 
[226] Smith, B., Fricker, H.A., Gardner, A.S., Medley, B., Nilsson, J., Paolo, F.S., Holschuh, N., Adusumilli, S., Brunt, K., Csatho, B., Harbeck, K., Markus, T., Neumann, T., Siegfried, M.R., Zwally, H.J. (2020): Pervasive ice sheet mass loss reflects competing ocean and atmosphere processes. Science 30. Apr. 2020. doi:10.1126/science.aaz5845.

[227] Lu, X., McElroy, M.B., Kiviluoma, J. (2009): Global potential for wind-generated electricity. Proceedings of the National Academy of Sciences of the United States of America 106, 10933-10938. doi:10.1073/pnas.0904101106.

[228] Feistel, R. (2017): Salzgehalt des Meeres und relative Feuchte der Luft: Rolle im Klimasystem und Probleme ihrer Definition. Vortrag in der Klasse für Naturwissenschaften und Technikwissenschaften am 10.11.2016. Leibniz Online 25. Available online: https://leibnizsozietaet.de/wp-content/uploads/2012/10/Portfolio-LO-25-2017-1.pdf (accessed on February 2021).

[229] Feistel, R. (2015): Salinity and relative humidity: climatological relevance and metrological needs. Acta Imeko 4, 57-61. doi:10.21014/acta_imeko.v4i4.216.

[230] Maule, C.F., Purucker, M.E., Olsen, N., Mosegaard, K. (2005): Heat flux anomalies in Antarctica revealed by satellite magnetic data. Science 309, 464-467. doi:10.1126/science.1106888.

[231] Pollack, H.N., Hurter, S.J., Johnson, J.R. (1993): Heat Flow from the Earth's Interior: Analysis of the Global Data Set. Reviews of Geophysics 30, 267-280. doi:10.1029/93RG01249.

[232] Lösing, M., Ebbing, J., Szwillus, W. (2020): Geothermal Heat Flux in Antarctica: Assessing Models and Observations by Bayesian Inversion. Front. Earth Sci. 8, 106. doi:10.3389/feart.2020.00105.

[233] Pallé, E., Goode, P.R., Montañés-Rodríguez, P., Koonin, S.E. (2004): Changes in Earth's Reflectance over the Past Two Decades. Science 304, 1299-1301. doi:10.1126/science.1094070.

[234] Schmutz, W., Fehlmann, A., Hüsen, G., Meindl, P., Winkler, R., Thuillier, G., Blattner, P., Buisson, F., Egorova, T., Finsterle, W., Fox, N., Gröbner, J., Hochedez, J.-F., Koller, S., Meftah, M., Meisonnier, M., Nyeki, S., Pfiffner, D., Roth, H., Rozanov, E., Spescha, M., Wehrli, C., Werner, L., Wyss, J.U. (2009): The PREMOS/PICARD instrument calibration. Metrologia, 46, S202-S206. doi:10.1088/0026-1394/46/4/S13.

[235] Bernhardt, A. (2014). Labor standards and the reorganization of work: Gaps in data and research. Annette Bernhardt - UC Berkeley Labor Center, California, United States.

[236] Goode, P.R., Pallé, E., Shoumko, A., Shoumko, S., Montañes-Rodriguez, P., Koonin, S.E. (2021): Earth's albedo 1998-2017 as measured from earthshine. Geophysical Research Letters 48, e2021GL094888. doi:10.1029/2021GL094888.

[237] Bryden, H.L., King, B.A., McCarthy, G.D., McDonagh, E.L. (2014): Impact of a 30\% reduction in Atlantic meridional overturning during 2009-2010. Ocean Sci. 10, 683-691. doi:10.5194/os-10-683-2014.

[238] Laskar, J., Fienga, A., Gastineau, M., Manche, H. (2011): La2010: a new orbital solution for the long-term motion of the Earth, Astronomy \& Astrophysics 532, A89. doi:10.1051/0004-6361/201116836.

[239] Steinhilber, F., Beer, J., Fröhlich, C. (2009): Total solar irradiance during the Holocene. Geophysical Research Letters 36, L19704. doi:10.1029/2009GL040142.

[240] Pausata, F.S.R., Gaetani, M., Messori, G., Berg, A., Maia de Souza, D., Sage, R.F., deMenocal, P.B. (2020): The Greening of the Sahara: Past Changes and Future Implications. One Earth 2, 235-250. doi:10.1016/j.oneear.2020.03.002.

[241] Monin, A.S. (1982): Vvedeniye v Teoriyu Klimata. Gidrometeoizdat, Leningrad.

[242] Ahmed, H.A., Yu-xin, T., Qi-chang, Y. Al-Helal, I.M., Shady, M.R., Abdel-Ghany. A.M. (2020): Estimation of Sky Thermal Irradiance in Arid Climate under Clear Sky Conditions. Int. J. Thermophys. 41, 76. doi:10.1007/s10765-020-02656-1.

[243] Mitchell, J.F.B. (1994): Modelling Clouds in GCMs for Climate Change Studies. In: IAMAS (1994), S. 40.

[244] Lindzen, R.S. (1997): Can increasing carbon dioxide cause climate change? PNAS 94, 8335-8342. doi:10.1073/pnas.94.16.8335.

[245] Tobiska, W., Nusinov, A. (2006): ISO 21348 - Process for determining solar irradiances. In: 36th COSPAR Scientific Assembly, vol. 36 of COSPAR, Plenary Meeting, p. 2621-2462.

[246] Hupfer, P. (1991): Das Klimasystem der Erde - Diagnose und Modellierungen - Schwankungen und Wirkungen. Akademie Verlag, Berlin, Germany.

[247] Trenberth, K.E, Hurrell, J.W., Solomon, A. (1995): Conservation of mass in three dimensions in global analyses. J. Climate 8, 692-708. doi:10.1175/1520-0442(1995)008<0692:COMITD>2.0.CO;2.

[248] Alexander, M.A., Schubert, S.D. (1990): Regional earth-atmosphere balance estimates based on assimilations with a GCM. Journal of Climate 3, 15-31. doi:10.1175/1520-0442(1990)003<0015:REAEBE>2.0.CO;2.

[249] Hansen, J., Sato, M., Kharecha, P., von Schuckmann, K. (2011): Earth's Energy Imbalance and Implications. Atmospheric Chemistry and Physics 11, 13421-13449. doi:10.5194/acp-11-13421-2011. 
[250] Griffies, S.M., Adcroft, A.J. (2008): Formulating the Equations of Ocean Models. In: Hecht, M.W., Hasumi, H. (eds.): Ocean Modeling in an Eddying Regime, Geophysical Monograph Series 177, American Geophysical Union, pp. 281-317. doi:10.1029/177GM18.

[251] Irving, D., Hobbs, W., Church, J., Zika, J. (2020): A Mass and Energy Conservation Analysis of Drift in the CMIP6 Ensemble. Journal of Climate, 1-43. doi:10.1175/JCLI-D-20-0281.1

[252] Gassmann, A., Herzog, H.-J. (2015): How is local material entropy production represented in a numerical model? Quarterly Journal of the Royal Meteorological Society 141, 854-869. doi:10.1002/qj.2404.

[253] JPOTS (1981): Tenth report of the joint panel on oceanographic tables and standards. Sidney, B.C., Canada, 1-5 September 1980. Unesco technical papers in marine science 36, Unesco. Available online: https://www.jodc.go.jp/jodcweb/info/ioc_doc/html/UNESCO_Tech.htm (accessed on March 2021).

[254] Pauluis, O., Czaja, A., Korty, R. (2008): The Global Atmospheric Circulation on Moist Isentropes. Science 321, $1075-1078$. doi:10.1126/science.1159649.

[255] Griffies, S. M., Danabasoglu, G., Durack, P. J., Adcroft, A. J., Balaji, V., Böning, C. W., ... Yeager, S. G. (2016). OMIP contribution to CMIP6: experimental and diagnostic protocol for the physical component of the Ocean Model Intercomparison Project. Geoscientific Model Development, 9(9), 3231-3296. doi:10.5194/gmd-9-3231-2016.

[256] IOC, SCOR, IAPSO (2010): The international thermodynamic equation of seawater - 2010: Calculation and use of thermodynamic properties. Intergovernmental Oceanographic Commission, Manuals and Guides No. 56, UNESCO (English), 196 pp., Paris, France.

[257] McDougall, T.J., Feistel, R., Pawlowicz, R. (2013): Thermodynamics of Seawater. In: Siedler, G., Griffies, S.M., Gould, J., Church, J.A. (eds.): Ocean Circulation and Climate, A 21st Century Perspective. Academic Press/Elsevier, Oxford/Amsterdam, pp. 141-158. doi:10.1016/B978-0-12-391851-2.00006-4.

[258] Hellmuth, O., Feistel, R., \& Foken, T. (2021). Intercomparison of different state-of-the-art formulations of the mass density of humid air. Bulletin of Atmospheric Science and Technology, 2(1), 1-43. doi:10.1007/s42865-021-00036-7.

[259] Laliberté, F., Zika, J., Mudryk, L., Kushner, P.J., Kjellsson, J., Döös, K. (2015): Constrained work output of the moist atmospheric heat engine in a warming climate. Science 347, 540-543. doi:10.1126/science.1257103.

[260] Feistel, R., Wielgosz, R., Bell, S. A., Camões, M. F., Cooper, J. R., Dexter, P., .. Wolf, H. (2015). Metrological challenges for measurements of key climatological observables: oceanic salinity and $\mathrm{pH}$, and atmospheric humidity. Part 1: overview. Metrologia, 53(1), R1-R11. doi:10.1088/0026-1394/53/1/r1.

[261] Hellmuth, O., Feistel, R., Lovell-Smith, J., Kalova, J. (2015): Metrological Aspects of Humidity: State of Discussion on Common Positions, Challenges, and Needs. Technical Report of the Joint BIPM, CCT-WG6/CCQM and JCS Workshop on Hygrometry, held during the 16th International Conference on the Properties of Water and Steam 2013 (ICPWS 2013), Greenwich, UK.

[262] Pawlowicz, R., McDougall, T., Feistel, R., Tailleux, R. (2012): Preface "An historical perspective on the development of the Thermodnamic Equation of Seawater - 2010”. Ocean Sci. 8, 161-174. doi:10.5194/os-8-161-2012.

[263] JCS (2020): IAPWS/SCOR/IAPSO Joint Committee on Seawater. Available online: https://scor-int.org/project/iapws-scoriapso-joint-committee-on-seawater/ (accessed on March 2021).

[264] Feistel, R., Wright, D. G., Miyagawa, K., Harvey, A. H., Hruby, J., Jackett, D. R., McDougall, T. J., and Wagner, W. (2008): Mutually consistent thermodynamic potentials for fluid water, ice and seawater: a new standard for oceanography, Ocean Sci., 4, 275-291. doi:10.5194/os-4-275-2008.

[265] Marquet, P. (2015): On the computation of moist-air specific thermal enthalpy. Q. J. R. Meteorol. Soc. 141, 67-84. doi:10.1002/qj.2335.

[266] Feistel, R. (2019b): Distinguishing between Clausius, Boltzmann and Pauling Entropies of Frozen Non-Equilibrium States. Entropy 2019, 21, 799. doi:10.3390/e21080799.

[267] Planck, M. (1906): Vorlesungen über die Theorie der Wärmestrahlung. Johann Ambrosius Barth, Leipzig, Germany.

[268] Planck, M. (1911): Vorlesungen über Thermodynamik, 3. Auflage. Veit \& Comp., Leipzig, Germany.

[269] Wright, D.G., Feistel, R., Reissmann, J.H., Miyagawa, K., Jackett, D.R., Wagner, W., Overhoff, U., Guder, C., Feistel, A., Marion, G.M. (2010): Numerical implementation and oceanographic application of the thermodynamic potentials of liquid water, water vapour, ice, seawater and humid air - Part 2: The library routines. Ocean Sci. 6, 695-718. doi:10.5194/os-6-6952010.

[270] Gatley, D.P. (2013): Understanding Psychrometrics. ASHRAE, Atlanta, Georgia.

[271] Sonntag, D. (1966): Hygrometrie. Akademie-Verlag, Berlin, Germany.

[272] de Groot, S.R., Mazur, P. (1984): Non-equilibrium Thermodynamics. Dover Publications, New York, United States. 
[273] Feistel, R., Lovell-Smith, J.W., Hellmuth, O. (2015): Virial Approximation of the TEOS-10 Equation for the Fugacity of Water in Humid Air. Int. J. Thermophys. 36, 44-68. doi:10.1007/s10765-014-1784-0.

[274] Feistel, R. (2019a): Defining relative humidity in terms of water activity. Part 2: relations to osmotic pressures. Metrologia 56 , 015015. doi:10.1088/1681-7575/aaf446.

[275] Durack, P.J., Wijffels, S.E. (2010): Fifty-Year Trends in Global Ocean Salinities and Their Relationship to Broad-Scale Warming. J. Climate 23, 4342-4362. doi:10.1175/2010JCLI3377.1.

[276] Durack, P.J. (2015): Ocean salinity and the global water cycle. Oceanography 28, 20-31. doi:10.5670/oceanog.2015.03.

[277] DeAngelis, A.M., Qu, X., Zelinka, M.D., Hall, A. (2015): An observational radiative constraint on hydrologic cycle intensification. Nature 528, 249-253. doi:10.1038/nature15770.

[278] Zhang, W., Furtado, K., Wu, P., Zhou, T., Chadwick, R., Marzin, C., Rostron, J., Sexton, D. (2021): Increasing precipitation variability on daily-to-multiyear time scales in a warmer world. Science Advances 7, eabf8021. doi:10.1126/sciadv.abf8021.

[279] Jacob, D. (1998): Intensivierung des Wasserkreislaufs? In: Lozan, J.E., Graß1, H., Hupfer, P. (1998): Warnsignal Klima. Wissenschaftliche Auswertungen, Hamburg, S. 177-178.

[280] Allen, M.R., Ingram, W.J. (2002): Constraints on future changes in climate and the hydrologic cycle. Nature 419, 224-232. doi:10.1038/nature01092.

[281] King, M.D., Howat, I.M., Candela, S.G., Noh, M.J., Jeong, S., Noël, B.P.Y., van den Broeke, M.R., Wouters, B., Negrete, A. (2020): Dynamic ice loss from the Greenland Ice Sheet driven by sustained glacier retreat. Communications Earth \& Environment 1, 1. doi:10.1038/s43247-020-0001-2.

[282] Alizadeh, M.R., Adamowski, J., Nikoo, M.R., AghaKouchak, A., Dennison, P., Sadegh, M. (2020): A century of observations reveals increasing likelihood of continental-scale compound dry-hot extremes. Sci. Adv. 6, eaaz4571. doi:10.1126/sciadv.aaz4571.

[283] DWD (2020): Was wir heute über das Extremwetter in Deutschland wissen. Deutscher Wetterdienst und Extremwetterkongress Hamburg. Available online: https://boettcher.science/wp-content/uploads/2020/09/Extremwetter_Deutschland_2020_09_23_ final.pdf (accessed on March 2021). 